NATIONAL LABORATORY

MANAGED BY UT-BATTELLE

FOR THE DEPARTMENT OF ENERGY

\title{
Large Scale Duty Cycle (LSDC) Project: Tractive Energy Analysis Methodology and Results from Long-Haul Truck Drive Cycle Evaluations
}

May 2011

Prepared by

Tim LaClair

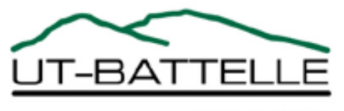





\section{LARGE SCALE DUTY CYCLE (LSDC) PROJECT: TRACTIVE ENERGY ANALYSIS METHODOLOGY AND RESULTS FROM LONG-HAUL TRUCK DRIVE CYCLE EVALUATIONS}

Tim LaClair

Date Published: May 2011

Prepared by

OAK RIDGE NATIONAL LABORATORY

Oak Ridge, Tennessee 37831-6283

managed by

UT-BATTELLE, LLC

for the

U.S. DEPARTMENT OF ENERGY

under contract DE-AC05-00OR22725 


\section{Contents}

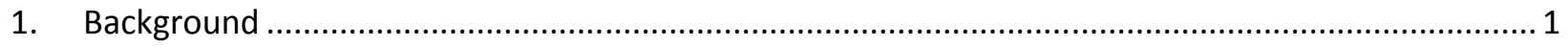

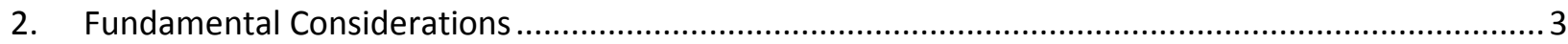

2.1. Tractive Energy during Different Periods of Vehicle Operation ................................................ 3

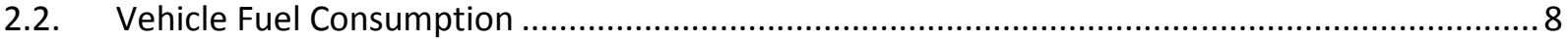

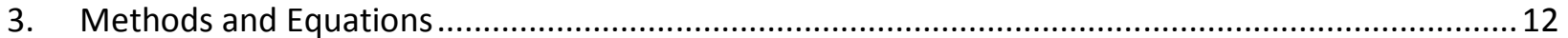

3.1. Tractive Energy Analysis and Overall Fuel Savings Potential ................................................ 12

3.2. Technologies considered and Corresponding Equations .....................................................13

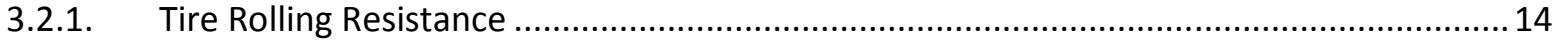

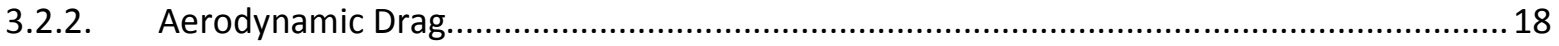

3.2.3. Hybridization (Regenerative Braking Energy Savings) ..................................................... 19

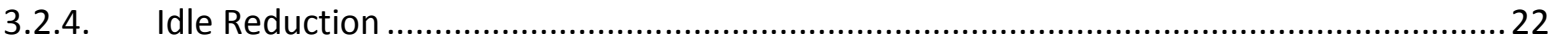

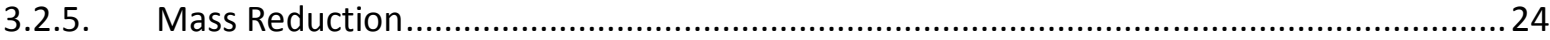

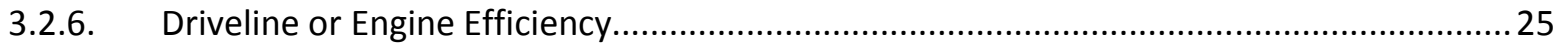

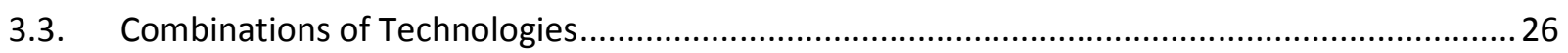

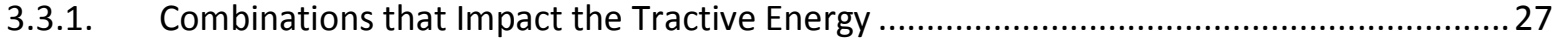

3.3.2. Converting Tractive Energy Reductions to Fuel Savings and Combining Tractive Energy

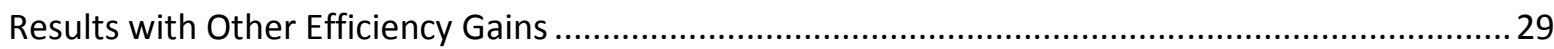

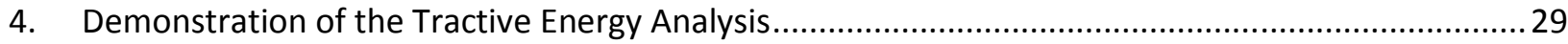

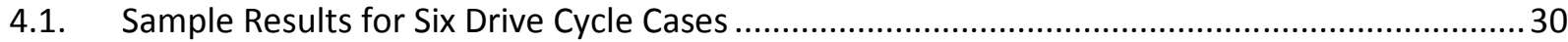

4.2. Estimation of Vehicle Mass from Engine Torque and Acceleration Data ................................50

4.2.1. Method for Vehicle Mass Estimation............................................................................ 51

4.2.2. Sample Evaluations for Vehicle Mass Estimation .........................................................52

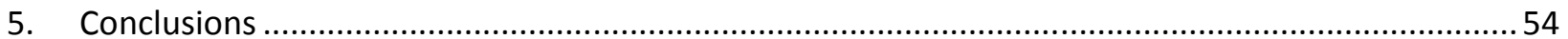

6. Recommendations for Future Research for the LSDC Project.........................................................55

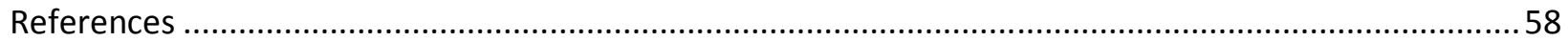




\begin{abstract}
:
This report addresses the approach that will be used in the Large Scale Duty Cycle (LSDC) project to evaluate the fuel savings potential of various truck efficiency technologies. The methods and equations used for performing the tractive energy evaluations are presented and the calculation approach is described. Several representative results for individual duty cycle segments are presented to demonstrate the approach and the significance of this analysis for the project. The report is divided into four sections, including an initial brief overview of the LSDC project and its current status. In the second section of the report, the concepts that form the basis of the analysis are presented through a discussion of basic principles pertaining to tractive energy and the role of tractive energy in relation to other losses on the vehicle. In the third section, the approach used for the analysis is formalized and the equations used in the analysis are presented. In the fourth section, results from the analysis for a set of individual duty cycle measurements are presented and different types of drive cycles are discussed relative to the fuel savings potential that specific technologies could bring if these drive cycles were representative of the use of a given vehicle or trucking application. Additionally, the calculation of vehicle mass from measured torque and speed data is presented and the accuracy of the approach is demonstrated.
\end{abstract}

\title{
1. Background
}

The LSDC project was launched as a research effort aimed at characterizing the usage of medium- and heavy-duty trucks throughout the U.S. by collecting basic duty cycle data (velocity, acceleration and elevation) over a one-year period during normal operations. This activity is being performed as part of a study sponsored by the Department of Energy (DOE) Office of Vehicle Technologies (OVT). The measured data will be analyzed to develop a broad understanding of truck fuel economy and emissions in normal everyday use, to identify advanced efficiency technologies that offer the greatest potential for improving truck efficiencies in each trucking application and to understand the variations in drive cycles that exist among vehicles within the same application. Tools will be developed to allow fleets and owner operators to evaluate the benefits that can be expected with any technology or combination of technologies for their particular application. Key objectives of this research include developing representative duty cycles for each truck vocation and evaluating the fuel savings potential for advanced efficiency technologies for different trucking applications. The term "representative drive cycle" in this case means that the drive cycles that will be developed should represent, in a statistical sense, the average driving characteristics for all trucks within each trucking application/vocation. The representative, or characteristic, drive cycles will therefore be developed by accumulating statistics for accelerations, velocities and loads, among all of the vehicles measured in the project, and developing drive cycles for each vocation that have characteristics as close as possible to those of the complete set of data collected. The data collected from this study will also benefit many other areas of transportation research since it will provide a detailed view of traffic encountered throughout the U.S. transportation 
network over an extended time period and it will contain information about driving behavior among a diverse set of trucking applications.

The LSDC project will be performed in five separate phases of research:

1. Feasibility Study (the current phase), to determine the feasibility of collecting the data and demonstrating the analysis approach that will be used to quantify the fuel savings potential of fuel efficiency technologies;

2. Proof of Concept Testing, to perform limited testing to demonstrate that the selected test approach will provide all of the data required;

3. Full-System Pilot Test (including preparation) and Data Evaluation, to develop the data management systems necessary to acquire and process the incoming data in an automated and time-efficient manner and to validate that the systems function as needed with large incoming data sets;

4. Assessment Tool Development, to develop web application tools that compare and assess the effectiveness of fuel efficiency technologies and technology combinations;

5. Field Operation Testing (FOT), to collect long-term drive cycle data that can be used to develop characteristic, application-specific drive cycles among the trucking applications with the greatest fuel consumption, perform analysis of the collected data, and integrate all results in the webbased software tools.

For the main testing phase of the project (the FOT), the goal is to measure the duty cycles of 100-500 separate vehicles among each of 12-15 selected truck vocations-for a total of 3000-7500 trucksduring a period of approximately 12 months. The measurements to be made will consist primarily of vehicle speed and route, with readings taken once every second of vehicle operation. The route information, based on real-time GPS coordinates, will allow road elevation data to be determined. Additional information will be collected for engine speed, torque and instantaneous fuel consumption, if possible, but the core drive cycle information is the primary data of interest. This research will help provide guidance to technology developers, government agencies, and fleets and individual truck owners for investing in technologies that are best suited to real-world use.

The project was launched in FY09 with a feasibility study, to evaluate what low cost technology solutions are available to collect the data required for the project, evaluate the expected costs for the data collection activities and to demonstrate the analysis approach that will be employed. This report addresses the analysis of duty cycle data for the purpose of quantifying the fuel savings that are possible with different advanced efficiency technologies. This analysis was conducted as one of the tasks in the feasibility study. The planned analysis approach will rely heavily on an analysis of the tractive energy, which can be used to quantify energy losses associated with a vehicle's usage (i.e. the duty cycle). Some basic information and theoretical considerations are presented initially to familiarize the reader with the concept of tractive energy and to explain how it relates to the vehicle's total fuel consumption. 


\section{Fundamental Considerations}

The objective of the duty cycle analysis in this project is to develop a simple approach to estimate the fuel savings potential of advanced fuel efficiency technologies. Fuel savings technologies function, in general, by reducing parasitic energy losses that the vehicle must overcome, and each technology has certain energy losses that they reduce or recover (e.g. aerodynamic drag, tire rolling resistance, braking energy losses, drivetrain frictional losses, or accessory power consumption). Analyzing the tractive energy required to overcome the various forces acting on the vehicle and accounting for the contribution of different parasitic losses during different regimes of the drive cycle provides a means to assess the energy savings potential of these technologies.

\subsection{Tractive Energy during Different Periods of Vehicle Operation}

The force acting at the interface between a vehicle and the ground (by means of driving and braking forces generated by the tires) is referred to as the tractive force, and it is this force that serves to accelerate (or decelerate) the vehicle, overcome the forces of aerodynamic drag and tire rolling resistance, and in the case of driving up a hill, to propel the vehicle up a grade. When a vehicle is being actively propelled and the engine is needed to provide power to the wheels the tractive force is positive, while the tractive force is negative during periods of braking or engine braking. The mechanical energy associated with generation of the tractive force is called the tractive energy and the corresponding instantaneous power requirement is the tractive power. The tractive energy can be calculated from knowledge of the forces acting on the vehicle over any distance traveled. The tractive energy provides a measure of the total mechanical energy required to follow a given drive cycle, and it plays an important role in the fuel consumption of a vehicle. It should be apparent that additional fuel is generally required for a drive cycle with higher tractive energy requirements, but not all energy contributors to the total tractive energy have the same impact on fuel consumption, as will be illustrated below.

Figure 1 is a force-body diagram of a truck while it is driven on the highway. The forces acting on the truck are the rolling resistance, the aerodynamic drag, and the gravitational body force, which depends on the slope of the roadway.

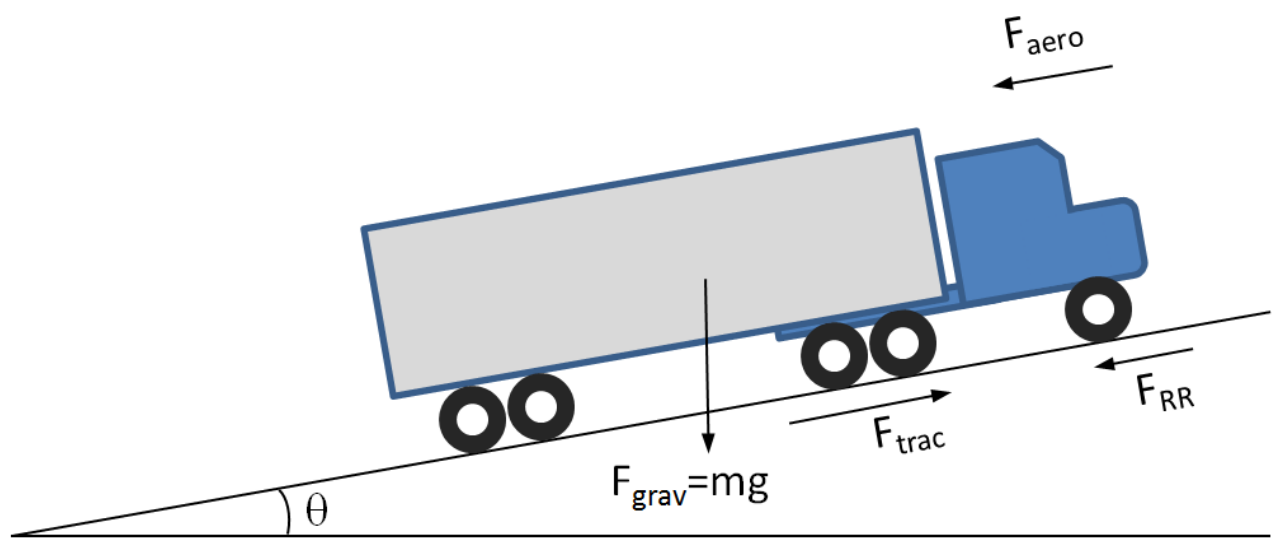

Figure 1. Free-body diagram of a truck driving on a roadway. 
The directions of the forces shown are taken to be positive and this is the sign convention used throughout this report. This figure represents a general case covering all regimes of operation, depending on the value of the slope, and the direction of the tractive force. The different forces shown acting on the truck are the tractive force, $F_{\text {trac }}$; the gravitational body force, $F_{\text {gravi }}$; the rolling resistance force, $F_{R R}$; and the aerodynamic drag force, $F_{\text {aero. }}$. Applying Newton's $2^{\text {nd }}$ law of motion results in the following equation, which describes the relationship between the tractive force, gravitational force, inertia and the resistive forces of rolling resistance and aerodynamic drag:

$$
F_{\text {trac }}=m \frac{d v}{d t}+m g \sin \theta+F_{\text {aero }}+F_{R R}
$$

Note that the tractive force will be a driving force (positive) if

$$
\frac{d v}{d t}>-g \sin \theta-\frac{F_{a e r o}+F_{R R}}{m}
$$

and will be braking if

$$
\frac{d v}{d t}<-g \sin \theta-\frac{F_{a e r o}+F_{R R}}{m} .
$$

The tractive force will be braking (negative) if this inequality is reversed, which indicates that the vehicle's brakes and/or engine braking are needed to provide a braking force with magnitude $F_{\text {trac }}$.

In Eq. (1), The aerodynamic drag and rolling resistance terms are always positive, while the gravitational force is positive when ascending a hill (positive $\theta$ ) and negative when descending (negative $\theta$ ). If we multiply Eq. (1) by the vehicle speed, we arrive at a relation for the tractive power,

$$
P_{\text {trac }}=m v \frac{d v}{d t}+m g v \sin \theta+P_{\text {aero }}+P_{R R}
$$

where the power terms, $P_{\text {trac }}, P_{\text {aero }}$ and $P_{R R}$ are given as the product of the respective force and the vehicle's speed. We note that $v \sin \theta$ is the rate of change of elevation, $\frac{d h}{d t}$, of the vehicle. Integrating Eq. (3) with respect to time over any period of time, i.e. between times $t_{0}$ and $t_{1}$, yields an expression for the tractive energy required to travel the distance traversed over that time period.

$$
\begin{aligned}
\Delta E_{\text {trac }} & =\frac{1}{2} m\left(v_{2}^{2}-\mathrm{v}_{1}^{2}\right)+m g\left(h_{2}-h_{1}\right)+\Delta E_{\text {aero }}+\Delta E_{R R} \\
& =\Delta E_{\text {kinetic }}+\Delta E_{\text {potential }}+\Delta E_{\text {aero }}+\Delta E_{R R}
\end{aligned}
$$

There are several different factors that contribute to the tractive energy requirement over a drive cycle, and some of the factors are dissipative in nature (rolling resistance, aerodynamic drag and vehicle braking, including engine braking) while others represent reversible energy contributions (kinetic and potential energy). Distinguishing between these contributions and accounting individually for the dissipative energy terms over different driving regimes can give a strong indication of where significant energy savings can be achieved. For such an analysis, however, it is very important to clearly distinguish between the net tractive energy over an entire drive cycle and the positive tractive energy inputs during the drive cycle. Only positive tractive energy inputs require additional fuel energy inputs to the engine, 
and two drive cycles that have the same net tractive energy can have very different positive tractive energy contributions, which, at least for a conventional vehicle that does not have regenerative braking capabilities, will cause the fuel consumption to be very different between the two cycles. The positive tractive energy is defined by integrating the tractive power only for periods of time when the tractive force is positive. We define the driving tractive energy,

$$
E_{\text {trac }, \text { drive }}=\int_{t_{\text {drive }}} P_{\text {trac }} d t
$$

where it is understood that the integration is performed over the set of times, $t_{\text {drive, }}$ for which Eq. (2a) is satisfied. For the energy that goes into braking the vehicle, the corresponding equation is

$$
E_{\text {trac,brake }}=-\int_{t_{\text {brake }}} P_{\text {trac }} d t .
$$

We have defined $E_{\text {trac,brake }}$ using the negative of the integral so that the resulting value is positive. The net tractive energy is given by Eq. (4), evaluated over the entire drive cycle, and it should be clear that $E_{\text {trac,net }}=E_{\text {trac,drive }}-E_{\text {trac,brake }}$.

Consider as an example, two identical trucks that operate at the same constant speed of $50 \mathrm{mph}$; but assume that the first operates on flat ground while the second climbs a hill with a constant $2 \%$ grade for the first half of the drive cycle and descends a hill of the same grade on the second half of the cycle. The total distance traveled is assumed to be the same for both cases, and since the speed is constant, the times are also equal. Fig. 2 shows a plot of both the total (net) tractive energy (driving minus the braking tractive energies) and the cumulative driving (positive) tractive energy, along with the elevation profile. Note that the elevation encountered by each truck is plotted as a function of time, not spatially. If the two cases were plotted geometrically, the width of the "symmetric hill" case would be slightly less than that of the flat elevation case due to the hypotenuse, but the total distance traveled (on the surface of the hill) is the same for the two cases since the speed is assumed to be constant and the duration of the cycle in both cases is the same. 


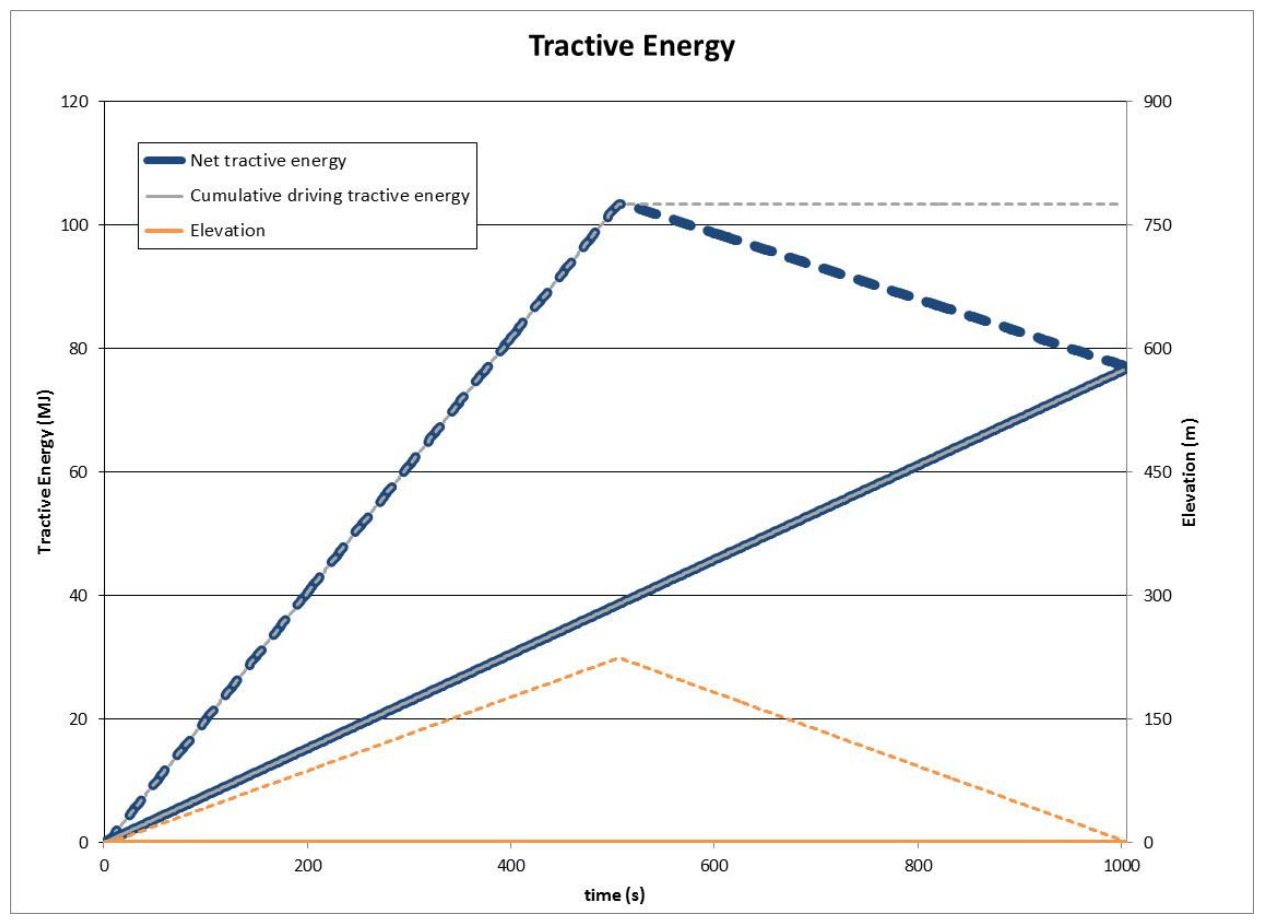

Figure 2. Tractive energy analysis for two trucks operating at a constant speed of $50 \mathrm{mph}$. The solid line is for a flat elevation profile, while the dashed line is for operation over a symmetric hill.

The results for both vehicles are shown together on the same plot for comparison purposes, with the results for the vehicle operating on the grade shown with dashed lines. Note that the net tractive energy values over the entire drive cycle are the same for the two cases (77 MJ). The potential energy gained during the first half of the drive cycle for the truck on the grade is lost during the second half, and conservation of energy ensures that the net tractive energies are equivalent. The positive tractive energy required from the engine $(104 \mathrm{MJ})$ is greater for the truck that climbed and descended the hill, however, since during the ascent a greater power input was required while on the descent the truck maintained its speed without requiring any additional energy input from the engine, and in fact had to actively brake to maintain its speed. Note that for a conventional vehicle, the driving tractive energy is most relevant to the total fuel consumption. For a hybrid vehicle with regenerative braking capability, at least some portion of the braking tractive energy could be recovered during the descent on this drive cycle. For a real regenerative braking system, there would still be some energy loss, so the net tractive energy is still not fully relevant. This fact suggests that the driving and braking tractive energy should be accounted for separately, and this is the approach that has been taken for the analyses in this project.

If a similar scenario is considered but the grade of the hills is $1 \%$ instead of $2 \%$, then the tractive energy result is somewhat different. The tractive energy results for a $1 \%$ symmetric hill are plotted with dashed lines in Fig. 3, and the flat grade results are shown again as solid lines for comparison. With this lower grade, the truck does not need to brake during the descent. Instead there is a small positive tractive energy requirement during the descent to overcome the rolling resistance and aerodynamic drag. The end result is that the positive tractive energy and the net tractive energy are identical for this case. 


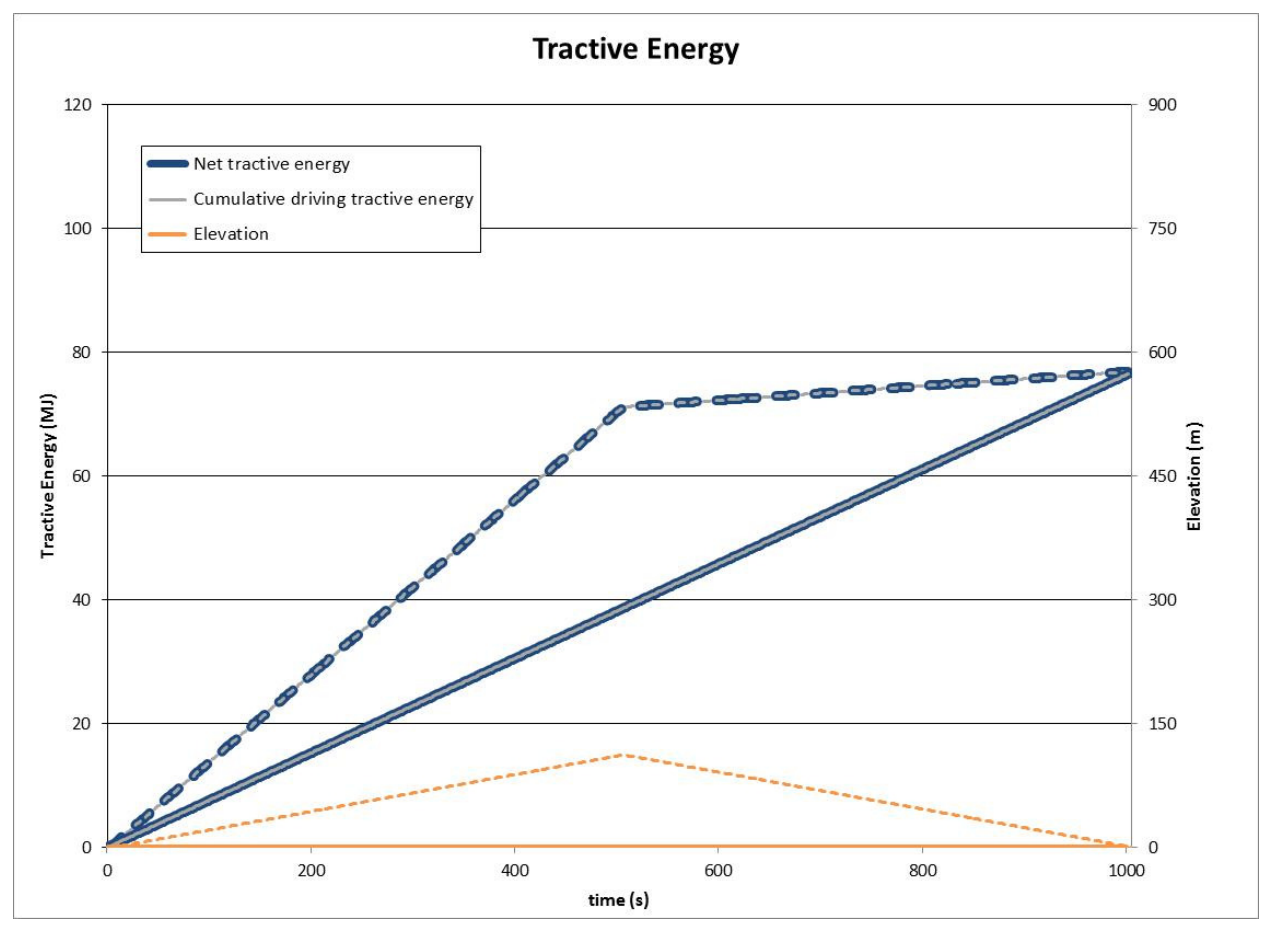

Figure 3. Tractive energy analysis for the same scenario but with a grade of only $1 \%$.

The main difference between these two examples is that for the $2 \%$ grade case, the greater elevation rise during the first half of the cycle required additional energy from the engine, and braking was required to keep the speed at $50 \mathrm{mph}$ during the descent along the steeper grade. Note that in the $1 \%$ grade case, the total driving tractive energy requirement is the same as in the case of the flat roadway (77 $\mathrm{MJ})$, and it is expected that there would be relatively little difference in fuel consumed between those two cases. (It is noted that there could be differences in engine efficiency at the different operating conditions, which can affect fuel economy, but the impact is much smaller than that caused by using the brakes.) These examples illustrate how braking consumes the potential energy in a traditional vehicle (non-hybrid without regenerative braking). If we consider speed variations as opposed to elevation changes, a similar analysis of braking vs. coasting decelerations would show that braking consumes kinetic energy in much the same way.

Although kinetic and potential energy are reversible and do not affect the net tractive energy, braking represents a dissipative force that depletes the energy that is effectively stored as kinetic and potential energy. In effect, the brakes consume additional energy that could be used to move the vehicle further down the road if the vehicle were allowed to coast or if the energy were stored and recovered, as is done with a hybrid vehicle. Beyond the consideration of hybrid vehicles, there is a more subtle role that braking plays in fuel economy with respect to the benefits that can be obtained from advanced fuel efficiency technologies. The need to decelerate the vehicle by using the brakes can have a negative impact on the energy savings attainable by using energy efficiency technologies other than regenerative braking. Consider, for example, the energy losses associated with braking if a vehicle uses low rolling resistance tires. There is an energy savings associated with the low rolling resistance when the vehicle 
cruises at steady speeds, which will lower the energy inputs required during these periods of driving. However, during the periods of braking, if we assume that the same speed will be followed, the lower dissipative force associated with the low rolling resistance tires results in higher required braking forces during the decelerations. This means that, for the periods of braking, all of the energy savings due to the low rolling resistance tires is simply lost through additional braking requirements for a traditional vehicle. Therefore, during any periods of braking, there is no energy saving benefit from the use of the low rolling resistance tires, and for drive cycles that include significant periods of braking, the fuel savings due to low rolling resistance is much lower than for drive cycles in which there is minimal braking. Technologies that reduce the aerodynamic drag or transmission energy losses will have a similar reduced benefit for drive cycles with significant periods of braking. These examples demonstrate the importance of the driving tractive energy for fuel consumption, as compared to the net tractive energy, and they also serve to highlight the importance of what drive cycles are driven for understanding the energy savings that can be obtained from various advanced vehicle efficiency technologies. Following the development of the tractive energy model, specific analysis examples using measured drive cycles will be presented in Section 4 that show quantitatively how different types of drive cycles impact the fuel savings that can be achieved when employing different technologies.

\subsection{Vehicle Fuel Consumption}

To develop a better understanding of the role of tractive energy on fuel consumption, it is useful to consider the energy losses internal to the vehicle, both in the engine and through the rest of the drivetrain. This section presents an overview of the energy conversion processes and energy losses associated with normal vehicle operation, and it further develops the justification for application of the tractive energy analysis.

Fig. 4 shows a basic accounting of the energy used in a vehicle [1], starting with the fuel energy and considering the conversion of the thermal energy to work, the energy losses that occur within the engine and drivetrain and ultimately the energy used to propel the vehicle. Each box in the figure represents the energy present at a given state of the drivetrain, and the areas with the arrow-shaped regions represent energy losses or the use of energy that occurs during the process corresponding to the preceding box. This figure was developed to graphically represent how the overall energy use is distributed in the vehicle, and the height of each energy term shown in the figure is in approximate proportion to the actual energy use. In the figure, the processes and energy terms shown to the left of the highlighted line occur within the engine, while everything to the right is associated with mechanical energy transmission and dissipative losses that occur downstream of the engine in the driveline. The conversion of the fuel's thermal energy to work (the leftmost process shown in the figure) is quite inefficient due to the thermodynamic limitations of operating a heat engine. Even for the most efficient engines today, over half of the fuel's input energy is dissipated as heat through the exhaust and cooling systems. Furthermore, the operation of the engine itself has some "overhead" energy losses associated with it in terms of frictional losses and pumping losses, and the output mechanical energy from the engine is reduced by these losses. The net mechanical energy produced by the engine is what is available at the drive shaft in order to perform the primary tasks the engine must perform, and this is often referred to as "brake work," as indicated in the figure. 


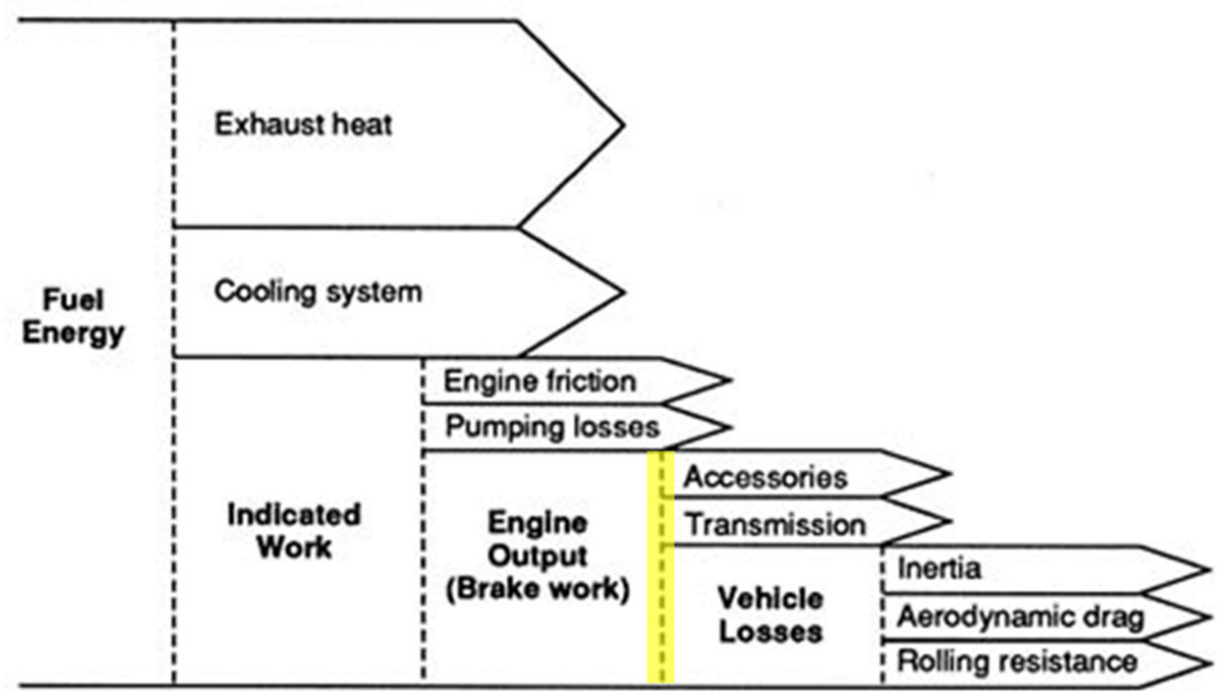

Figure 4. Typical fuel energy distribution for a vehicle operating on a level road (modified from [1]).

Most of the energy loss that takes place in the conversion of the fuel energy to mechanical energy is due to thermodynamic irreversibility, and to first order, the mechanical energy produced is proportional to the fuel energy. The engine's operating load and speed do have an impact on the efficiency of the energy conversion process, but the efficiency range is relatively narrow, particularly for conditions that are typical during normal driving, and if the vehicle is driven in a manner that maintains relatively high load conditions and low engine speed. The tractive energy analysis effectively assumes that the overall fuel consumption due to the specific drive cycle is proportional to the mechanical energy required during all periods of positive tractive force. This is consistent with an assumption that the engine efficiency is constant at different operating conditions while driving. This first assumption is expressed by the following equation:

$$
W_{\text {brake,drive }}=\eta_{\text {engine }} E_{\text {fuel,drive }} .
$$

The term $W_{\text {brake, drive }}$ is the total mechanical energy output from the engine during all periods of positive (driving) tractive power output over the drive cycle; $E_{\text {fuel,drive }}$ is the corresponding fuel energy during the same periods; and $\eta_{\text {engine }}$ is an engine thermal efficiency, which is assumed to be constant. (A typical value for $\eta_{\text {engine }}$ is taken to be 0.42 .) While this assumption is not highly accurate at all operating conditions, it is believed to be reasonable for the purposes of the tractive energy evaluation, and it allows an analysis to be performed that does not require detailed information corresponding to a specific vehicle configuration, which is a particularly attractive characteristic of this approach. Refinements to this assumption could be made in the model based on a linearization of the engine efficiency as a function of engine speed and load (as in [2]), but it would require assuming specific gear ratios in the drivetrain, and specific gear shifting points would have to be assumed in order to implement this approach for a given vehicle and drive cycle. While the latter approach is more rigorous, the added complexity would reduce the intended generality of the analysis and it is not believed to be necessary to obtain results that will quantify reasonably well the benefits of different technologies when 
characteristic drive cycles are used in the evaluation. Nonetheless, a validation of the approach used in the tractive energy analysis, and an evaluation of its accuracy, will be performed as a final step in the feasibility study by analyzing the fuel efficiency with a high fidelity vehicle model (using Autonomie) for some of the drive cycles analyzed.

Returning back to Fig. 4, we now consider energy losses that occur downstream of the engine itself. The mechanical energy output is reduced further before any energy reaches the wheels. The engine must provide energy to various accessories of the vehicle, such as the alternator, fan and air conditioning system, and there is frictional energy loss associated with the transmission of mechanical power from the engine to the wheels. The energy use associated with operating the accessories varies in time, but an average value is often used in analysis, and this approach has been found to provide good results for predicting the total fuel consumption even for high fidelity vehicle performance models $[3,4]$. The transmission energy loss due to friction within the gears, differential, bearings, etc., is approximately proportional to the power transmitted, with approximately $90 \%$ of the energy transmitted to the wheels. It is assumed that the transmission efficiency is constant, so that

$$
E_{\text {trac }}=\eta_{\text {trans }}\left(W_{\text {brake }}-E_{\text {acces }}\right)
$$

where $\eta_{\text {trans }}$ is the overall driveline efficiency.

The energy required to overcome inertial forces, aerodynamic drag, and tire rolling resistance, which are shown at the bottom right of Fig. 4, represents the full required tractive energy to drive on a flat roadway (energy corresponding to gravitational forces also need to be considered for operations on a grade). It is seen in the figure that the tractive energy actually represents a relatively small portion of the total fuel energy use, although it is the dominant use of the mechanical energy from the engine. It should be noted that production of the tractive energy is generally the main purpose for operating a vehicle, although in certain situations or during certain periods of operation, running the accessories may be the primary objective, such as while idling to maintain the air conditioning running or when the engine drives a compressor or hydraulic systems for a work truck. For the purpose of this study, we shall limit our consideration primarily to periods when the vehicle is being driven and the main energy use is to propel the vehicle along with the load it is carrying. It should be apparent that the tractive power is what the driver ultimately controls through accelerator inputs and that the fuel consumption and drivetrain power losses are a function of the driver's tractive power demand. Furthermore, if the demanded tractive energy is reduced as a result of reduced aerodynamic drag, rolling resistance, or other factors while following the same drive cycle, there will be a corresponding reduction in the upstream energy losses. Reducing the tractive energy reduces the load on the transmission so that there is a lower transmission loss, and, consequently, reduction in the brake work from the engine. This means that the engine power is reduced, and the pumping losses will also be lower, etc. Therefore, the fuel energy is reduced in a nearly proportional manner to reductions in the required tractive energy. Based on the arguments made above and the assumptions that we have outlined, the fuel energy can be related to the tractive energy through the following relationship:

$$
E_{\text {trac,drive }}=\eta_{\text {trans }}\left(\eta_{\text {engine }} E_{\text {fuel,drive }}-E_{\text {acces, drive }}\right) \text {, }
$$


where $E_{\text {access }}$ is the energy consumption of the accessories. An important consequence of this is that the change in the fuel energy requirement associated with tractive energy changes is constant, i.e.

$$
\frac{d E_{\text {fuel }}}{d E_{\text {trac }}}=\frac{1}{\eta_{\text {trans }} \eta_{\text {engine }}} .
$$

This result, which shows that any reduction in the positive tractive energy will generate a proportional savings in fuel consumption, is an important conclusion that forms a basis for all of the remaining analysis. This result also provides motivation for considering savings in the driving tractive energy associated with different technologies and making direct comparisons between the tractive energy savings potential that different technologies can provide.

As discussed, the assumptions used in the derivation above are not based on rigorous theoretical concepts, and the reader may question how appropriate it is to use the assumptions made. Before proceeding with the remainder of the development and analysis, a sample result from the drive cycle evaluations is presented to demonstrate the adequacy of the above assumptions and the primary conclusion. Fig. 5 shows a measured speed cycle along with the (measured) cumulative fuel consumption during periods of driving tractive power and the calculated driving tractive energy. It can be seen that the fuel consumption does increase in a similar manner to the tractive energy.

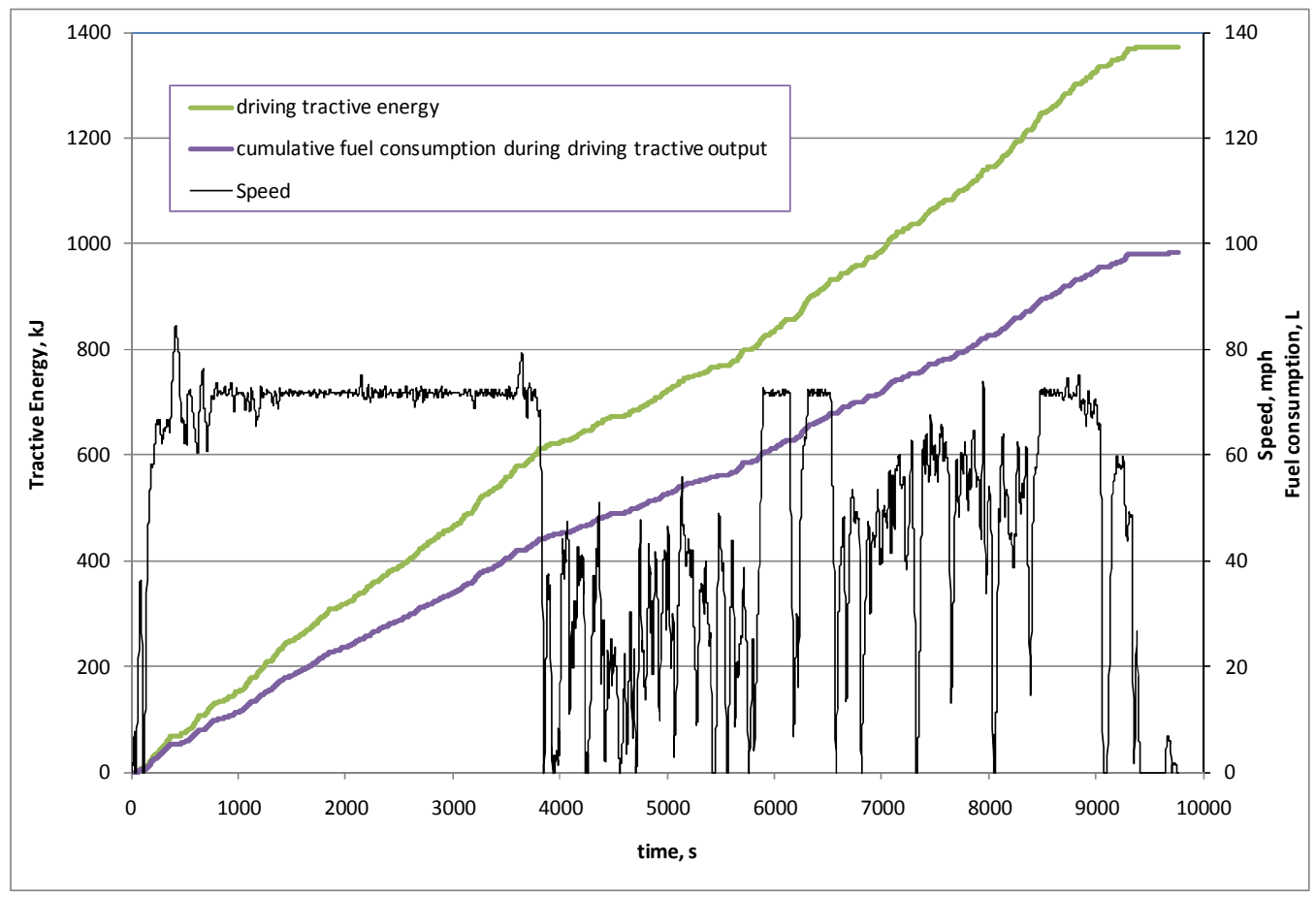

Figure 5. Comparison of tractive energy and cumulative fuel consumption during periods of positive tractive power during a measured drive cycle.

To make the relationship more clear, the cumulative fuel consumption (during positive tractive power periods) is cross-plotted against the tractive energy requirement during the drive cycle in Fig. 6 . This 
result shows that the trend is indeed quite linear throughout the drive cycle, in spite of the fact that the drive cycle includes periods of both steady highway driving and variable speeds in off-freeway travel. This result confirms the relevance of the assumptions made and validates the appropriateness of the tractive energy evaluations.

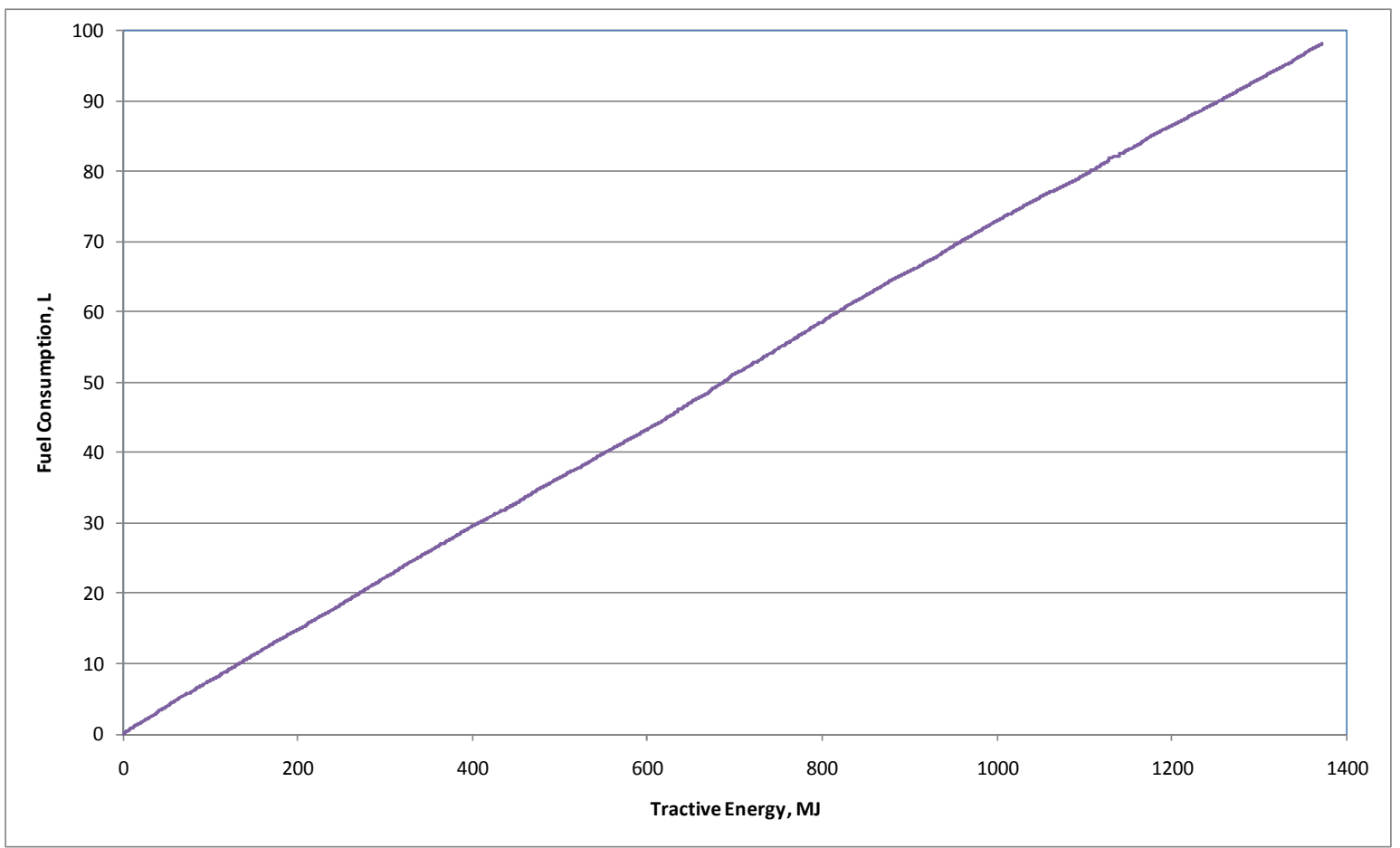

Figure 6. Cumulative fuel consumption during periods of tractive power output vs. tractive energy requirement

\section{Methods and Equations}

As described in the previous sections, analysis of the driving tractive energy can provide a clear indication of the fuel savings that are possible with reductions in various contributions to the tractive energy. This section presents the equations that are used in the analysis to quantify the energy savings potential of each technology individually, and the theoretical justification for the approach is described.

\subsection{Tractive Energy Analysis and Overall Fuel Savings Potential}

The equations developed in section 2 can be used to provide a direct relationship between the driving tractive energy change and fuel consumption. The reader is reminded, however, that the assumptions used in deriving the equations in this analysis are somewhat coarse and the intention of using the tractive energy approach is to identify technologies that hold the greatest overall potential for fuel savings within a given trucking application. Precise predictions of the total fuel consumption are not expected to be highly accurate with this analysis since this will depend on specific details of the vehicle configuration. However, relative comparisons between technologies should be reasonable and approximations of the fuel savings achievable with different technologies while driving are also possible 
based on typical efficiencies. Using Eq. (8), one can derive a relationship between the driving tractive energy requirement and the fuel energy necessary to produce it. The fuel consumption associated with the tractive energy requirement is obtained by dividing the fuel energy by the heat of combustion, and the lower heating value (LHV) is used for this purpose. The result for the fuel consumption, $F_{c}$, is the following:

$$
F_{c, \text { trac }}=\frac{E_{\text {fuel }}}{L H V}=\frac{1}{\eta_{\text {engine }} L H V}\left(\frac{E_{\text {trac }}}{\eta_{\text {trans }}}+E_{\text {acces }}\right) .
$$

This equation can be used to estimate the fuel savings potential associated with a specific technology, although relative savings can be predicted relatively accurately by using Eq. (9). This equation is most useful when we consider technologies or technology combinations (in section 3.3) for which a pure tractive energy comparison is not possible.

\subsection{Technologies considered and Corresponding Equations}

The drive cycle and tractive energy analysis will be applied to evaluate the energy savings potential for the following technologies: regenerative braking (hybrid vehicles), low rolling resistance tires, aerodynamic drag reduction devices, idle reduction systems, technologies that reduce vehicle mass, high efficiency drivelines (transmission, differential, etc.), and improved efficiency engines. These technologies have different characteristics that relate to the drive cycle and the tractive energy in different ways, and the analysis to determine the fuel savings potential for each is somewhat different depending on how the technology functions. Tire rolling resistance, aerodynamic drag, and regenerative braking all directly impact the tractive energy requirement through forces that they reduce. Mass of the vehicle and its payload also have a direct impact on the tractive energy requirement for a given drive cycle as a result of the vehicle inertia and gravitational forces, and mass also plays a strong role in the tire rolling resistance force. Since mass reduction affects the driving tractive energy through several forces simultaneously, its treatment for the tractive energy analysis is different than that for the other factors that influence individual forces associated with the tractive energy. Efficiency improvements of the engine itself and of the driveline reduce energy losses that are "upstream" of the tractive energy contributions, and the fuel savings associated with these technologies are generally in proportion to the driving tractive energy. Idle reduction technologies are not related to the tractive energy during driving, but a representative drive cycle, including periods of idle operation, is still important for being able to estimate the energy savings that are possible through idle reduction.

The tractive energy analysis is intended to be used to evaluate characteristic drive cycles in order to quantify the fuel savings potential that can be achieved with various advanced efficiency technologies. Each technology reduces fuel consumption by reducing or eliminating the energy losses associated with some physical process occurring on the vehicle during its operation. By accounting for all of the energy losses that affect fuel consumption over a drive cycle separately, the relative contribution from each can be determined. Knowing the contribution of each energy loss factor (rolling resistance, aerodynamic drag and braking) allows the fuel savings that a specified technology can provide to be estimated if the associated energy losses are known for each factor. By characterizing how much the energy losses associated with a fuel efficiency technology are reduced, the impact on the total tractive energy can be 
directly quantified. For example, if the contribution of tire rolling resistance is found to be $20 \%$ of the driving tractive energy requirement for a given drive cycle when the initial coefficient of rolling resistance is $8 \mathrm{~kg} /$ ton, then using low rolling resistance tires to obtain an average rolling resistance coefficient of $6 \mathrm{~kg} /$ ton (i.e. a $25 \%$ reduction) would be expected to reduce the tractive energy requirement by $5 \%$ ( 0.25 multiplied by 0.20 ). Based on Eq. (9), the fuel consumption during the driving periods of the drive cycle would be expected to improve by approximately the same percentage.

As discussed earlier in this report, the tractive energy contributions during periods of braking tractive force are not relevant to the fuel consumption for conventional vehicles, but for hybrid vehicles with regenerative braking, the energy that would otherwise be dissipated through the brakes can be recovered and used later. With regenerative braking, this recovered energy (or some portion of it) does reduce the driving tractive energy required from the engine during a later portion of the drive cycle when the previously stored energy is used to propel the vehicle instead of just the engine. Since the impact of driving tractive energy on fuel consumption does not depend on when the energy is required, we can evaluate the fuel savings potential of a hybrid vehicle by accounting for the energy losses that take place during the braking tractive power segments of a drive cycle. By accounting for the contributions to the braking tractive energy from each energy loss factor separately, as will be seen in the next section, we are also able to evaluate the fuels savings that can be achieved with combinations of the technologies including hybridization. Therefore, the contributions to both the driving and the braking tractive energy will be accounted for in each of the energy loss factors.

Before proceeding with the analysis, it is noted that coasting (defined as periods when the tractive force is zero) represents a special case with respect to the contributions of the energy loss factors to the driving tractive energy. Since the tractive force is zero during coasting, there is no change to the tractive energy during these periods. However, energy dissipation due to the tire rolling resistance and aerodynamic drag continue during coasting, so their contribution to the driving tractive energy can continue to accumulate even as the tractive energy does not change. The increase in the dissipated energy must be offset by a reduction in the combined kinetic and potential energy, as can be seen in Eq. (4) for periods of time when the net tractive energy does not change. To keep an accurate account of the driving tractive energy changes, either the changes in the kinetic and potential energy need to be tracked or the accumulated energy dissipation from the rolling resistance and aerodynamic drag. Since we are more interested in the energy associated with the dissipative forces than the speed and elevation changes that are traversed while coasting, it is more desirable to account for the rolling resistance and aerodynamic drag energy. Even during periods of coasting, a change in these forces will result in fuel savings since less energy is consumed to travel the same distance and smaller energy inputs will be required at the end of the coasting period to bring the speed back to the desired level.

The remainder of this section develops the equations needed to determine the contributions to the tractive energy and/or total fuel consumption for each of these technologies independently.

\subsubsection{Tire Rolling Resistance}

Tire rolling resistance is a force that opposes the motion of a vehicle as it rolls down the road. Rolling resistance is generated through energy dissipation associated with the deformation of a tire as it rolls, 
and the magnitude of rolling resistance is a function of the tire design. Rolling resistance is approximately proportional to the load carried by each tire, and this allows the rolling resistance to be characterized through the use of a coefficient of rolling resistance for each tire. The rolling resistance force, $F_{R R}$ is given by the following equation:

$$
F_{R R}=C_{R R} m g,
$$

where $C_{R R}$ is the coefficient of rolling resistance for the tire and $m g$ is the load on the tire (mass times the gravitational constant). A typical range of $C_{R R}$ for truck tires is from 0.006 to 0.008 for normal dual tires, and the value can be as low as about 0.004 for new generation wide base single (NGWBS) tires. The value of $C_{R R}$ is dimensionless, but for convenience, it is often expressed in values of kilograms of rolling resistance force per metric ton of load $(\mathrm{kg} / \mathrm{T})$, which gives an overall range of $4.0-8.0 \mathrm{~kg} / \mathrm{T}$. Equation (11) can be used to calculate the total rolling resistance acting on the vehicle for any load if an average value of the rolling resistance coefficient is used, but the average value should be calculated based on weighting the $C_{R R}$ values by the load on each tire on the vehicle. While the rolling resistance coefficient for a given tire does vary somewhat as a function of operating and environmental conditions (including pressure, temperature, load and speed), the variation is relatively small and a single value of rolling resistance coefficient corresponding to average operating conditions is generally sufficient to characterize the overall performance of a tire.

Based on Eq. (11), the instantaneous power associated with the tire rolling resistance is given by

$$
P_{R R}=F_{R R} v=C_{R R} m g,
$$

where $v$ is the speed of the vehicle. The rolling resistance energy associated with traveling a distance $\Delta s$ during any segment of time is therefore given by

$$
E_{R R}=C_{R R} m g \Delta \mathrm{s}
$$

This equation allows the rolling resistance contribution to the tractive energy and power to be calculated for any segment of a drive cycle. Specifically, when the periods of the drive cycle corresponding to braking and non-braking tractive forces are determined based on Eq. (2b), then the portion of the tractive energy associated with the tire rolling resistance can be summed over the corresponding segments to obtain the rolling resistance contribution to both the driving tractive energy and the braking tractive energy.

The rolling resistance contribution to the driving tractive energy over the drive cycle, following Eq. (5a), is given by

$$
E_{R R, \text { drive }}=\int_{t_{\text {drive }}} P_{R R} d t=C_{R R} m g \sum_{\text {non-braking }} \Delta s_{i}
$$


where the summation of the distance travelled is performed over all segments for which the tractive force is non-braking, i.e. for which $\frac{d v}{d t} \geq-g \sin \theta-\frac{F_{a e r o}+F_{R R}}{m}$. Similarly, the rolling resistance contribution to the braking tractive energy is given by

$$
E_{R R, \text { braking }}=C_{R R} m g \sum_{\text {braking }} \Delta s_{i}
$$

where the summation gives the total distance travelled during segments of the drive cycle when a braking tractive force is applied. This term will be considered in more detail when discussing regenerative braking.

Eq. (14) provides the portion of the total driving tractive energy over a drive cycle that is due to rolling resistance. The ratio of $E_{R R \text {,drive }}$ to $E_{\text {trac, drive }}$ gives an indication of the relative importance of rolling resistance for the given drive cycle, and this of course depends on the coefficient of rolling resistance of the tires used on the vehicle. If low rolling resistance tires are being considered as a fuel efficiency improvement, the reduction in the tractive energy associated with the lower rolling resistance level can be estimated using the same equation, but with the value of $C_{R R}$ replaced with the change in the coefficient of rolling resistance, $\Delta C_{R R}$, that would be obtained by using the low rolling resistance tires. The tractive energy savings achievable due to a reduction in rolling resistance is

$$
\Delta E_{R R, \text { drive }}=\Delta C_{R R} m g \sum_{\text {non-braking }} \Delta s_{i}
$$

A convenient way to express the energy savings with respect to rolling resistance is to consider the relative savings in tractive energy that can be obtained from a reduction in the coefficient of rolling resistance, so that we can expect a reduction of the driving tractive energy of say, $2 \% \mathrm{per} \mathrm{kg} / \mathrm{ton}$ improvement in rolling resistance. This sensitivity is calculated simply as the ratio

$$
S_{R R, \text { drive }}=\frac{\Delta E_{R R, \text { drive }} / E_{\text {trac }, \text { drive }}}{\Delta \mathrm{C}_{R R} /(1 \mathrm{~kg} / \text { ton })}=\frac{E_{R R, \text { drive }} / E_{\text {trac }, \text { drive }}}{\mathrm{C}_{R R}} .
$$

Where the value of $C_{R R}$ used in the calculation should be expressed on a $\mathrm{kg} / \mathrm{ton}$ basis. A similar ratio is calculated for the braking contribution of the rolling resistance, but with $E_{R R, \text { drive }}$ replaced by $E_{R R, \text { braking: }}$ :

$$
S_{R R, \text { braking }}=\frac{E_{R R, \text { braking }} / E_{\text {trac,braking }}}{\mathrm{C}_{R R}} .
$$

The model accounts for the rolling resistance energy during the appropriate periods of time for the rolling resistance contributions to the driving and braking tractive energy. To illustrate the approach necessary for the calculation, Fig. 7 shows an example of a 10-minute highway segment from a trip that included travel through a region for which grades up to about 3 percent were experienced. The periods on the speed plot for which the tractive force is non-braking, indicating periods for which the rolling resistance is contributing to the driving tractive energy, are shown in black. Both the measured elevation and speed are shown in the plot to allow the braking tractive energy periods to be analyzed. It can be seen that most of the non-braking periods occur when the speed is increasing or constant as 
expected, but there are some periods of tractive braking (the speed is not highlighted in black) when the speed is increasing since these are times when the truck was forced to brake (or used the engine brake) while the truck descended a hill. Similarly, there are periods of decreasing speed for which the tractive force is driving due to a significant uphill grade.

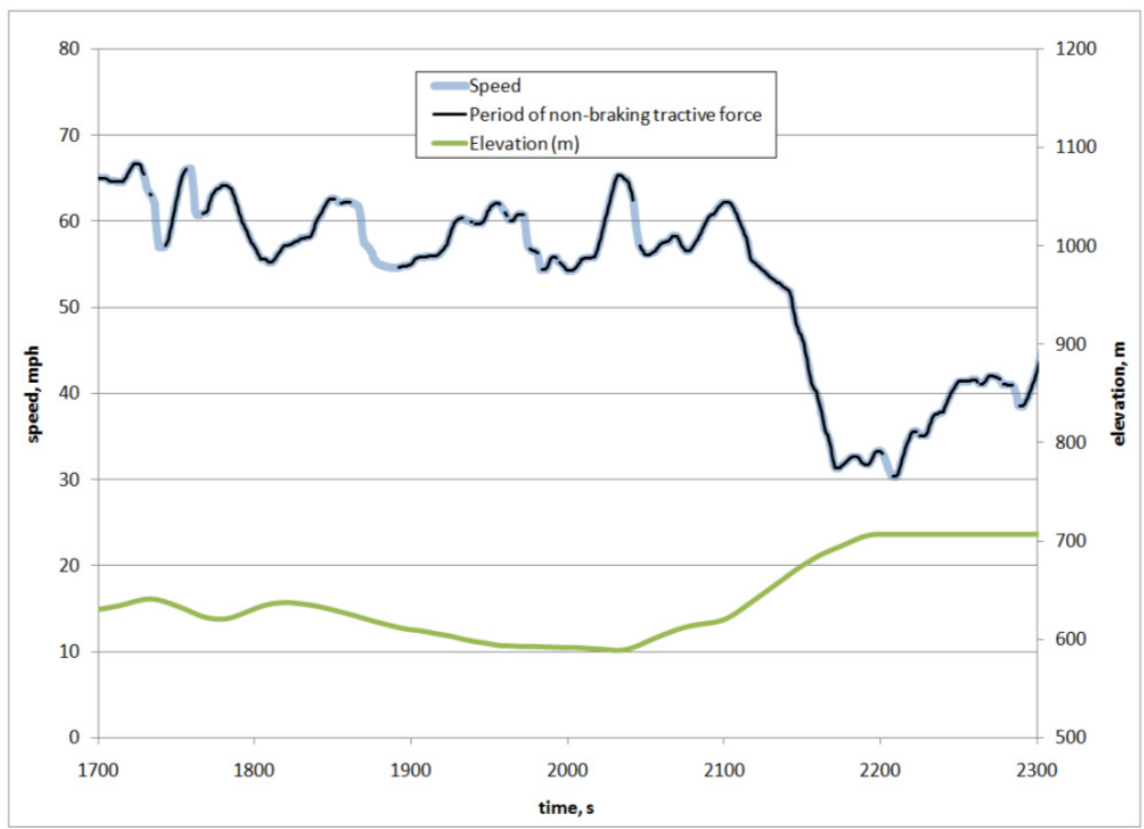

Figure 7. A drive cycle segment, including measured speed and elevation data, showing the period for which reduced rolling resistance will contribute to fuel savings.

The power and cumulative energy associated with the contributing rolling resistance are shown in Fig. 8 for the same drive cycle segment. Although not shown in the figure, the braking contribution of the rolling resistance energy is accounted for in the same way, but the energy terms are summed over the periods of the drive cycle for which the tractive force is braking. 


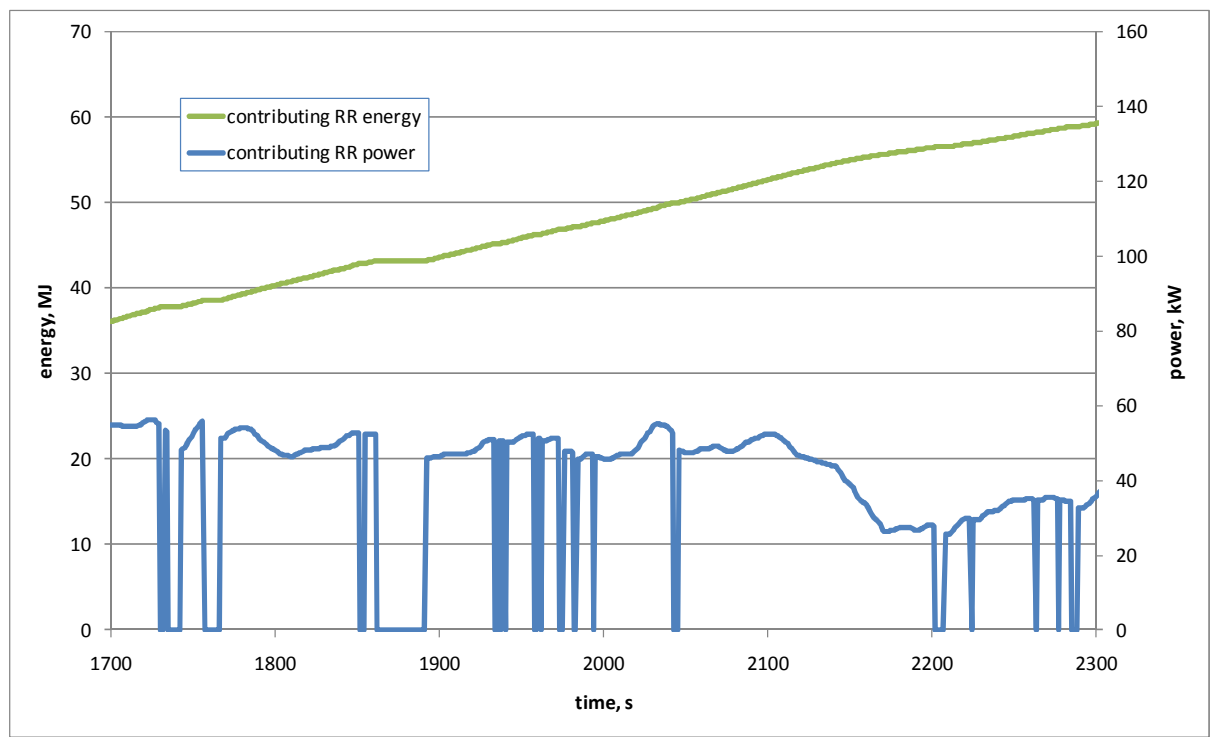

Figure 8. Power and cumulative energy due to tire rolling resistance during segments of non-braking tractive force.

\subsubsection{Aerodynamic Drag}

The effect of aerodynamic drag on the driving and braking tractive energy is very similar to that of tire rolling resistance. Therefore, detailed arguments from the preceding section will not be repeated here and only the main analysis will be presented instead. The aerodynamic drag force is given by the following equation

$$
F_{\text {aero }}=\left(C_{D} A_{f}\right) \frac{1}{2} \rho v^{2}
$$

where $C_{D}$ is the coefficient of aerodynamic drag for the truck, $A_{f}$ is the frontal area, $\rho$ is the density of air and $v$ is the speed. The drag coefficient and frontal area are characteristics of the overall truck configuration, and aerodynamic drag reduction devices act to reduce the value of $C_{D}$ and/or $A_{f}$. The power associated with the aerodynamic drag is therefore given by

$$
P_{\text {aero }}=\left(C_{D} A_{f}\right) \frac{1}{2} \rho v^{3}
$$

With the velocity appearing to the $3^{\text {rd }}$ power, there is no closed form solution for the energy associated with the aerodynamic drag, but the power can be integrated numerically with respect to time using the velocity of the drive cycle. The driving and braking contributions of the aerodynamic drag force to the tractive energy over a drive cycle are given by

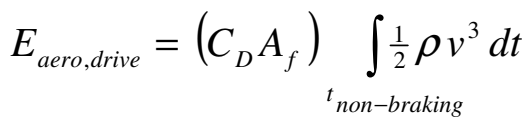

and 


$$
E_{\text {aero,braking }}=\left(C_{D} A_{f}\right) \int_{t_{\text {braking }}} \frac{1}{2} \rho v^{3} d t
$$

where the integrals are performed over all periods of the drive cycle for which the tractive force is determined to be non-braking and braking, respectively. In the same way that the expected tractive energy savings due to lower rolling resistance can be calculated from a reduction in the coefficient of rolling resistance, the savings associated with aerodynamic drag reductions can be estimated based on a change to the product $C_{D} A_{f}$. The value of $C_{D}$ and $A_{f}$ are not generally known very precisely for a particular configuration, and the reduction of $C_{D} A_{f}$ due to individual drag reduction devices can depend on the initial configuration. Nonetheless, the reduction in the drag can be quantified through aerodynamic testing, and expected percentage improvements in the aerodynamic drag may be available for specific devices or combinations of devices.

A suggested method to express the potential for reducing the driving tractive energy for aerodynamic devices is to consider the relative savings in tractive energy that can be obtained from a given percentage reduction in the coefficient of aerodynamic drag. For example, aerodynamic drag reductions on the order of $10 \%-25 \%$ are feasible with some of the existing aerodynamic drag reduction devices available. It makes sense, therefore, to quantify the benefits in energy savings in terms of a reduction of the driving tractive energy per percentage improvement in the aerodynamic drag. This is calculated as

$$
S_{\text {aero, drive }}=\frac{\Delta E_{\text {aero,drive }} / E_{\text {trac,drive }}}{\Delta\left(\mathrm{C}_{D} A_{f}\right) /\left(C_{D} A_{f}\right)}=E_{\text {aero,drive }} / E_{\text {trac, drive }}
$$

Note that the frontal area typically does not change, and in this case the denominator reduces to a percentage change in just the aerodynamic drag coefficient. The corresponding sensitivity value for the braking tractive energy is given by

$$
S_{\text {aero,braking }}=E_{\text {aero,braking }} / E_{\text {trac,braking }} .
$$

Note that the sensitivity values for the aerodynamic drag are defined differently than the rolling resistance sensitivity terms (which are based on an absolute change in the rolling resistance coefficient) since the drag coefficient is not normally characterized precisely, and quantifying the savings with respect to a percentage change in the drag coefficient is expected to be easier to comprehend than basing the sensitivity on an absolute change in the drag coefficient. Of course, a definition in terms of the absolute change in $C_{D}$ can be used if this is more desirable for a particular application.

\subsubsection{Hybridization (Regenerative Braking Energy Savings)}

For a hybrid vehicle that uses regenerative braking, energy savings are achieved by recovering kinetic and potential energy with the regenerative braking system as opposed to dissipating the energy by applying the brakes. The mechanical energy is converted to another form, is stored temporarily in a storage device, and is later converted back to mechanical energy to propel the vehicle when needed at a later time. There are many subtleties and practical complexities associated with the design of a hybrid vehicle, and for different vehicle applications, the control strategies and hardware used need to be 
carefully selected to provide performance that is optimal but balanced with the cost of the additional complexity of the system. Different design approaches will lead to different efficiencies of the hybrid system, which will obviously impact the actual fuel efficiency improvements achieved. The tractive energy analysis presented here does not directly deal with these complexities, but rather addresses the maximum efficiency improvement that can be realized if the braking tractive energy can be recovered and reused, assuming optimal performance. The braking energy losses normally represent the greatest impact on fuel consumption that hybridization can affect, and understanding the overall energy savings potential associated with characteristic drive cycles is the primary objective of this analysis. It is noted that the actual benefit of a real system can be estimated from the tractive energy savings potential by applying appropriate efficiency factors to the tractive energy results. For example, if the tractive energy analysis predicts that $20 \%$ of the tractive energy is lost through braking, the savings that would be possible for an actual hybrid system that is $80 \%$ efficient overall would be $16 \%$ ( 0.8 multiplied by 0.2 ). And while there may be other complexities in the hybrid operation, such as maximum power limitations or total energy capacity of the energy storage system, these can be evaluated in more detailed studies if energy savings potential with hybrid systems is identified for particular trucking applications. In summary, while it is noted that there are limitations to the tractive energy analysis, the benefits of its simplicity make it very applicable for the intended use of the results.

The energy that regenerative braking can recover is the braking energy, and the braking force can come either from the vehicle braking system or engine braking. The tractive energy analysis does not treat the two differently since the calculations are based only on the vehicle speed and do not rely on information about brake application, etc. The force required for braking is equal to the absolute value of the tractive force during the periods of braking tractive force, and is obtained from Eq. (1),

$$
F_{\text {brakes }}=-\left(m \frac{d v}{d t}+m g \sin \theta+F_{\text {aero }}+F_{R R}\right) .
$$

Positive values for the braking force are taken for convenience. The braking power, during periods of negative tractive force, is therefore calculated from the following equation:

$$
P_{\text {brakes }}=-\left(m v \frac{d v}{d t}+m g v \sin \theta+P_{\text {aero }}+P_{R R}\right) \text {, }
$$

and the value is 0 otherwise. The braking energy over the drive cycle is calculated by integrating the braking power, and the result is

$$
E_{\text {brakes }}=-\left[\frac{1}{2} m \sum_{i, \text { braking }}\left(v_{e, i}^{2}-v_{s, i}^{2}\right)+m g \sum_{i, \text { braking }}\left(h_{e, i}-h_{s, i}\right)+E_{\text {aero,braking }}+E_{R R, \text { braking }}\right]
$$

where $v_{s, i}$ and $v_{e, i}$ are the speeds at the start and end of each braking time segment $i$, and $h_{s, i}$ and $h_{e, i}$ are the elevations at the start and end of each braking segment. The summations are performed over all of the segments where the tractive force is braking.

The energy consumed by the brakes is not included explicitly in the driving tractive energy, but vehicle braking does act as a dissipative force, in a manner similar to rolling resistance and aerodynamic drag, 
that results in additional tractive energy being required to travel the distance traveled over the drive cycle. As observed in section 2, dissipative braking applied during any portion of the drive cycle results in the required driving tractive energy (which is provided by the engine) increasing relative to the net tractive energy. The braking is, in fact, the only reason that the driving tractive energy exceeds the net tractive energy. While the nature of braking causes it to be treated somewhat differently in the tractive energy analysis than the rolling resistance or aerodynamic drag, it is still a fundamental dissipative force. Regenerative braking allows the energy that would otherwise be dissipated to be converted to another form of energy and stored so that it can be used at a later time during the drive cycle. (It should be noted that, in many cases, if a driver can avoid the need to actively brake the vehicle, by anticipating traffic slowdowns ahead and allowing the vehicle to coast early-on as opposed to maintaining a higher speed and then braking at the last minute, this can be more effective for improving fuel efficiency than regenerative braking, since the energy conversions associated with the regenerative braking are not fully reversible and therefore reduce the total energy that was initially available as kinetic and/or potential energy.) The contribution of the brakes to the driving tractive energy (this wording seems logically incorrect, but use of the brakes does in fact cause the driving tractive energy to increase) is a function of how the vehicle is driven, so there is no characteristic coefficient associated with the braking energy as was the case with the rolling resistance and aerodynamic drag, and the magnitude of the braking energy contribution to the driving tractive energy can vary significantly among different drivers and certainly for different trucking applications. This is the main reason that the effectiveness of vehicle hybridization depends strongly on the type of driving that is done, and clearly distinguishing between the various vocations and understanding the benefits of each is a significant issue that the LSDC project aims to address. For quantifying the impact of braking on the tractive energy and understanding the energy savings potential of regenerative braking, we characterize the braking energy contribution with respect to its percentage contribution to the overall driving tractive energy requirement, i.e. by the value of

$$
S_{\text {brakes, drive }}=\frac{E_{\text {brakes }}}{E_{\text {trac,drive }}} \text {. }
$$

Figure 9 shows the braking power and the measured engine power during a 20-minute segment of a drive cycle, along with the speed and elevation. Notice that the periods of braking occur during periods when the engine power is reduced to very low levels, as would be expected. This demonstrates that the calculated braking energy, which is based on the speed and elevation data, gives a realistic signal for the true braking experienced. There are a couple of short periods (e.g., at 860 seconds) during which the calculated braking occurs concurrently with a positive engine power. With the data collected from the Heavy Truck Duty Cycle (HTDC) project, it cannot be ascertained if the brakes were actually applied during these periods, and it is possible that errors (noise) in the speed or elevation data are responsible for such apparent anomalies. In fact, the raw elevation data includes a fair amount of noise, which was filtered from the data in this analysis (this is discussed in a later section), and some additional errors very likely exist in the data. Nonetheless, the impact of these short duration and low magnitude braking signals are minimal on the total braking energy, and for the cases evaluated, their impact on the relative contribution of the braking energy to the positive tractive energy was found to be only a fraction of a percent. For the purposes of this assessment, these relatively small errors are acceptable. For this 
segment of driving, the braking energy accounted for $20.6 \%$ of the total tractive energy input. This level is relatively high, particularly for the long haul application that the data represent. However, in several of the drive cycles analyzed, when significant grades and speed variations were present, the contribution of braking to the driving tractive energy (which is equal to the potential energy savings associated with regenerative braking) was found to be quite large, and in a large portion of the overall cases, the regenerative braking potential exceeded $6 \%$. This result was unexpected, and it may be specific to the fleet for which the duty cycle data was measured. Nonetheless, this result clearly shows the value of this analysis and the importance of collecting additional drive cycle data for a broad crosssection of the trucking industry. We will return to examine results from several drive cycles and compare the energy savings potential from different technologies in section 4 , but this case is very illustrative of the benefits that the tractive energy analysis can provide overall.

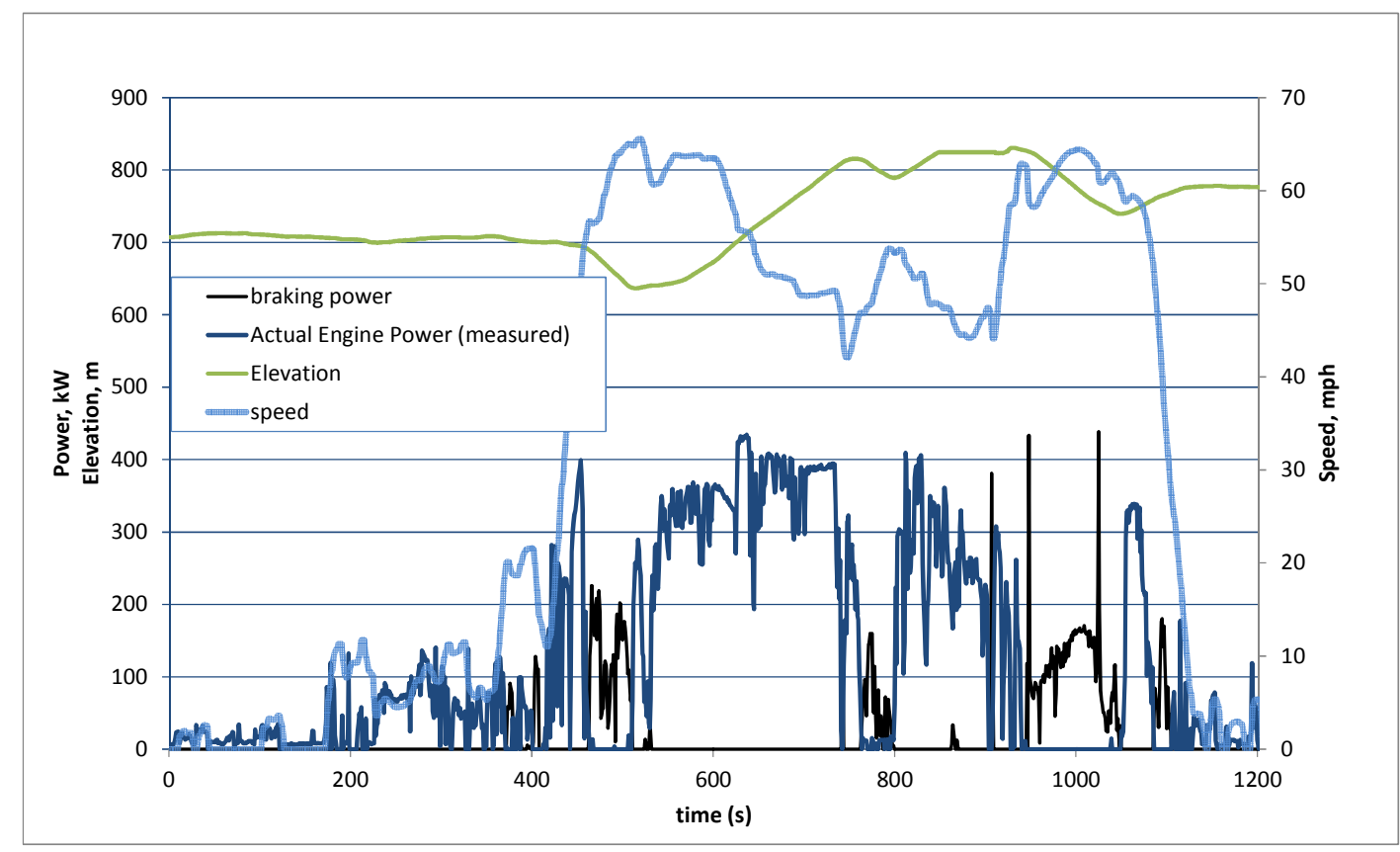

Figure 9. Calculated braking power, plotted with engine power, for a drive cycle with significant elevation and speed variations.

It should be noted that once the savings in tractive driving energy are calculated, the impact on the fuel consumption can be determined using Eq. (10). This allows a comparison of the fuel savings potential for technologies impacting the tractive energy to be compared to other technologies that reduce fuel consumption without modifying the tractive energy requirements.

\subsubsection{Idle Reduction}

Idling accounts for a large amount of fuel consumption in the U.S., and there have been recent initiatives in many states to curb idling, with new regulations that specify maximum durations that trucks are permitted to idle when stopped. Several studies have been undertaken to provide estimates of the idling that takes place and the fuel that can be saved [5-7], but it is acknowledged that these estimates are not highly accurate. The fuel savings associated with truck idle reduction has largely been 
addressed only for class 8 long-haul operations, where drivers regularly stop at a location and allow the engine to run in order to provide "hotel" functions for the driver, including in-cab temperature control and power for electronic systems. Nonetheless, there are likely other applications for which the fuel savings associated with idle reduction are large enough to justify the investment in idle reduction systems. A secondary issue regarding idle reduction is whether or not engine shutoff at stops during normal driving is worthwhile for trucks. For passenger cars, this function is provided with most hybrid vehicles and it can reduce fuel consumption by modest amounts when operating under stop-and-go conditions. However, this kind of engine on-off operation can lead to deleterious emissions performance [8]. It also generally requires that many of the vehicle accessories, which are traditionally powered by engine-driven belts, be electrically powered if they must function even when the vehicle is at a stop. For trucks, particularly for applications that do not involve a high proportion of stops (e.g. long-haul operations), it is not clear if engine start-stop operation is effective at reducing fuel use and emissions. Collecting operational data from trucks among different trucking applications can allow designers to answer this question and develop systems that can be effective for each application. Analysis of idle reduction will be included as part of the drive cycle evaluations in the LSDC project since it can be easily quantified from the speed data collection. It should be noted that long-term idling (as opposed to idling during stops in traffic) can be quantified only if the data acquisition system is designed to identify when the truck is idling as opposed to stopped with the engine shut off. This can be accomplished if data is collected any time that the engine is running but shuts off when the engine stops, but there are other ways to collect the information needed to quantify the idling operations. In any event, the collection of basic idling data will be specified as part of the request for duty cycle data acquisition services.

While analysis of idling does not involve a tractive energy analysis, we can integrate the evaluation of energy savings potential from idling with the rest of the analysis conducted, and with some basic characterization of the fuel consumption rates associated with the vehicle and the idle reduction device in use, the fuel savings potential can be assessed in much the same way as that of other technologies.

The fundamental measure of the drive cycle that relates to idling fuel consumption is simply the cumulative time spent at idling. For the model, the idle time is calculated based on the total time that the vehicle is stopped. The fuel savings potential for an idle reduction device is given by

$$
\Delta F_{c, \text { idle reduc }}=t_{\text {idle }} \Delta r_{F c}
$$

where $t_{\text {idle }}$ is the total time spent at idle over the drive cycle and $\Delta r_{F c}$ is the difference in the rate of fuel consumption between operations with the engine idling vs. when the idle reduction device is in use. (Typically, an auxiliary power unit, or APU, is used to provide basic cab energy needs during extended periods of idling, but this approach also allows considerations of idle reduction by other means, such as engine start-stop for short-term idling operations.)

Since recorded speed data signals can contain small errors, even at low speeds, a threshold speed value can be used to identify periods of idling. For the analysis of the data from the HTDC project, the vehicle was considered stopped (idling) when the speed at two consecutive times was less than $0.1 \mathrm{~m} / \mathrm{s}(0.36$ 
kph or $0.22 \mathrm{mph}$ ). Differentiating between long- and short-term idling based on a stop duration exceeding a given time value (for example 10 minutes) can be easily implemented, although this was not done for the evaluation of the HTDC data. In order to quantify the fuel savings that an APU can provide, this analysis uses the difference in the rates of fuel consumption when idling the engine and when operating the APU. For the present evaluation, a value of $1.4 \mathrm{~L} / \mathrm{hr}$ was used, but values more appropriate to a particular vehicle and APU selection can be used in a general analysis. For evaluations of the potential fuel savings benefits of engine stop-start technology, quantifying the percentage of the stops and their average duration is usually adequate. When data is collected from multiple vehicles to develop characteristic duty cycles for individual vocations, the full distribution of stops can be provided for more detailed evaluations, if necessary. The details of the idling for drive cycles evaluated will be reviewed in section 4 .

\subsubsection{Mass Reduction}

Quantifying the effect of vehicle mass on fuel consumption is complicated for trucks, for several different reasons. For trucks that carry cargo and operate regularly at the maximum load allowable, if the vehicle mass is reduced, then additional cargo can be carried, which allows greater quantities of goods to be transported with fewer vehicles, and the total vehicle miles traveled (VMT) will be reduced. The mass reduction by itself does not result in any change to the tractive energy if an equivalent mass of additional payload is carried so that the total vehicle mass is the same. Nonetheless, each truck carrying a greater load provides fuel savings over the entire trucking fleet, even if the fuel consumption for individual vehicles is not reduced. To quantify this effect, it is appropriate to consider the load specific fuel consumption [9], defined as the fuel consumed per distance traveled and per ton of cargo transported.

When a vehicle does not operate at its maximum load capacity, either for cargo applications for which the maximum load is not carried (e.g., for a low density payload that is "cubed out" - the volume of the trailer is filled before the maximum payload weight is reached-or for less than truckload (LTL) operations) or trucking applications that do not rely on hauling cargo, the reduced mass results in a reduction of the tractive energy. In this situation, there is a proportional decrease in the contributions to the driving tractive energy associated with the tire rolling resistance and gravitational contributions, but the contribution from aerodynamic drag does not depend on the vehicle mass, nor are the braking energy losses directly proportional to the mass. For these reasons, the fuel savings that can be achieved from a change in mass for the same drive cycle cannot be quantified by applying the same type of differential analysis that was used for the rolling resistance and aerodynamic drag. As an alternative, the tractive energy analysis can be repeated at different mass levels and the energy savings associated with the mass reduction can be quantified directly. The difference in the driving tractive energy for the full mass case and the reduced mass case gives the overall savings potential for the mass effect, and we quantify the savings on a per metric ton basis:

$$
S_{\text {mass,drive }}=\frac{\Delta E_{\text {drive,due to mass }} / E_{\text {trac,drive }}}{\Delta \mathrm{m} / 1000 \mathrm{~kg}}=\frac{E_{\text {trac }, \text { drive }}(\text { full mass })-E_{\text {trac }, \text { drive }}(\text { reduced mass })}{E_{\text {trac,drive }}(\text { full mass })} / \frac{\Delta m}{1000 \mathrm{~kg}} \cdot(27 \mathrm{a})
$$

The sensitivity to mass changes for the braking tractive energy is calculated as 


$$
S_{\text {mass,braking }}=\frac{E_{\text {trac,braking }}(\text { full mass })-E_{\text {trac,braking }}(\text { reduced mass })}{E_{\text {trac,braking }}(\text { full mass })} / \frac{\Delta m}{1000 \mathrm{~kg}} .
$$

This approach can give reasonable estimates for mass changes that are relatively small, but a large percentage change in mass can fundamentally change the characteristics of a drive cycle, so assuming that the same accelerations will be followed is not likely to yield very accurate results. If one considers the accelerations of a fully-loaded truck as compared to an empty truck, this effect should be apparent. Differences in acceleration performance and safety limitations with different vehicle masses, in addition to differences in driver behavior as a result of these performance differences, can have an important effect on the acceleration levels followed when mass changes significantly, and there is no obvious way to adequately model these effects. Fortunately, these considerations are not expected to be of great practical significance. In general, one would not expect that dramatic mass savings can be achieved technically for realistic truck designs, so it seems appropriate to consider relatively small changes to the mass following the approach outlined.

Although the tractive energy analysis by itself cannot provide the complete data necessary to quantify the effect of mass reduction on the entire U.S. trucking fleet (due to the effect of fully loaded vehicles vs. partially loaded vehicles), the LSDC project will quantify the loads carried by freight trucks along with the drive cycles. The vehicle mass is required for calculating the tractive energy and will be determined as part of the analysis for each vehicle. The approach for estimating the vehicle mass is developed in Section 4.2. The distribution of loads can then be used to perform a detailed evaluation of the total fuel savings potential that can be achieved with mass reductions, both for fully loaded and partially loaded trucks, as described above. Within individual trucking fleets, the load distributions are well known, and the fuel efficiency benefits of mass reductions can be evaluated quite accurately using this approach.

For the purposes of the evaluations performed with the HTDC data for the current evaluation, only the effects of mass reductions that impact the tractive energy were evaluated, and no effort was made to consider the efficiency gains associated with additional load carrying capacity for cases where the trucks operate regularly at the maximum gross load. For these evaluations, the mass impact on the driving tractive energy was estimated with an assumed mass reduction of 2,000 kg. This is small enough relative to the total vehicle load that the accelerations corresponding to the original drive cycle is believed to remain relevant.

\subsubsection{Driveline or Engine Efficiency}

Energy losses due to friction that are present in the transmission, differential, bearings and any other elements of the driveline are typically responsible for dissipation of about $10 \%$ of the brake work, and these energy losses are accounted for through the use of a single transmission efficiency value $\eta_{\text {trans, }}$ as shown in Eq. (7). The transmission efficiency is upstream of the tractive energy inputs, so accounting for these energy losses and evaluating energy savings benefits from improved transmission efficiency must use the required driving tractive energy as an input. By using Eq. (10), which relates the tractive energy to the fuel consumption due to the tractive energy inputs, and includes both the engine and driveline efficiencies, we can determine the fuel energy savings associated with reductions in the transmission 
efficiency. If the driveline or the engine efficiency are improved with a given technology, Eq. (10) can be used to estimate the fuel consumption associated with the efficiency improvement by direct calculation. Since these efficiencies do not affect the tractive energy directly, the tractive energy calculation can be done independently of the efficiency calculations. This fact makes the calculation of the impact of engine or driveline efficiency improvements quite straightforward. For engine efficiency improvements, the net fuel savings is a function of the ratio of the engine efficiency values:

$$
\Delta F_{c, \text { engine }}=F_{c, \text { trac }, 1}-F_{c, \text { trac }, 2}=\left(1-\frac{\eta_{\text {engine }, 1}}{\eta_{\text {engine }, 2}}\right) F_{c, \text { trac }, 1}
$$

where subscript 1 refers to the lower efficiency value, and subscript 2 refers to the improved efficiency. The percentage fuel savings due to an improvement in engine efficiency is therefore

$$
\left(\frac{\Delta F_{c, t r a c}}{F_{c, \text { trac }}}\right)_{\text {engine }}=1-\frac{\eta_{\text {engine }, 1}}{\eta_{\text {engine }, 2}}
$$

which is entirely independent of the tractive energy. This equation assumes an average value of engine efficiency and might not be appropriate for all engine efficiency improvements if the efficiency gains are not uniform across different operating conditions. However, for the intended use in evaluating general energy savings potential due to technology applications, this should be sufficient.

For an improvement in the transmission efficiency, the net fuel savings can be calculated from the following:

$$
\Delta F_{c, \text { trans }}=\frac{E_{\text {trac,drive }}}{\eta_{\text {engine }} \text { LHV }}\left(\frac{1}{\eta_{\text {trans }, 1}}-\frac{1}{\eta_{\text {trans }, 2}}\right)
$$

In this case, the fuel savings is not proportional to the initial consumption, so the relative fuel savings due to an improvement in driveline efficiency, if desired, should be calculated directly from the ratio of fuel savings to the original fuel consumption.

\subsection{Combinations of Technologies}

The equations developed in section 3.2 allow the fuel savings benefits of individual technologies (based on parameter changes associated with each technology) to be compared for any input drive cycle. This approach, when used with drive cycles that are representative of a given trucking application or of a particular fleet's operations, can be used to quantify the fuel savings that each of these technologies can be expected to generate for the corresponding application. By determining the energy savings potential, the technologies can be prioritized relative to the efficiency improvements and a selection of technologies that offer the greatest benefits relative to the cost is possible so that better decisions can be made regarding technology investments. Also of interest is to evaluate the fuel savings potential when multiple technologies are used in combination with one another.

The driving tractive energy and the fuel consumption corresponding to the tractive energy requirement can be estimated, by direct calculation, for any combination of input parameters using the equations 
developed in earlier sections of this report. While such an approach provides a means to consider any range of combinations of technologies, the time to perform a set of calculations for different sets of parameter combinations, especially for long drive cycles, can be impractical. The analysis in section 3.2 included discussions of, and laid the groundwork for estimating, the fuel savings when combinations of technologies are deployed simultaneously. This was done by developing sensitivity values for each of the parameters of interest for the various technologies. Not only do the fuel efficiency sensitivities allow a means to quickly quantify the benefits that can be achieved with individual technologies, but they can also be used to estimate the fuel consumption for different values of the input parameters without the need to repeat the tractive energy analysis for a new set of parameters. This analysis allows accurate estimates to be made for any combination of input parameters. The equations necessary to estimate the fuel consumption benefits of any combination of the technologies considered are fully developed in this section.

As was observed in the preceding sections, the impact on fuel consumption of technologies that change the driving tractive energy is different than those that do not, and the net effect of combining changes from these two classes of efficiency technologies can be treated by first quantifying the tractive energy changes and then applying the non-tractive efficiency parameters to determine the effect on the fuel consumption. Combinations among those technologies that impact the tractive energy directly-low rolling resistance, aerodynamic drag reduction, vehicle mass reduction and regenerative braking - can influence the fuel consumption in a way that the associated fuel savings are not simply additive to one another and cannot be determined without considering interactions among the different tractive energy contributions. On the other hand, the effect of idle reduction, as well as engine and/or driveline efficiency changes, do not influence the tractive energy calculation, and the impact on fuel consumption of these technologies can be easily calculated for any values of the associated parameters without considering interactions among the technologies that do impact the tractive energy. This situation makes the approach needed for calculating the fuel savings associated with any combination of parameters clear: the tractive energy variations must first be evaluated using the sensitivity analysis, followed by a calculation of the fuel consumption, which includes the effects associated with the changes to the tractive energy combined with any other changes to the parameters that do not influence the tractive energy. The remainder of this section develops the equations needed to perform these calculations.

\subsubsection{Combinations that Impact the Tractive Energy}

To estimate the change in driving tractive energy that can be expected when advanced efficiency technologies are used, the first step is to calculate the driving tractive energy and the sensitivity values for the base set of input parameters that impact the driving tractive energy (i.e., the coefficient of rolling resistance, aerodynamic drag coefficient, and vehicle mass). In the initial calculation, it is assumed that the vehicle does not use regenerative braking, so the driving tractive energy is the appropriate measure of the required work input from the engine. The baseline parameter set is not critical as long as the vehicle mass used in the calculation is relevant to the drive cycle collected. The importance of vehicle mass was discussed in section 3.2.5 and will not be repeated here. For the rolling resistance and aerodynamic drag coefficient parameters, it is the evaluation of variations to the tractive energy that 
matter, not the original value, so it is not important in the initial calculation to use values corresponding to the specific vehicle being evaluated. Changes to the driving tractive energy relative to the baseline configuration are then calculated using a variational analysis based on the sensitivity values for each parameter variation. If vehicle hybridization is being considered, the energy savings potential for regenerative braking is calculated by reducing the driving tractive energy by the braking tractive energy, but changes to the braking tractive energy due to variations of the other parameters must be accounted for in the same manner as those of the driving tractive energy.

In terms of the parameters developed in the earlier sections, the change in the driving tractive energy for variations to the rolling resistance, aerodynamic drag coefficient and mass is determined from the following equation:

$$
\begin{aligned}
& \Delta E_{\text {trac, drive }}=E_{\text {trac,drive }}\left(C_{R R}, C_{D}, m\right)-E_{\text {trac,drive }}\left(C_{R R}-\Delta C_{R R}, C_{D}-\Delta C_{D}, m-\Delta m\right)= \\
& \quad-E_{\text {trac,drive }}\left(C_{R R}, C_{D}, m\right)\left[S_{R R, \text { drive }}\left(\frac{\Delta C_{R R}}{1 \mathrm{~kg} / \text { ton }}\right)+S_{\text {aero,drive }}\left(\frac{\Delta \mathrm{C}_{\mathrm{D}}}{\mathrm{C}_{\mathrm{D}}}\right)+S_{\text {mass,drive }}\left(\frac{\Delta m}{1000 \mathrm{~kg}}\right)\right] .
\end{aligned}
$$

The variation in braking tractive energy is calculated in the same way:

$$
\begin{aligned}
\Delta E_{\text {trac,braking }} & =-E_{\text {trac,braking }}\left(C_{R R}, C_{D}, m\right) . \\
& {\left[S_{R R, \text { braking }}\left(\frac{\Delta C_{R R}}{1 \mathrm{~kg} / \text { ton }}\right)+S_{\text {aero,braking }}\left(\frac{\Delta C_{D}}{C_{D}}\right)+S_{\text {mass,braking }}\left(\frac{\Delta m}{1000 \mathrm{~kg}}\right)\right] . }
\end{aligned}
$$

When vehicle hybridization is considered, regenerative braking provides the opportunity to recover the dissipated energy from the brakes, $E_{\text {brakes. }}$. If we assume that the regenerative braking has an overall efficiency $\eta_{\text {regen, }}$, the total tractive energy is given by

$$
E_{\text {trac, hybrid }}=E_{\text {trac,drive }}-\eta_{\text {regen }} E_{\text {trac,brakes }} .
$$

Using the sensitivity analysis, the variation to the braking energy is given by $\Delta E_{\text {trac,braking, }}$ and the relevant tractive energy when regenerative braking is used in combination with variations to the rolling resistance, aerodynamic drag and/or mass is given by

$$
\begin{aligned}
& E_{\text {trac,hybrid }}\left(C_{R R}-\Delta C_{R R}, C_{D}-\Delta C_{D}, m-\Delta m\right)= \\
& \quad\left(E_{\text {trac,drive }}\left(C_{R R}, C_{D}, m\right)-\Delta E_{\text {trac,drive }}\right)-\eta_{\text {regen }}\left(E_{\text {trac,brakes }}\left(C_{R R}, C_{D}, m\right)-\Delta E_{\text {trac,braking }}\right)
\end{aligned}
$$

This result reflects an interesting synergy that occurs when regenerative braking is combined with other energy efficiency technologies. To see this more clearly, note that if variations to the rolling resistance, aerodynamic drag and/or mass are used without regenerative braking, then the tractive energy savings

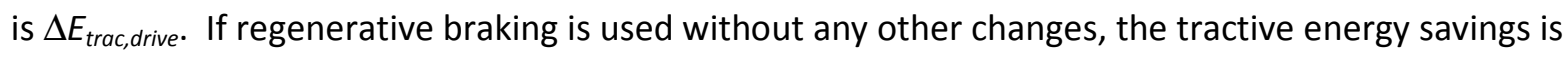
$\eta_{\text {regen }} E_{\text {trac,brakes }}\left(\mathrm{C}_{\mathrm{RR}}, \mathrm{C}_{\mathrm{D}}, \mathrm{m}\right)$. By combining the regenerative braking with other tractive energy savings technologies, the additional term, $\eta_{\text {regen }} \Delta E_{\text {trac,braking, }}$, is present in the tractive energy savings. Since the contributions from the rolling resistance and aerodynamic drag cause the braking energy to increase when the respective coefficients decrease, this term is additive for these changes (although mass reductions do cause the braking energy to decrease). The additional savings occurs since any reductions in tractive energy associated with rolling resistance or aerodynamic drag during periods of 
braking are simply dissipated by the brakes for a conventional vehicle (which means a greater torque is required from the brakes to produce the same deceleration), while this additional energy can be recovered when regenerative braking is used. This additional energy savings potential can increase the fuel savings potential of aerodynamic drag reductions and low rolling resistance to the point that they become favorable for a hybrid application even when their benefits without regenerative braking is not worthwhile.

\subsubsection{Converting Tractive Energy Reductions to Fuel Savings and Combining Tractive Energy Results with Other Efficiency Gains}

Once the tractive energy savings potential for selected technologies is accounted for, the next step is to estimate the fuel savings associated with the tractive energy reductions. For this calculation, if engine or driveline efficiency improvements will be evaluated simultaneously, the higher efficiency values are simply used in the fuel consumption calculation to account for their effect on the total fuel savings. As discussed previously, the engine and driveline efficiency values are largely independent of the drive cycle itself, so there are no interactions between this calculation step and those used for evaluating the tractive energy. As a final step, if an idle reduction technology is to be considered for the evaluation scenario, the fuel savings potential calculated from Eq. (27) is added to those coming from the tractive energy and engine efficiency improvements. Since idle reduction technologies are associated with portions of the drive cycle for which there is no tractive energy requirement, the associated fuel savings are independent of those from the preceding step. The end result is the total fuel consumption for the set of operational parameters and technologies under consideration. This is calculated by combining Eq. (10) with the appropriate tractive energy requirement and including the idle reduction fuel savings, if appropriate:

$$
F_{c, \text { final }}=\frac{1}{\eta_{\text {engine }}^{\prime} L H V}\left(\frac{E_{\text {trac } \text { final }}}{\eta_{\text {trans }}^{\prime}}+E_{\text {acces }}\right)+\Delta F_{c, \text { idle reduction }}
$$

The values of $\eta_{\text {trans }}^{\prime}$ and $\eta_{\text {engine }}^{\prime}$ are the driveline and engine efficiency used in the scenario under consideration, and the value of $E_{\text {trac,final }}$ is the appropriate tractive energy result for the selected technology evaluation scenario. If idle reduction is not considered as part of the evaluation, then the $\Delta F_{c, \text { idle reduction }}$ value should be set to zero, but the value from Eq. (27) is used otherwise. The overall fuel savings associated with the selected technologies is calculated simply as the difference between the consumption for the reference vehicle configuration and that of the final configuration under consideration.

\section{Demonstration of the Tractive Energy Analysis}

The tractive energy analysis is intended to provide a measure of the energy savings potential that can be achieved with various technologies or technology combinations. In order to demonstrate the calculation procedure and to compare results from different types of drive cycles, the equations presented in this report for the fuel savings estimates were programmed into an Excel spreadsheet, and macros were developed to import selected drive cycle data for analysis, and to perform various operations for post-processing of the results. Most of the figures presented in this report were 
extracted from these analysis spreadsheets, and the various intermediate results presented have substantiated that the overall methodology and the accuracy of the tractive energy analysis approach is acceptable.

This section shows several specific results of individual technology scenarios and drive cycles to highlight the usefulness of the tractive energy analysis as well as to demonstrate a range of results that can be obtained with different types of drive cycles. Although the data from the Heavy Truck Duty Cycle (HTDC) project used for this analysis was all measured from class 8 combination trucks, the drive cycles include some off-highway driving in addition to a large percentage of driving on the freeway. This data set is somewhat unique in that the trucking fleet measured for the project is located in central Tennessee, and the highways traveled include a relatively high level of elevation changes. Consequently, the tractive energy results from this data are not likely to be typical of long-haul trucking operations in different regions of the U.S. Nonetheless, the measurements from the HTDC project provide a rich data set from which different examples are used to demonstrate the importance of various duty cycle characteristics on the benefits that can be realized with different technology categories, and the variety of data shows the broad range of variation that exists even within the same trucking application. The drive cycle measurements and analysis planned for the LSDC project will be used to characterize this variation for each trucking application and help understand how it influences vehicle fuel consumption and the savings that can be achieved with different technologies. Even though the HTDC data were recorded from long-haul operations, some of the drive cycles considered have characteristics that one might expect from other trucking applications such as urban delivery. The results from these analyses are therefore interesting from the standpoint of comparing the benefits of different technologies for drive cycles that are more representative of different trucking applications.

For the present evaluation of the tractive energy analysis method, no effort was made to develop a single characteristic duty cycle that is representative of the average usage. As part of the Medium Truck Duty Cycle (MTDC) project, which is on-going, a tool currently under development at ORNL, referred to as the Duty Cycle Generation Tool (DCGen Tool), will allow the automated combination of multiple sets of duty cycle data to create a reduced, synthetic drive cycle that has similar speed, acceleration and elevation characteristics to the original drive cycles. At the current stage of development, the tool is capable of performing the duty cycle synthesis without considering the elevation data. For the purposes of the present analysis, it was not considered worthwhile to use the DCGen Tool without the functionality to include elevation data. As an alternative, several different raw duty cycles were evaluated. The drive cycle data was initially reviewed using the DCGen Tool to consider the distribution of speed and acceleration data. Several cycles with different characteristics, including varying degrees of road grade and different combinations of highway vs. off-highway operations, were selected to perform the analysis.

\subsection{Sample Results for Six Drive Cycle Cases}

Over 100 days' worth of drive cycle data were reviewed and considered for analysis, and over 30 cases were run using the approach developed in this project to quantify the energy savings potential. Of these, we present results that illustrate how differences in drive cycle characteristics cause the benefits of various fuel efficiency technologies to vary. Since the data from the HTDC project that was analyzed 
was recorded from trucks that operate predominantly in long-haul operations, the majority of results are from freeway driving. Nevertheless, variations in drive cycle do exist, and cases with very constant speed are compared to cases with greater speed variation and drive cycles where significant elevation changes are present. Also, segments from some of the drive cycles including off-freeway driving are presented to characterize the energy savings potential that might be expected from trucking applications that do not include significant freeway travel. The following set of drive cycles were selected to make these comparisons and illustrate the tractive energy analysis methodology:
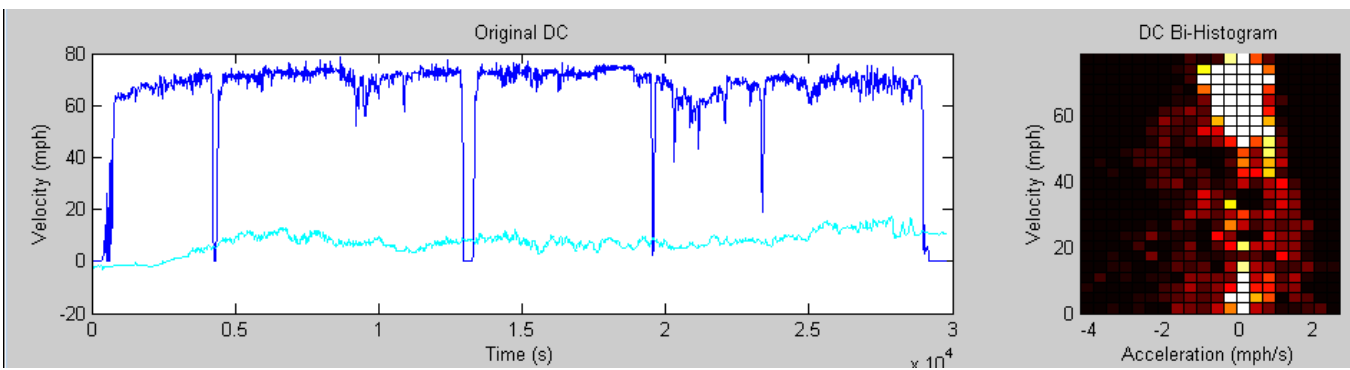

Cycle 4
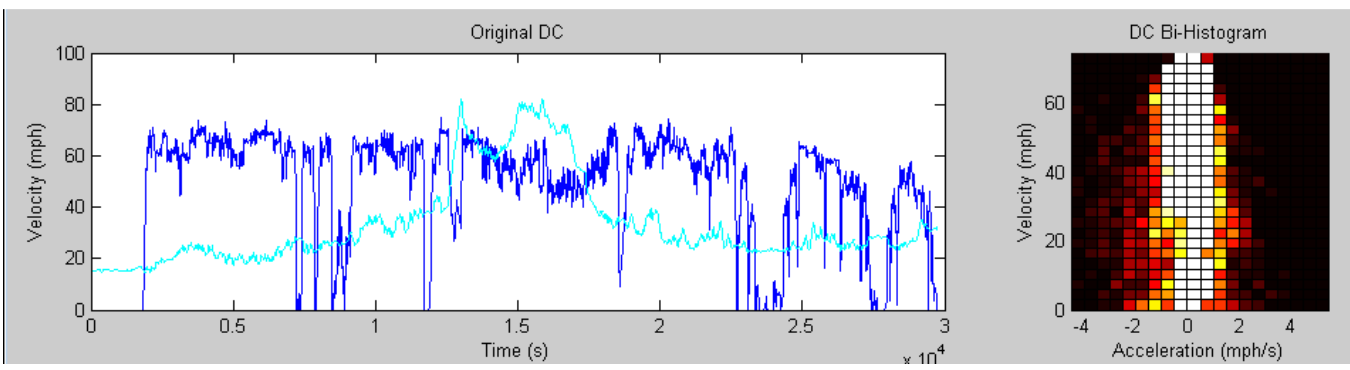

Cycle 5
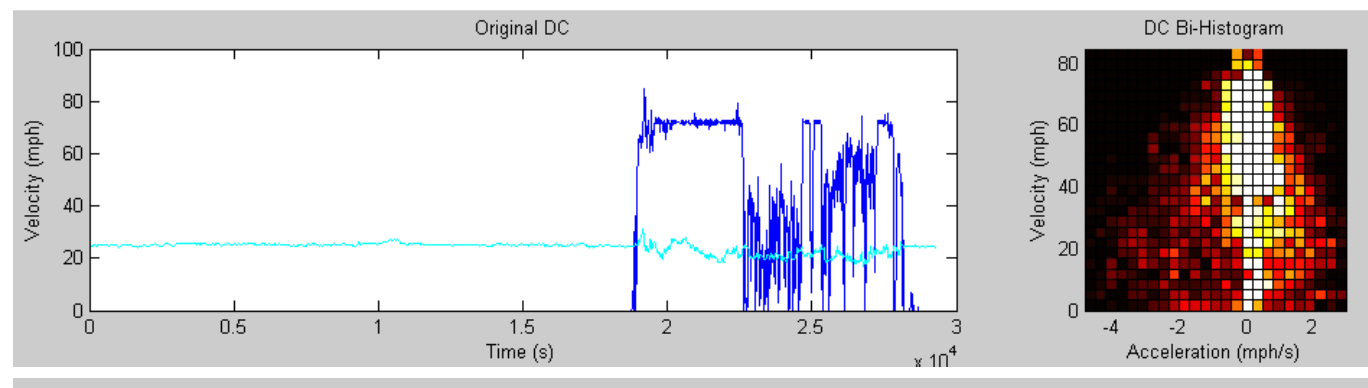

Cycle 18
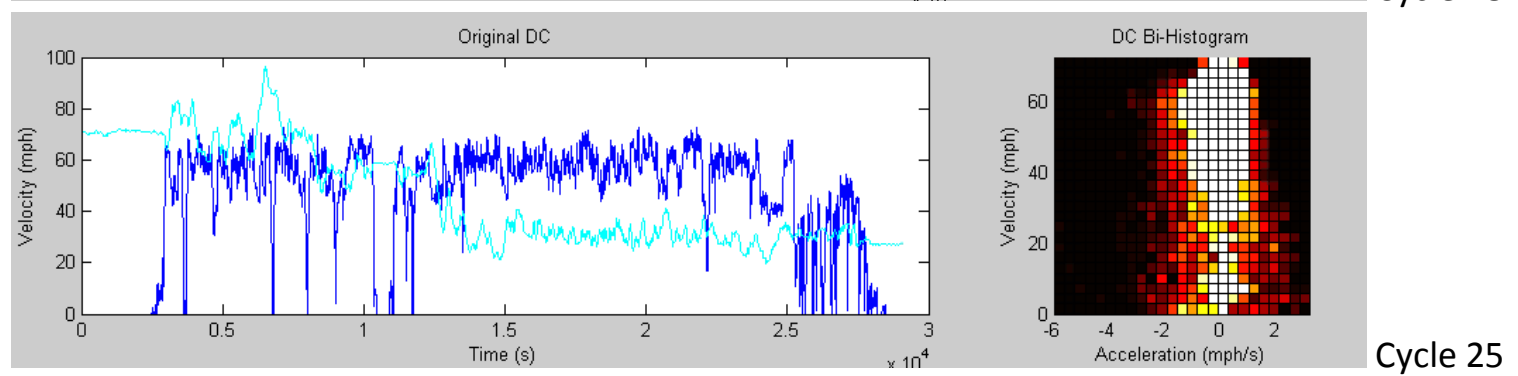

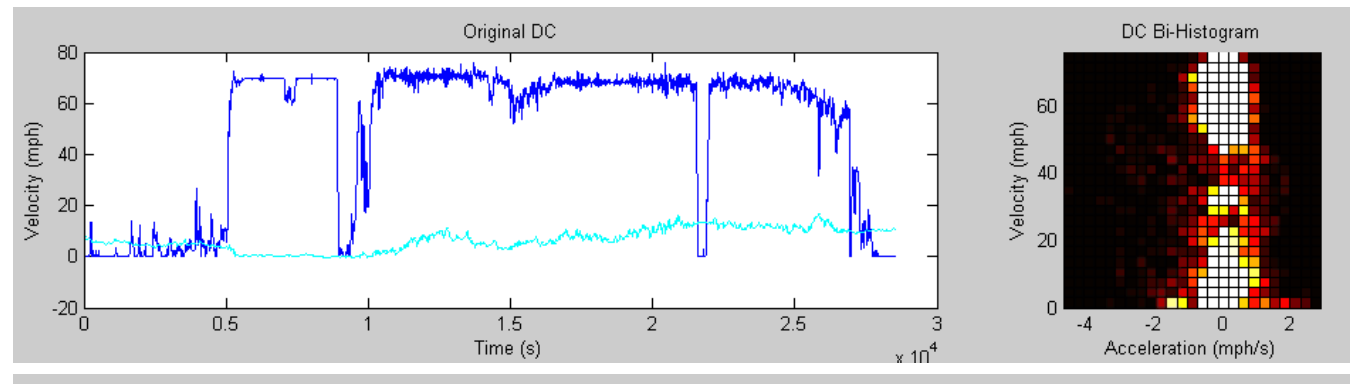

Cycle 38
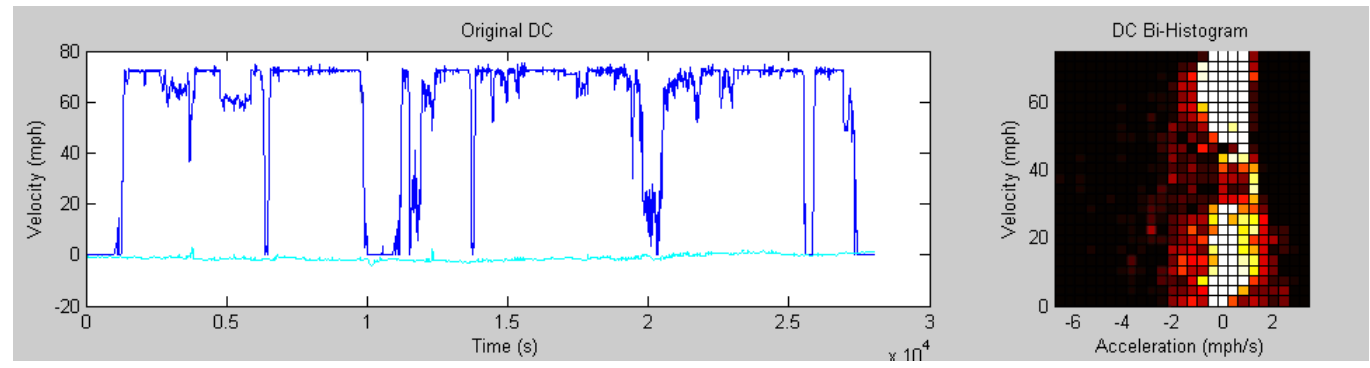

Cycle 54

Figure 10. Drive cycles selected for the analysis demonstration.

The dark blue curve in each cycle presented Fig. 10 is the speed history trace for the drive cycle, while the cyan curve represents elevation data (in $\mathrm{m}$ ) plotted at $1 / 10$ scale on the same axis. This provides a general indication of the magnitude of elevation changes for each cycle. The bivariate histogram to the right of each drive cycle shows graphically the frequency of occurrences of accelerations at each speed. This is an important characteristic of each drive cycle that can provide an indication of the its severity. The bivariate histogram is also used by the DCGen Tool for providing a metric to compare synthetic drive cycles and the original cycles that they were derived from.

For all of the calculations performed, the value of the lower heating value (LHV) used was $35.8 \mathrm{MJ} / \mathrm{L}$, corresponding to that of U.S. conventional diesel [10]. Table 1 shows the default values for the primary parameters used in the analysis. These values were selected to be representative of typical class 8 tractor trailers. Although precise values are not known for each parameter for each of the vehicles measured, the primary data of interest-the sensitivity values corresponding to each of the technologies-do not depend strongly on the values of the parameters used in the analysis.

Table 1. Default parameters used for the tractive energy analysis

\begin{tabular}{|c|c|c|c|c|c|c|}
\hline $\mathrm{C}_{\mathrm{d}}$ & $\mathrm{C}_{\mathrm{RR}}, \mathrm{kg} / \mathrm{T}$ & $\eta_{\text {eng }}$ & $\eta_{\text {trans }}$ & LHV, MJ/L & $\mathrm{P}_{\text {access, }} \mathrm{kW}$ & $\eta_{\text {regen }}$ \\
\hline 0.62 & 7.0 & 0.42 & 0.9 & 35.8 & 14.9 & 0.80 \\
\hline
\end{tabular}

Of the drive cycles selected for this evaluation, Cycle 18 (see Fig. 10) is the only case that includes a period of extended idling, which lasts about 5 hours at the beginning of the drive cycle. Nonetheless, this was relatively common among the full set of drive cycles from the HTDC database that were examined. About 15\% of all the drive cycles reviewed included idling of durations exceeding 3 hours. Since the data files were recorded for any periods of continuous engine operation, these long duration idle sessions are, in most cases, times when the drivers rested in their vehicles overnight. As in the Cycle 18 case, the idling most frequently occurred at the beginning of the data file. Since new files were 
automatically opened when the date changed (at midnight each day), these cases represent periods when drivers were sleeping in the cabs of their trucks and allowed the engine to idle to maintain climate control, etc. This timing was verified for a number of cases, although not all, and this is clearly the situation in most of the cases. For most of these conditions, it is also likely that the idle durations were longer than the periods recorded, assuming that the drivers arrived at their resting location before midnight. In any event, the extended periods of idling were evaluated in only a few cases since this consists only of determining the total duration of the idling to estimate the fuel consumption corresponding to those periods (and the fuel savings potential of idle reduction devices). In the other cases, any extended periods of idling were removed from the drive cycle. Since the idling present in the remainder of the drive cycle was still evaluated, the idle reduction potential that is reported for these cycles mainly represents savings that could be achieved by using engine start-stop technology (although there were some periods of intermediate-term idling-10 minutes or more-present in the drive cycles that were not removed. For example, in Cycle 54, there is a period of idling starting at about 10,000s that lasts about 1000 s. The total duration of such idling in most cases is fairly small, however.

To provide some indication of the benefits of idle reduction, for Cycle 18 the analysis was conducted including the long-duration idle segment at the beginning of the drive cycle. The fuel consumption due to idling was calculated to be $10.6 \mathrm{~L}$, which represents $9.5 \%$ of the total fuel consumed for this drive cycle. The total duration of driving for this drive cycle is relatively short in relation to the idling, so the percentage benefit for idling is probably exaggerated relative to the overall savings potential for this fleet. Since this analysis did not develop statistics relative to average overnight idling for trucks in the fleet, we will not spend more time considering this aspect of fuel savings; nonetheless, with about $15 \%$ of the drive cycles including long-duration idling due to hotel functions, the total fuel savings potential of idle reduction technologies for this fleet is expected to be quite large.

We will now consider each of the drive cycles separately. Cycle 4 represents a pure freeway drive cycle that would generally be considered typical of long-haul freight operations. The cycle includes only occasional stops and the average speed of the drive cycle, including stops, is very close to $100 \mathrm{kph}$ (62 $\mathrm{mph}$ ). The speed during the drive cycle is rather consistent between 60 and $75 \mathrm{mph}$, but there are relatively frequent speed variations of several $\mathrm{mph}$ throughout the drive cycle, and these required braking in many cases (one braking event every few minutes was typical), as shown in Fig. 11. These types of variations are typical when cruise control is not used. The periodic occurrences of braking seen in the drive cycle were likely due to traffic constraints (other vehicles) encountered while operating at this speed. 


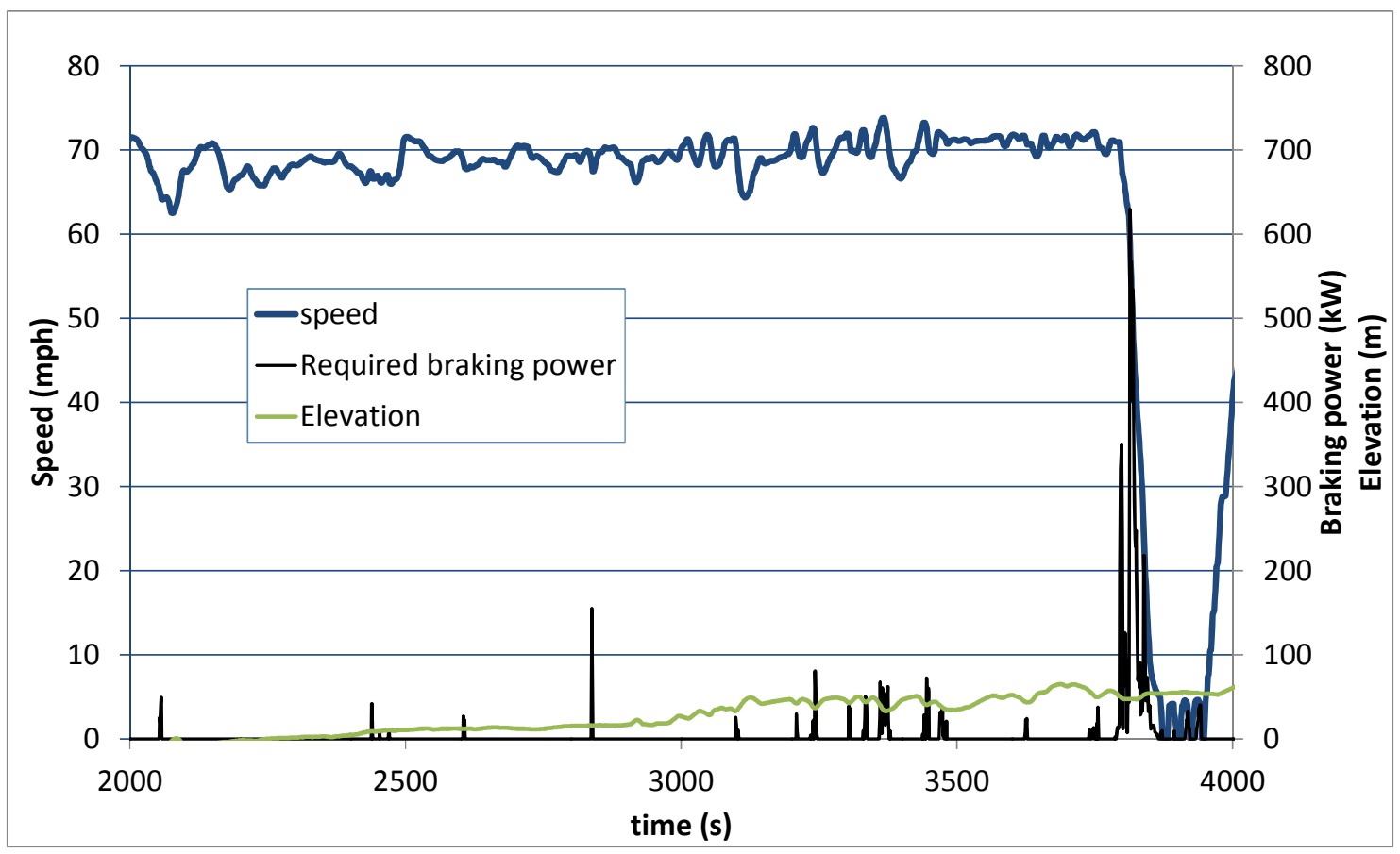

Figure 11. A typical segment from Cycle 4, showing speed variations and braking power requirements.

Table 2 provides a summary of data from the tractive energy analysis for this drive cycle. The rolling resistance contribution to the tractive energy was calculated to be about $35 \%$ of the total, which means that with the coefficient of rolling resistance of $7 \mathrm{~kg} / \mathrm{T}$ used in the calculation, the tractive energy can be reduced by about $5 \%$ for each $\mathrm{kg} / \mathrm{T}$ reduction in the rolling resistance coefficient. This value of $5.0 \% /(\mathrm{kg} / \mathrm{T})$ is the rolling resistance sensitivity factor that appears in the third portion of Table 2 . The aerodynamic drag contributed nearly $56 \%$ to the driving tractive energy for this cycle. This large contribution can be reduced through the use of aerodynamic drag reduction devices and through better streamlining in the tractor design. For each $10 \%$ reduction in the aerodynamic drag coefficient, the tractive energy will therefore decrease by $5.6 \%$, which corresponds to the aerodynamic drag sensitivity factor appearing in the table. Any such reductions in tractive energy will have a nearly proportional impact on the total fuel consumption, which indicates that large benefits can be achieved with rolling resistance and aerodynamic drag reductions for class 8 tractor-trailers operating in a long-haul application. 
Table 2. Summary results of the tractive energy analysis for Cycle 4.

Inputs:
\begin{tabular}{|l|r|r|r|}
\hline Mass $(\mathrm{kg})$ & 22,000 & Time start (s) & 0 \\
$C_{d}$ & 0.62 & Time finish (s) & 28,787 \\
$C_{R R},(\mathrm{~kg} / \mathrm{T})$ & 7.0 & Mass Reduction $(\mathrm{kg})$ & 2,000 \\
\hline
\end{tabular}

\section{Drive cycle characteristics:}

\begin{tabular}{|c|c|c|c|c|c|c|c|c|}
\hline $\begin{array}{c}\text { Cycle } \\
\text { Distance } \\
(\mathrm{km})\end{array}$ & $\begin{array}{c}\text { Total Fuel } \\
\text { Consumed } \\
\text { (L) }\end{array}$ & $\begin{array}{l}\text { Average } \\
\text { Speed } \\
\text { (kph) }\end{array}$ & $\begin{array}{c}\text { Maximum } \\
\text { Speed } \\
\text { (kph) }\end{array}$ & $\begin{array}{c}\text { Maximum } \\
\text { Acceleration } \\
\left(\mathrm{m} / \mathrm{s}^{2}\right)\end{array}$ & $\begin{array}{c}\text { Maximum } \\
\text { Deceleration } \\
\left(\mathrm{m} / \mathrm{s}^{2}\right)\end{array}$ & $\begin{array}{l}\text { Percent } \\
\text { of Time } \\
\text { stopped }\end{array}$ & $\begin{array}{l}\text { Standard } \\
\text { Deviation of } \\
\text { the Speed } \\
(\mathrm{m} / \mathrm{s})\end{array}$ & $\begin{array}{l}\text { Average Speed, } \\
\text { with Stops } \\
\text { Removed } \\
(\mathrm{kph})\end{array}$ \\
\hline 858.92 & 285.66 & 107.41 & 126.86 & 1.21 & 1.93 & 1.31 & 5.94 & 108.77 \\
\hline
\end{tabular}

\section{Tractive Energy Summary results:}

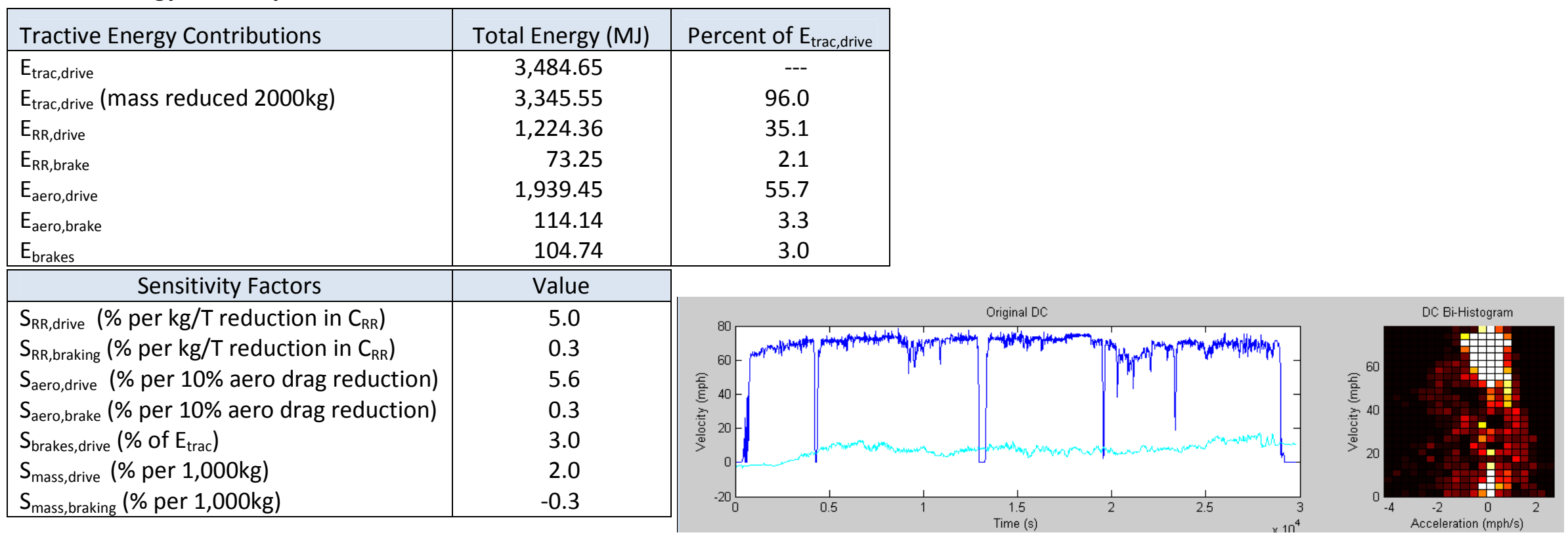


To use the sensitivity factors to evaluate a scenario of combining technologies, assume that low rolling resistance tires can reduce the coefficient of rolling resistance by $1.5 \mathrm{~kg} / \mathrm{T}$ and that an $8 \%$ improvement in aerodynamic drag can be achieved by using trailer skirts and a gap reduction device between the tractor and trailer. (These levels of reductions for the rolling resistance and aerodynamic drag are of a magnitude that would be within a normal range for changes from a somewhat typical configuration to an efficient configuration using technologies that are currently available and commonly used. For example, for the rolling resistance, a typical average rolling resistance coefficient for efficient dual tires is $6.5 \mathrm{~kg} / \mathrm{T}$. This would be representative of efficient dual tires, but not the lowest rolling resistance available for dual tires. Replacing both the drive and trailer tires with relatively efficient NGWBS tires (but still not the lowest rolling resistance selections) could reduce the average rolling resistance coefficient to about $5.0 \mathrm{~kg} / \mathrm{T}$. Greater improvements in these values are certainly possible, but the reduction levels selected are believed to be relatively typical of what might be expected.) If a new tractor is also being considered for which the engine efficiency is improved by $1 \%$ relative to the 0.42 initial value (for a final thermal efficiency of 0.43 ), and the mass is reduced by $1,200 \mathrm{~kg}$, then we can use the equations presented in this report to calculate the impact on the fuel consumption for combining these technologies. Using Eq. (31a), the reduction in the driving tractive energy in the new configuration is: $3485 \mathrm{MJ} *[(0.050 /(\mathrm{kg} / \mathrm{T}) * 1.5 \mathrm{~kg} / \mathrm{T})+(0.056 * 8 \% / 10 \%)+(0.020 * 1200 \mathrm{~kg} / 1000 \mathrm{~kg})]=$ $501 \mathrm{MJ}$ (about 14.4\%). With the engine efficiency improvement, the final fuel consumption calculated from Eq. (34) is $242.9 \mathrm{~L}$ for the drive cycle, representing a fuel savings of $42.8 \mathrm{~L}$, or about $15.0 \%$. Without the engine efficiency improvement, the fuel savings is predicted to be $13.0 \%$, which is only slightly lower than the $14.4 \%$ savings in the driving tractive energy, as expected.

Even with the periodic braking that occurs in this drive cycle, as indicated above, the contribution of braking to the driving tractive energy was only $3.0 \%$ for the full cycle. This represents the maximum possible energy recovery that can be achieved with regenerative braking for this cycle. In reality, irreversibilities associated with the energy conversions will reduce the actual energy savings by some factor, and only about $80 \%$ of the available energy is likely to be usable for a real hybrid system. This yields a tractive energy savings of $2.4 \%$. At $80 \%$ efficiency, the model predicts that regenerative braking, by itself, would reduce fuel consumption by only $2.2 \%$ for this drive cycle. Fig. 12 shows the relative reduction in the driving tractive energy for each of the contributing factors considered, both for the case with and without regenerative braking. The relative fuel savings that can be achieved by combining the technologies is not simply additive for combining technologies and the fuel savings are not directly proportional to the tractive energy savings (although it is nearly the case). For this reason, the relative comparison of the benefits of each technology is shown in Fig. 12 in terms of the tractive energy reduction as opposed to the overall fuel savings. Nonetheless, this figure provides a convenient way to compare the benefits of the different technologies both for scenarios with and without regenerative braking.

The $2.4 \%$ tractive energy savings potential from regenerative braking would not normally justify the complexity and cost of implementing a hybrid power system for class 8 tractor trailers if this drive cycle were representative of operations for this application. This type of drive cycle has long been presented as very typical of a long-haul trucking application, and the corresponding low energy savings potential of 
hybrid technology for this application has largely been accepted as fact. On the other hand, trucks used in long-haul service do drive for some portion of their operations at conditions that are outside of these pure freeway conditions. In spite of the fact that this drive cycle shows relatively low energy savings potential for the hybrid operation, the remaining drive cycles presented below, all of which were recorded from the same trucking fleet, do show higher levels of braking energy, and the potential for energy savings is significantly higher in several cases.

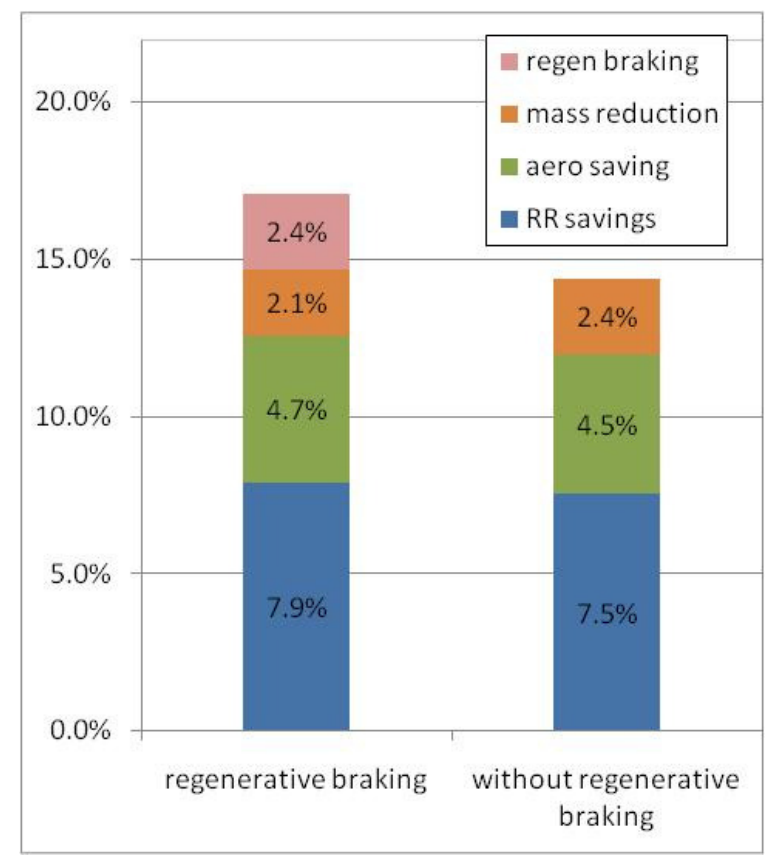

Figure 12. Summary of the tractive energy results for Cycle 4 for the variations considered. 
Table 3. Summary results of the tractive energy analysis for Cycle 5.

Inputs:
\begin{tabular}{|l|r|r|r|}
\hline Mass $(\mathrm{kg})$ & 26,000 & Time start (s) & 0 \\
$\mathrm{C}_{\mathrm{d}}$ & 0.62 & Time finish $(\mathrm{s})$ & 27,898 \\
$\mathrm{C}_{\mathrm{RR}},(\mathrm{kg} / \mathrm{T})$ & 7.0 & Mass Reduction $(\mathrm{kg})$ & 2,000 \\
\hline
\end{tabular}

\section{Drive cycle characteristics:}

\begin{tabular}{|c|c|c|c|c|c|c|c|c|}
\hline $\begin{array}{c}\text { Cycle } \\
\text { Distance } \\
(\mathrm{km})\end{array}$ & $\begin{array}{c}\text { Total Fuel } \\
\text { Consumed } \\
\text { (L) }\end{array}$ & $\begin{array}{l}\text { Average } \\
\text { Speed } \\
\text { (kph) }\end{array}$ & $\begin{array}{l}\text { Maximum } \\
\text { Speed } \\
\text { (kph) }\end{array}$ & $\begin{array}{c}\text { Maximum } \\
\text { Acceleration } \\
(\mathrm{m} / \mathrm{s} 2)\end{array}$ & $\begin{array}{c}\text { Maximum } \\
\text { Deceleration } \\
(\mathrm{m} / \mathrm{s} 2)\end{array}$ & $\begin{array}{l}\text { Percent } \\
\text { of Time } \\
\text { stopped }\end{array}$ & $\begin{array}{l}\text { Standard } \\
\text { Deviation of } \\
\text { the Speed } \\
(\mathrm{m} / \mathrm{s})\end{array}$ & $\begin{array}{l}\text { Average Speed, } \\
\text { with Stops } \\
\text { Removed } \\
(\mathrm{kph})\end{array}$ \\
\hline 634.45 & 231.46 & 81.87 & 120.41 & 2.43 & 2.02 & 4.28 & 8.57 & 85.41 \\
\hline
\end{tabular}

\section{Tractive Energy Summary results:}

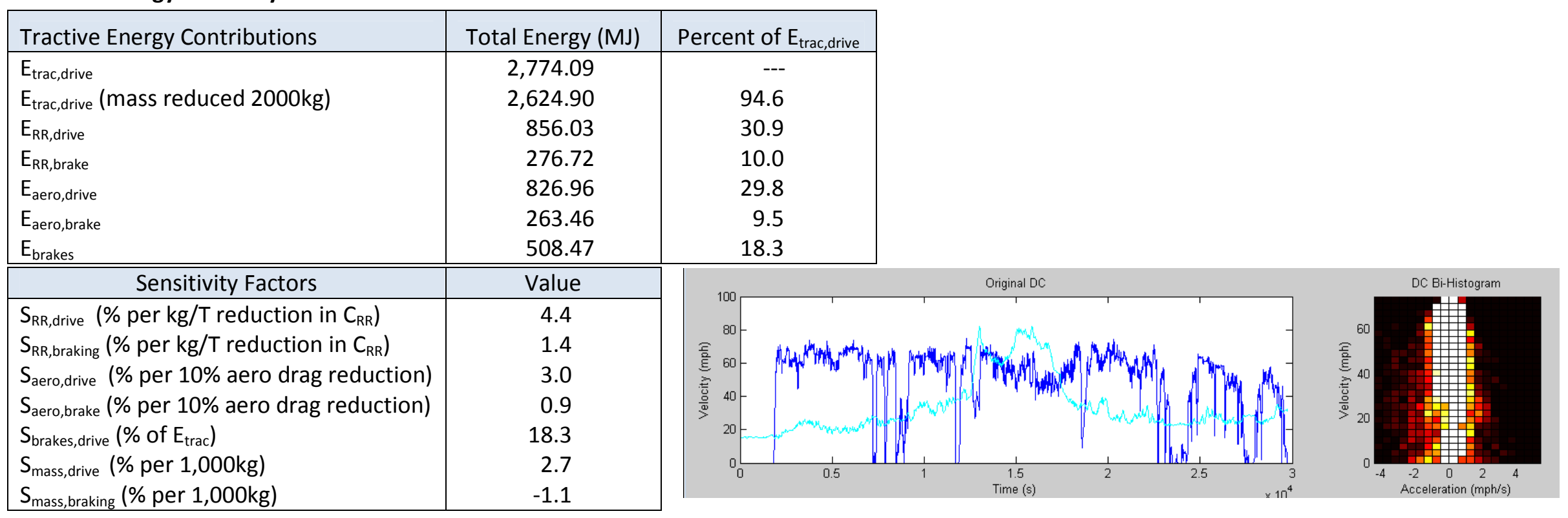


Table 3 shows the tractive energy analysis results for Cycle 5. This drive cycle includes much greater elevation changes than did Cycle 4, and there are also greater variations in speed as well as additional stops. These factors result in quite different characteristics for the tractive energy results. In this case, the rolling resistance and aerodynamic drag are each responsible for about $30 \%$ of the total driving tractive energy requirement, while braking accounts for $18.3 \%$. This result indicates that regenerative braking could provide a relatively large energy savings for this drive cycle, with reductions in the tractive energy requirement of $14.7 \%$ possible, assuming an $80 \%$ efficiency for the regenerative braking system. The fuel savings associated with this level of regenerative braking, assuming other vehicle/engine parameters remained the same, is about $13.0 \%(30.1 \mathrm{~L})$ for this drive cycle. It should be noted that the multiple stops from full highway speeds account for about $20 \%$ of the braking energy in this case. Since these periods of braking represent high power, high energy events, it may not be possible to capture and store all of the available energy, given current limitations of hybrid electric technology.

Nonetheless, there is a large quantity of energy available for recovery during other short-term braking events throughout the drive cycle that could be effectively exploited with regenerative braking.

Furthermore, if it is found for the trucking application overall that there is a significant potential for regenerative braking energy savings that is not being taken advantage of, an understanding of the characteristics of the energy recovery opportunities can lead to the development of better approaches for recovering the available energy. Providing information to technology developers regarding the characteristics of representative drive cycles will lead to highly optimized systems for each application, and this is one of the objectives of the LSDC project.

If we consider the energy savings potential when regenerative braking is used simultaneously with the other technologies impacting the tractive energy, the overall benefits are quite impressive. The total reduction in tractive energy is $28.2 \%$ for the full combination of technologies ( $8 \%$ reduction in aerodynamic drag, improvement in the tire rolling resistance coefficient by $1.5 \mathrm{~kg} / \mathrm{T}$ and a $1200 \mathrm{~kg}$ reduction in mass) and the corresponding fuel savings, calculated from Eq. (10), is $25.0 \%$. Fig. 13 shows the percentage savings in tractive energy with and without regenerative braking. For the case where regenerative braking is used, the rolling resistance and aerodynamic drag reductions provide an extra $2.3 \%$ savings in the tractive energy requirement relative to the non-hybrid case (as a result of the $S_{\text {aero,brake }}$ and $S_{R R, \text { brake }}$ terms in Eq. (33)). This increases the benefits from the low rolling resistance and aerodynamic drag reductions by about $25 \%$ relative to the savings they generated without regenerative braking. The same mass reduction is used in the figure to compare the cases with and without regenerative braking. As shown in the figure, the benefits associated with a mass reduction decrease when regenerative braking is used, and the converse is also true, i.e. any mass penalty associated with adding new technologies will have less impact on the fuel economy when regenerative braking is used than would be estimated from the mass sensitivity when regenerative braking is not used. It should be noted that mass reductions when regenerative braking is used are not very effective for reducing fuel consumption. 


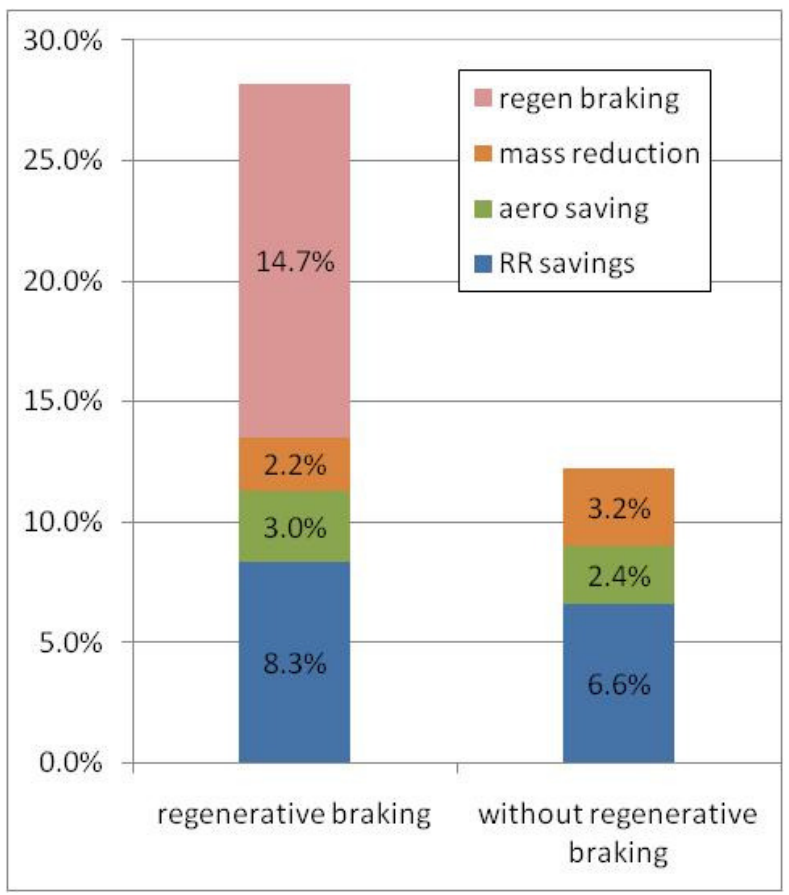

Figure 13. Comparison of the relative reduction in driving tractive energy, with and without regenerative braking, when the rolling resistance coefficient is reduced by $1.5 \mathrm{~kg} / \mathrm{T}$, the aerodynamic drag coefficient is reduced by $8 \%$ and the mass reduced by $1200 \mathrm{~kg}$ for Cycle 5 .

The energy savings potential from regenerative braking for Cycle 5, even though the drive cycle is almost entirely in freeway driving, is at a level that employing hybrid technology should receive serious consideration. If this level and frequency of braking is common among long-haul operations, the fuel savings potential of hybridization could be much greater than what is generally believed. Several of the drive cycles evaluated for this study showed braking contributions to the tractive energy of $6 \%$ or higher, and it appears that there is at least a modest fuel savings potential for regenerative braking in long-haul trucking. A more complete evaluation of the range of drive cycles that are experienced in each trucking application/ vocation is needed to determine which technologies can provide significant improvements in fuel efficiency for the set of vehicles used in that application. This is the main objective of the LSDC project, and detailed analysis of the tractive energy results, using the approach demonstrated here, will be conducted as part of the project to determine the energy savings potential associated with various advanced technologies for each trucking application. 
Table 4. Summary results of the tractive energy analysis for Cycle 18.

Inputs:
\begin{tabular}{|l|r|r|r|}
\hline Mass $(\mathrm{kg})$ & 36,000 & Time start (s) & 0 \\
$C_{d}$ & 0.62 & Time finish (s) & 29,293 \\
$C_{R R},(\mathrm{~kg} / \mathrm{T})$ & 7.0 & Mass Reduction $(\mathrm{kg})$ & 2,000 \\
\hline
\end{tabular}

\section{Drive cycle characteristics:}

\begin{tabular}{|c|c|c|c|c|c|c|c|c|}
\hline $\begin{array}{c}\text { Cycle } \\
\text { Distance } \\
(\mathrm{km})\end{array}$ & $\begin{array}{c}\text { Total Fuel } \\
\text { Consumed } \\
\text { (L) }\end{array}$ & $\begin{array}{l}\text { Average } \\
\text { Speed } \\
\text { (kph) }\end{array}$ & $\begin{array}{c}\text { Maximum } \\
\text { Speed } \\
\text { (kph) }\end{array}$ & $\begin{array}{c}\text { Maximum } \\
\text { Acceleration } \\
\left(\mathrm{m} / \mathrm{s}^{2}\right)\end{array}$ & $\begin{array}{c}\text { Maximum } \\
\text { Deceleration } \\
\left(\mathrm{m} / \mathrm{s}^{2}\right)\end{array}$ & $\begin{array}{l}\text { Percent } \\
\text { of Time } \\
\text { stopped }\end{array}$ & $\begin{array}{l}\text { Standard } \\
\text { Deviation of } \\
\text { the Speed } \\
(\mathrm{m} / \mathrm{s})\end{array}$ & $\begin{array}{l}\text { Average Speed, } \\
\text { with Stops } \\
\text { Removed } \\
(\mathrm{kph})\end{array}$ \\
\hline 223.86 & 114.69 & 27.51 & 136.36 & 1.35 & 2.20 & 68.10 & 12.49 & 85.89 \\
\hline
\end{tabular}

\section{Tractive Energy Summary results:}

\begin{tabular}{|c|c|}
\hline Tractive Energy Contributions & Total Energy (MJ) \\
\hline $\mathrm{E}_{\text {trac,drive }}$ & $1,426.68$ \\
\hline$E_{\text {trac,drive }}$ (mass reduced $2000 \mathrm{~kg}$ ) & $1,367.60$ \\
\hline $\mathrm{E}_{\mathrm{RR} \text {, drive }}$ & 427.99 \\
\hline $\mathrm{E}_{\mathrm{RR}, \text { brake }}$ & 125.41 \\
\hline $\mathrm{E}_{\text {aero,drive }}$ & 362.06 \\
\hline $\mathrm{E}_{\text {aero,brake }}$ & 97.00 \\
\hline E brakes & 417.86 \\
\hline Sensitivity Factors & Value \\
\hline $\mathrm{S}_{\mathrm{RR} \text {,drive }}\left(\%\right.$ per $\mathrm{kg} / \mathrm{T}$ reduction in $\mathrm{C}_{\mathrm{RR}}$ ) & 4.3 \\
\hline $\mathrm{S}_{\mathrm{RR} \text {,braking }}\left(\%\right.$ per $\mathrm{kg} / \mathrm{T}$ reduction in $\mathrm{C}_{\mathrm{RR}}$ ) & 1.3 \\
\hline $\mathrm{S}_{\text {aero,drive }}$ ( $\%$ per $10 \%$ aero drag reduction) & 2.5 \\
\hline $\mathrm{S}_{\text {aero,brake }}(\%$ per $10 \%$ aero drag reduction) & 0.7 \\
\hline$S_{\text {brakes,drive }}\left(\%\right.$ of $\left.E_{\text {trac }}\right)$ & 29.3 \\
\hline$S_{\text {mass,drive }}(\%$ per $1,000 \mathrm{~kg})$ & 2.1 \\
\hline$S_{\text {mass,braking }}(\%$ per $1,000 \mathrm{~kg})$ & -1.0 \\
\hline
\end{tabular}

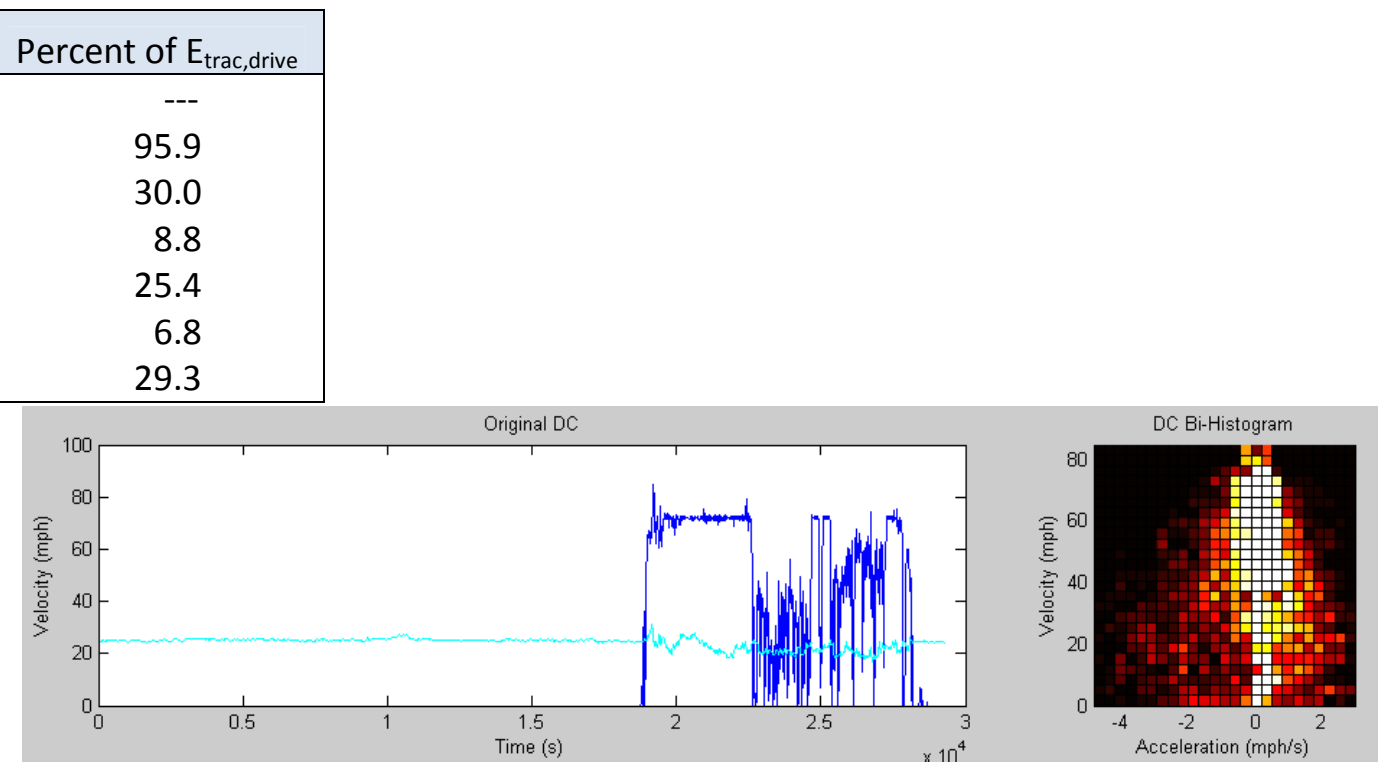


Cycle 18, the results for which are shown in Table 4, is included in this presentation of results to examine different types of drive cycles and evaluate how the fuel savings potential might differ among different applications. This drive cycle, which includes a significant amount of non-freeway travel with frequent stops and lower speeds than freeway operations, is not believed to be typical of what is commonly experienced in true long-haul operations but is more representative of a regional operation with considerable off-highway travel. Cycle 18 includes about 50\% freeway travel, but the remainder is more representative of urban or inter-city travel on secondary highways. The fuel savings potential associated with idle reduction for this drive cycle was already addressed above, and the remainder of the analysis addressed here does not consider the idle reduction further (the savings due to idle reduction is simply additive to any other fuel savings).

For this type of drive cycle-with relatively high average speed, a large degree of stopping and high load operations - the contribution from rolling resistance, aerodynamic drag, and the brakes to the driving tractive energy are all fairly high, with relative contributions for this drive cycle of $30 \%, 25.4 \%$ and $29.3 \%$, respectively. Regenerative braking offers the greatest potential for fuel savings in this case, and by itself, yields a fuel savings potential of $21.5 \%$ using the same assumptions as above. A $1.5 \mathrm{~kg} / \mathrm{T}$ reduction in rolling resistance coefficient and $8 \%$ reduction in the aerodynamic drag coefficient are predicted to yield fuel savings of about $5.9 \%$ and $1.9 \%$, respectively, for this drive cycle. The total fuel savings potential that can be achieved for this drive cycle by combining regenerative braking with these reduced levels of rolling resistance and aerodynamic drag is $31.1 \%$.

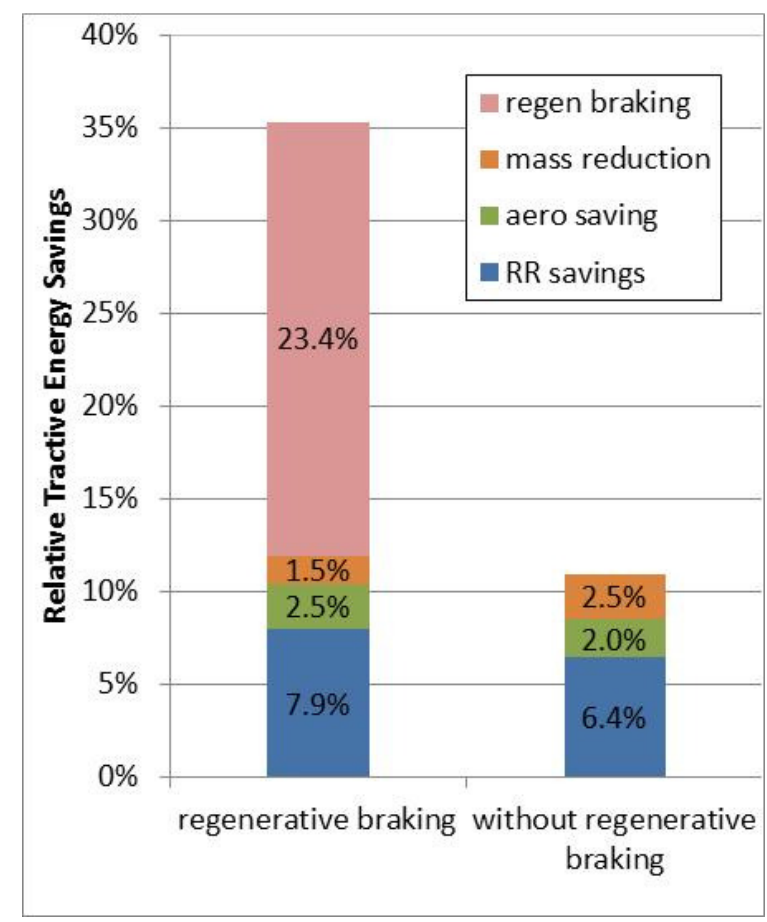

Figure 14. Comparison of the tractive energy savings potential, with and without regenerative braking, with rolling resistance, aerodynamic drag and mass reductions (Cycle 18). 
A segment of lower speed operations from this drive cycle, immediately following the long segment of near-constant speed freeway driving, was analyzed to give an indication of the energy savings potential for more urban types of driving with regular stops and starts and lower speed operations. Fig. 15 shows a detailed view of the speed history for this portion of Cycle 18. This type of driving might occur in various applications for delivery or service trucks around metropolitan areas. In an effort to use parameters more relevant to the smaller vehicles that would normally be used in applications where this kind of drive cycle might be characteristic of the normal operations, the mass used for the analysis was $8850 \mathrm{~kg}$ (about 19,500 lb.), as opposed to the $36,000 \mathrm{~kg}$ of the tested vehicle, and the accessory power was reduced to $7.5 \mathrm{~kW}(10 \mathrm{hp})$. This mass level corresponds to the upper limit for a class 5 vehicle. For this drive cycle and the modified conditions representing a class 5 vehicle, the aerodynamic drag contribution to the driving tractive energy is $15.5 \%$, while the rolling resistance contribution is $16.7 \%$. Note that these are significantly lower than what was determined for other drive cycles with higher speeds and greater vehicle mass. The contribution from braking is found to be very significant for this drive cycle, at $56.2 \%$, and the fuel savings potential associated with regenerative braking is correspondingly quite large at $36.2 \%$. The large frequency of acceleration events, in addition to the lower assumed initial mass, results in a high energy savings potential associated with reduced vehicle mass. The mass sensitivity was calculated to be $9.5 \%$ per $1000 \mathrm{~kg}$, which is significantly greater on a percentage basis than the mass sensitivity in other drive cycles. These mass benefits, however, are severely reduced if regenerative braking is employed. This result is logical since the benefits of reducing the vehicle mass are due in large part to the energy needed to accelerate the vehicle. With an efficient hybrid system for a drive cycle with many stops and starts, the engine does not need to participate significantly in the accelerations, so a portion of the mass benefits are lost.

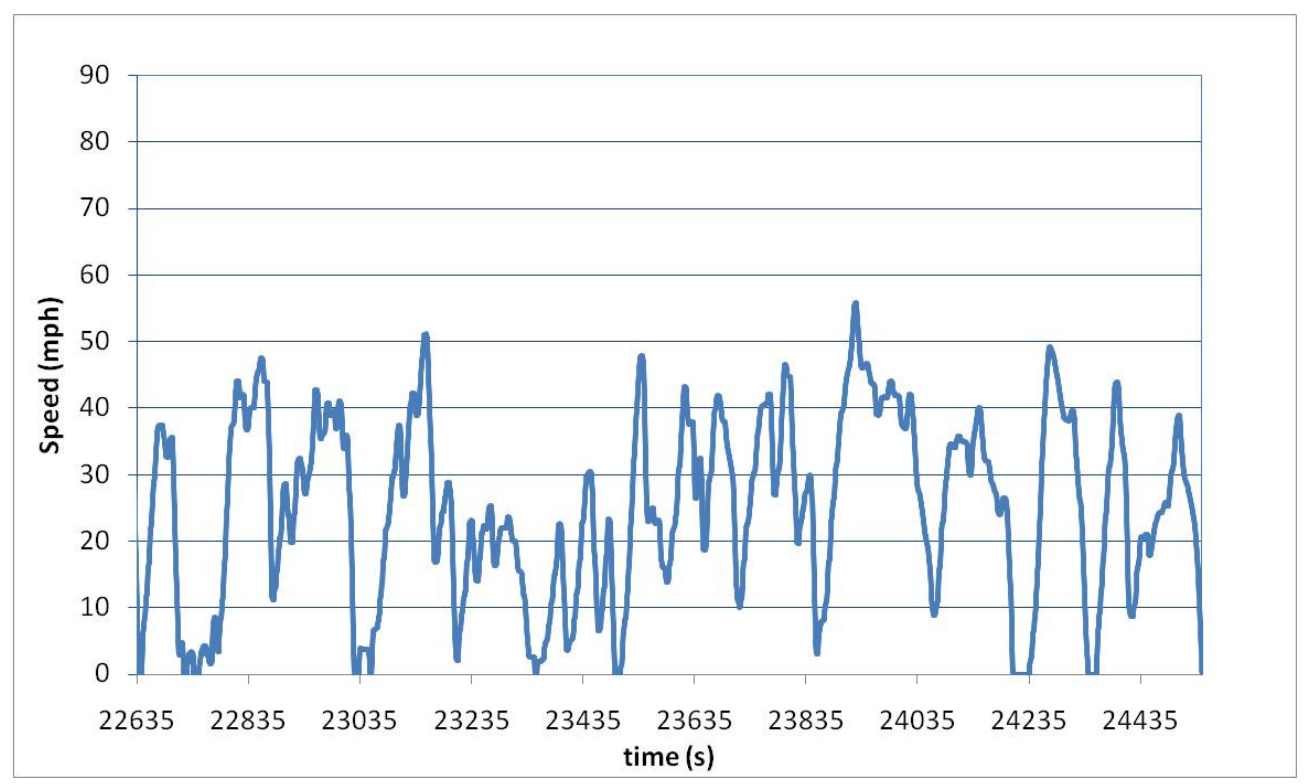

Figure 15. Segment of Cycle 18 with the extended highway operation removed.

Fig. 16 shows the driving tractive energy savings potential for the technology combination corresponding to a $1.5 \mathrm{~kg} / \mathrm{T}$ reduction in rolling resistance coefficient, $8 \%$ reduction in aerodynamic drag 
and $1200 \mathrm{~kg}$ mass reduction. The calculated fuel savings for the combined technologies is $45.3 \%$ for the case with regenerative braking and $13.1 \%$ without regenerative braking. The savings from regenerative braking is clearly the most significant for this drive cycle. The fuel savings potential from rolling resistance and aerodynamic drag are relatively small when regenerative braking is not used, but their benefits increase by more than $40 \%$ on a relative basis when regenerative braking is used concurrently. According to the model, low rolling resistance tires, without regenerative braking, can reduce the fuel consumption by about $2.9 \%$, but with regenerative braking will yield $4.1 \%$ in fuel savings beyond what is achieved with regenerative braking by itself. The fuel savings can therefore become worthwhile when regenerative braking is used, even if the benefits without hybridization are not very significant.

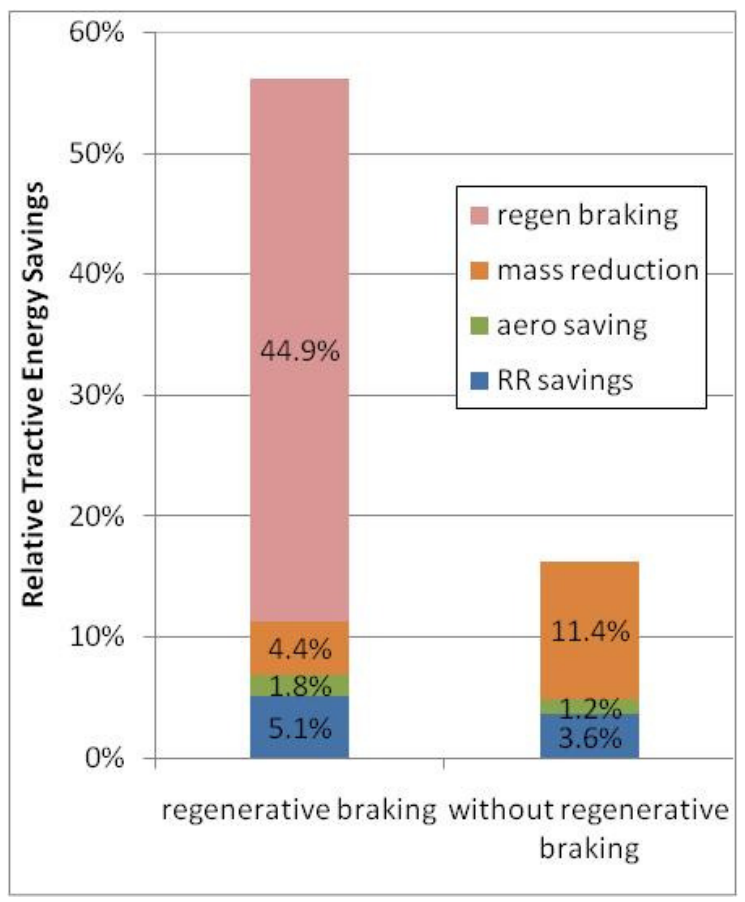

Figure 16. Tractive energy savings potential for mass, aerodynamic drag and rolling resistance, with and without regenerative braking, for the low speed segment of Cycle 18. Vehicle parameters are representative of a class 5 vehicle for this case.

Cycle 25 is another example of a highway drive cycle combined with some lower speed operations including considerable stops and starts. The summary of the tractive energy analysis for this drive cycle appears in Table 5. This case is included to show another example of a more regional usage, demonstrating the large savings associated with regenerative braking. 
Table 5. Summary results of the tractive energy analysis for Cycle 25.

Inputs:
\begin{tabular}{|l|r|r|r|}
\hline Mass $(\mathrm{kg})$ & 28,000 & Time start (s) & 0 \\
$\mathrm{C}_{\mathrm{d}}$ & 0.62 & Time finish (s) & 25,979 \\
$\mathrm{C}_{\mathrm{RR}},(\mathrm{kg} / \mathrm{T})$ & 7.0 & Mass Reduction $(\mathrm{kg})$ & 2,000 \\
\hline
\end{tabular}

\section{Drive cycle characteristics:}

\begin{tabular}{|c|c|c|c|c|c|c|c|c|}
\hline $\begin{array}{c}\text { Cycle } \\
\text { Distance } \\
(\mathrm{km})\end{array}$ & $\begin{array}{c}\text { Total Fuel } \\
\text { Consumed } \\
\text { (L) }\end{array}$ & $\begin{array}{c}\text { Average } \\
\text { Speed } \\
\text { (kph) }\end{array}$ & $\begin{array}{l}\text { Maximum } \\
\text { Speed } \\
\text { (kph) }\end{array}$ & $\begin{array}{c}\text { Maximum } \\
\text { Acceleration } \\
\left(\mathrm{m} / \mathrm{s}^{2}\right)\end{array}$ & $\begin{array}{c}\text { Maximum } \\
\text { Deceleration } \\
\left(\mathrm{m} / \mathrm{s}^{2}\right)\end{array}$ & $\begin{array}{l}\text { Percent } \\
\text { of Time } \\
\text { stopped }\end{array}$ & $\begin{array}{l}\text { Standard } \\
\text { Deviation of } \\
\text { the Speed } \\
(\mathrm{m} / \mathrm{s})\end{array}$ & $\begin{array}{l}\text { Average Speed, } \\
\text { with Stops } \\
\text { Removed } \\
(\mathrm{kph})\end{array}$ \\
\hline 574.03 & 246.20 & 79.54 & 116.83 & 1.47 & 2.70 & 4.30 & 8.02 & 82.98 \\
\hline
\end{tabular}

\section{Tractive Energy Summary results:}

\begin{tabular}{|c|c|}
\hline Tractive Energy Contributions & Total Energy (MJ) \\
\hline$E_{\text {trac,drive }}$ & $2,998.34$ \\
\hline $\mathrm{E}_{\text {trac,drive }}$ (mass reduced $2000 \mathrm{~kg}$ ) & $2,828.79$ \\
\hline$E_{R R \text {,drive }}$ & 749.87 \\
\hline$E_{R R, \text { brake }}$ & 353.84 \\
\hline$E_{\text {aero,drive }}$ & 622.07 \\
\hline$E_{\text {aero,brake }}$ & 291.45 \\
\hline$E_{\text {brakes }}$ & $1,100.13$ \\
\hline Sensitivity Factors & Value \\
\hline$S_{R R, \text { drive }}\left(\%\right.$ per $\mathrm{kg} / \mathrm{T}$ reduction in $\left.\mathrm{C}_{\mathrm{RR}}\right)$ & 3.6 \\
\hline $\mathrm{S}_{\mathrm{RR} \text {,braking }}\left(\%\right.$ per $\mathrm{kg} / \mathrm{T}$ reduction in $\mathrm{C}_{\mathrm{RR}}$ ) & 1.7 \\
\hline $\mathrm{S}_{\text {aero,drive }}(\%$ per $10 \%$ aero drag reduction) & 2.1 \\
\hline $\mathrm{S}_{\text {aero,brake }}(\%$ per $10 \%$ aero drag reduction) & 1.0 \\
\hline $\mathrm{S}_{\text {brakes,drive }}\left(\%\right.$ of $\left.\mathrm{E}_{\text {trac }}\right)$ & 36.7 \\
\hline$S_{\text {mass,drive }}(\%$ per $1,000 \mathrm{~kg})$ & 2.8 \\
\hline$S_{\text {mass,braking }}(\%$ per $1,000 \mathrm{~kg})$ & -1.7 \\
\hline
\end{tabular}

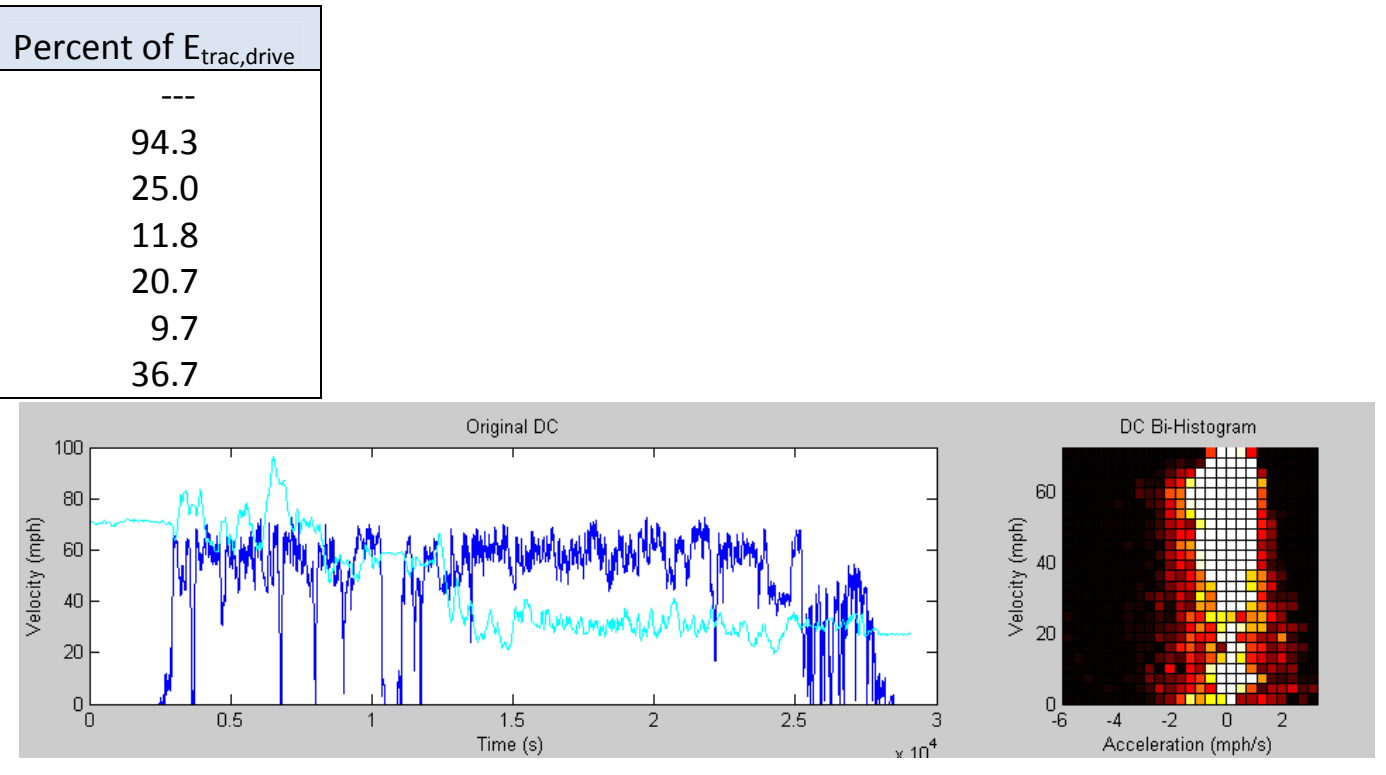


Figure 17 shows the tractive energy savings potential of the combined technologies based on the same mass, rolling resistance and aerodynamic drag reductions used in earlier analysis. The fuel savings when employing these technologies without regenerative braking is estimated at $9.4 \%$ while that with regenerative braking is calculated to be $36.7 \%$. For operations where such a drive cycle is common, it is clear that regenerative braking offers very significant gains in fuel efficiency, and for class 8 vehicles that are used in regional applications, hybridization should therefore be aggressively pursued.

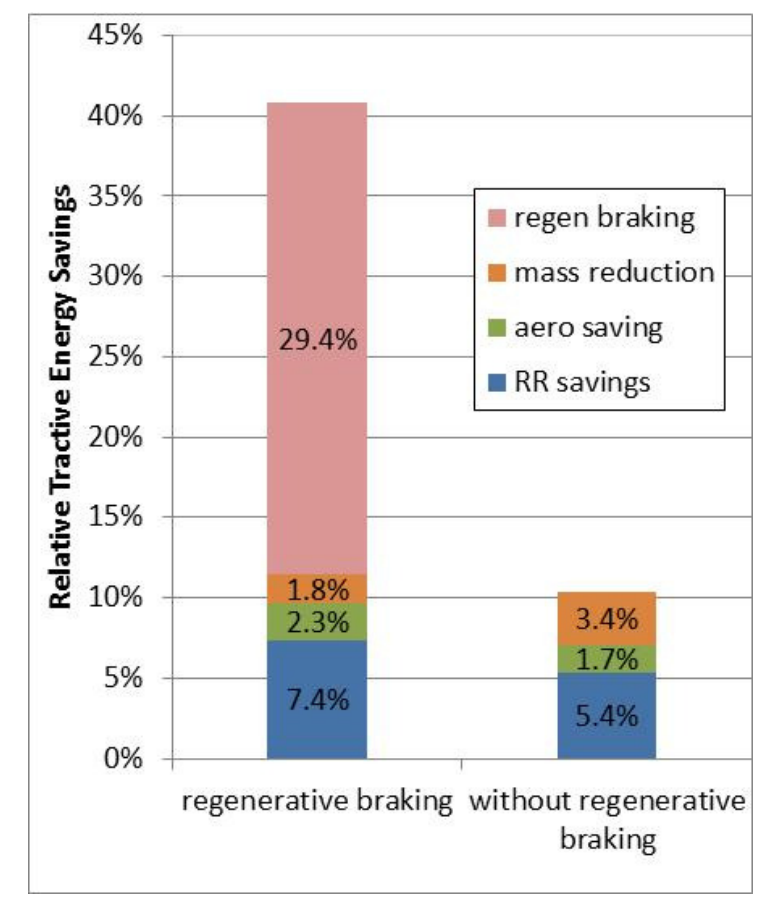

Figure 17. Comparison of the tractive energy savings potential for Cycle 25.

Cycle 38 and Cycle 54 are included to present additional highway driving cases for which the driving tractive energy savings potential of regenerative braking is at a level that merits further consideration. These cases both represent almost purely highway driving (except for some very slow operations at the beginning of Cycle 38 , for which the fuel consumption was only $1.6 \%$ of that over the complete drive cycle). In contrast to several of the preceding cases, the terrain for these cycles is relatively flat, with about 50m maximum elevation change occurring over either cycle. The results are similar in the two cases, and the contribution to the driving tractive energy from braking is $6.2 \%$ and $6.6 \%$ for Cycle 38 and Cycle 54, respectively. This level of about $6 \%$ seems to be rather common for drive cycles that include a large portion of highway operations, and the fuel savings potential for just the regenerative braking is about $4.4 \%$, which is fairly comparable to what can be achieved with aerodynamic drag reductions. Although implementing regenerative braking in a hybrid option is expected to be more expensive than what other advanced technologies will cost to deploy, the energy savings potential is not negligible as has often been believed, and as fuel prices continue to increase, the regenerative braking option may be favorable even for pure long-haul applications. 
Table 6. Summary results of the tractive energy analysis for Cycle 38.

Inputs:
\begin{tabular}{|l|r|r|r|}
\hline Mass $(\mathrm{kg})$ & 25,000 & Time start (s) & 0 \\
$\mathrm{C}_{\mathrm{d}}$ & 0.62 & Time finish $(\mathrm{s})$ & 27,740 \\
$\mathrm{C}_{\mathrm{RR}},(\mathrm{kg} / \mathrm{T})$ & 7.0 & Mass Reduction $(\mathrm{kg})$ & 2,000 \\
\hline
\end{tabular}

\section{Drive cycle characteristics:}

\begin{tabular}{|c|c|c|c|c|c|c|c|c|}
\hline $\begin{array}{l}\text { Cycle } \\
\text { Distance } \\
(\mathrm{km})\end{array}$ & $\begin{array}{l}\text { Total Fuel } \\
\text { Consumed } \\
\text { (L) }\end{array}$ & $\begin{array}{l}\text { Average } \\
\text { Speed } \\
\text { (kph) }\end{array}$ & $\begin{array}{l}\text { Maximum } \\
\text { Speed } \\
\text { (kph) }\end{array}$ & $\begin{array}{l}\text { Maximum } \\
\text { Acceleration } \\
\left(\mathrm{m} / \mathrm{s}^{2}\right)\end{array}$ & $\begin{array}{l}\text { Maximum } \\
\text { Deceleration } \\
\left(\mathrm{m} / \mathrm{s}^{2}\right)\end{array}$ & $\begin{array}{l}\text { Percent } \\
\text { of Time } \\
\text { stopped }\end{array}$ & $\begin{array}{l}\text { Standard } \\
\text { Deviation } \\
\text { of the } \\
\text { Speed } \\
(\mathrm{m} / \mathrm{s})\end{array}$ & $\begin{array}{l}\text { Average } \\
\text { Speed, with } \\
\text { Stops } \\
\text { Removed } \\
\text { (kph) }\end{array}$ \\
\hline 634.71 & 220.35 & 82.37 & 122.37 & 1.30 & 2.13 & 10.05 & 12.25 & 91.32 \\
\hline
\end{tabular}

Tractive Energy Summary results:

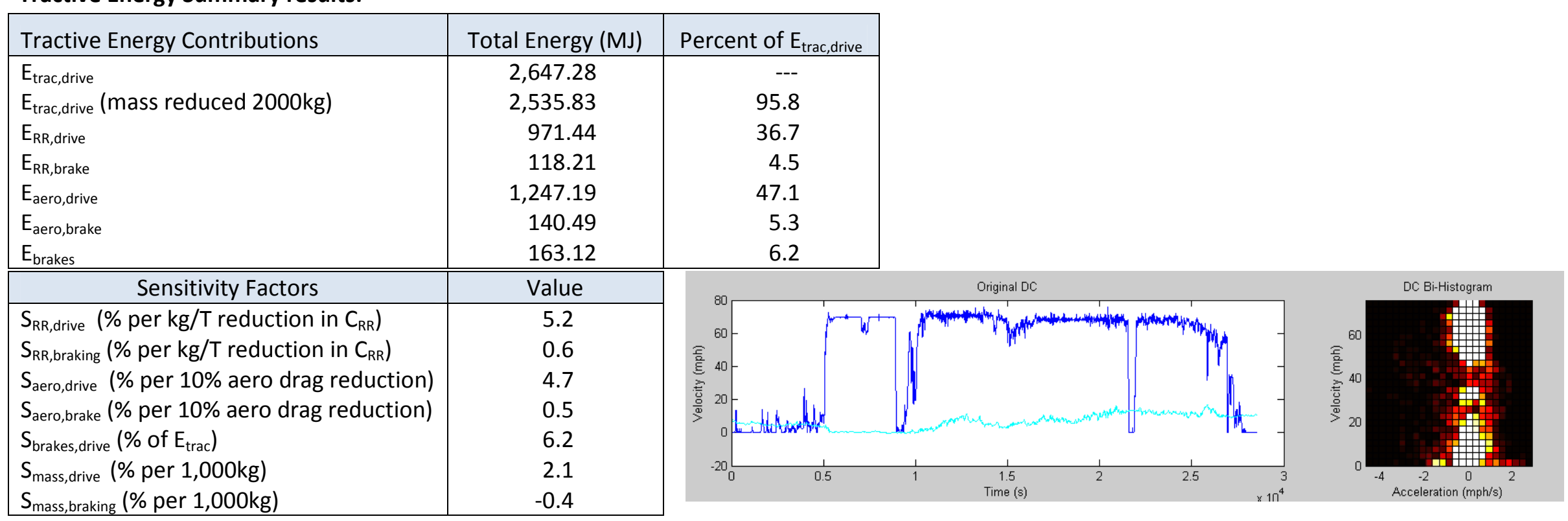




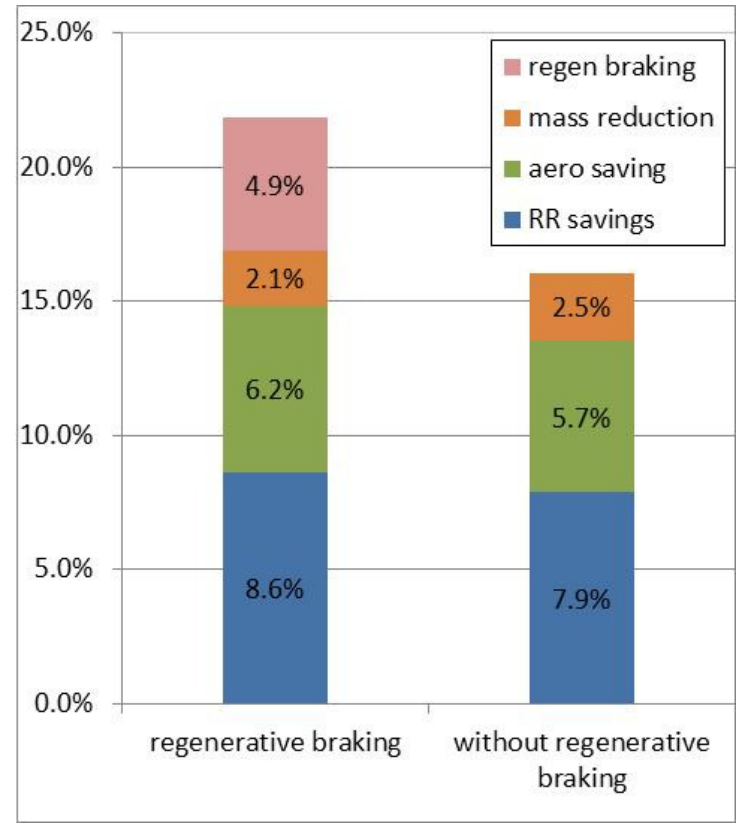

Figure 18. Tractive energy savings potential for Cycle 38.

For Cycle 38 , the model predicts a $12 \%$ reduction in fuel consumption when the aerodynamic drag and rolling resistance reductions are employed (the normal reduction levels used in this analysis), while if regenerative braking is also used, the fuel savings increases to $17.5 \%$. The corresponding numbers for Cycle 54 are $11.0 \%$ and $16.4 \%$. From these predictions, it is seen that the benefits of combined technologies can enhance the energy savings potential, which may help justify the implementation of a given technology.

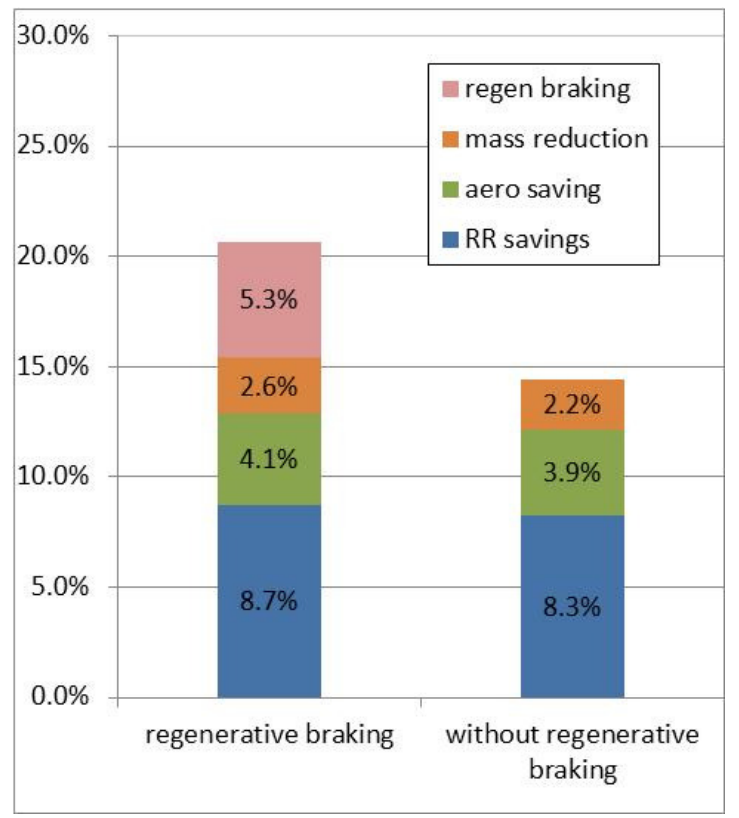

Figure 19. Tractive energy savings potential for Cycle 54. 
Table 7. Summary results of the tractive energy analysis for Cycle 54.

Inputs:
\begin{tabular}{|l|r|r|r|}
\hline Mass $(\mathrm{kg})$ & 27,500 & Time start (s) & 0 \\
$C_{d}$ & 0.62 & Time finish (s) & 26,423 \\
$C_{R R},(\mathrm{~kg} / \mathrm{T})$ & 7.0 & Mass Reduction $(\mathrm{kg})$ & 2,000 \\
\hline
\end{tabular}

\section{Drive cycle characteristics:}

\begin{tabular}{|c|c|c|c|c|c|c|c|c|}
\hline $\begin{array}{c}\text { Cycle } \\
\text { Distance } \\
(\mathrm{km})\end{array}$ & $\begin{array}{c}\text { Total Fuel } \\
\text { Consumed } \\
\text { (L) }\end{array}$ & $\begin{array}{l}\text { Average } \\
\text { Speed } \\
\text { (kph) }\end{array}$ & $\begin{array}{c}\text { Maximum } \\
\text { Speed } \\
\text { (kph) }\end{array}$ & $\begin{array}{c}\text { Maximum } \\
\text { Acceleration } \\
\left(\mathrm{m} / \mathrm{s}^{2}\right)\end{array}$ & $\begin{array}{c}\text { Maximum } \\
\text { Deceleration } \\
\left(\mathrm{m} / \mathrm{s}^{2}\right)\end{array}$ & $\begin{array}{l}\text { Percent } \\
\text { of Time } \\
\text { stopped }\end{array}$ & $\begin{array}{c}\text { Standard } \\
\text { Deviation of } \\
\text { the Speed } \\
(\mathrm{m} / \mathrm{s})\end{array}$ & $\begin{array}{l}\text { Average Speed, } \\
\text { with Stops } \\
\text { Removed } \\
(\mathrm{kph})\end{array}$ \\
\hline 723.49 & 268.71 & 98.57 & 120.89 & 1.54 & 3.08 & 5.29 & 9.59 & 103.96 \\
\hline
\end{tabular}

\section{Tractive Energy Summary results:}

\begin{tabular}{|c|c|}
\hline Tractive Energy Contributions & Total Energy (MJ) \\
\hline$E_{\text {trac,drive }}$ & $3,300.76$ \\
\hline $\mathrm{E}_{\text {trac,drive }}$ (mass reduced $2000 \mathrm{~kg}$ ) & $3,178.21$ \\
\hline$E_{R R \text {,drive }}$ & $1,272.93$ \\
\hline$E_{R R, \text { brake }}$ & 93.33 \\
\hline$E_{\text {aero,drive }}$ & $1,612.19$ \\
\hline$E_{\text {aero,brake }}$ & 101.00 \\
\hline$E_{\text {brakes }}$ & 217.30 \\
\hline Sensitivity Factors & Value \\
\hline$S_{R R, \text { drive }}\left(\%\right.$ per $\mathrm{kg} / \mathrm{T}$ reduction in $\left.\mathrm{C}_{\mathrm{RR}}\right)$ & 5.5 \\
\hline $\mathrm{S}_{\mathrm{RR} \text {,braking }}\left(\%\right.$ per $\mathrm{kg} / \mathrm{T}$ reduction in $\mathrm{C}_{\mathrm{RR}}$ ) & 0.4 \\
\hline $\mathrm{S}_{\text {aero,drive }}(\%$ per $10 \%$ aero drag reduction) & 4.9 \\
\hline $\mathrm{S}_{\text {aero,brake }}(\%$ per $10 \%$ aero drag reduction) & 0.3 \\
\hline $\mathrm{S}_{\text {brakes,drive }}\left(\%\right.$ of $\left.\mathrm{E}_{\text {trac }}\right)$ & 6.6 \\
\hline$S_{\text {mass,drive }}(\%$ per $1,000 \mathrm{~kg})$ & 1.9 \\
\hline$S_{\text {mass,braking }}(\%$ per $1,000 \mathrm{~kg})$ & -0.3 \\
\hline
\end{tabular}
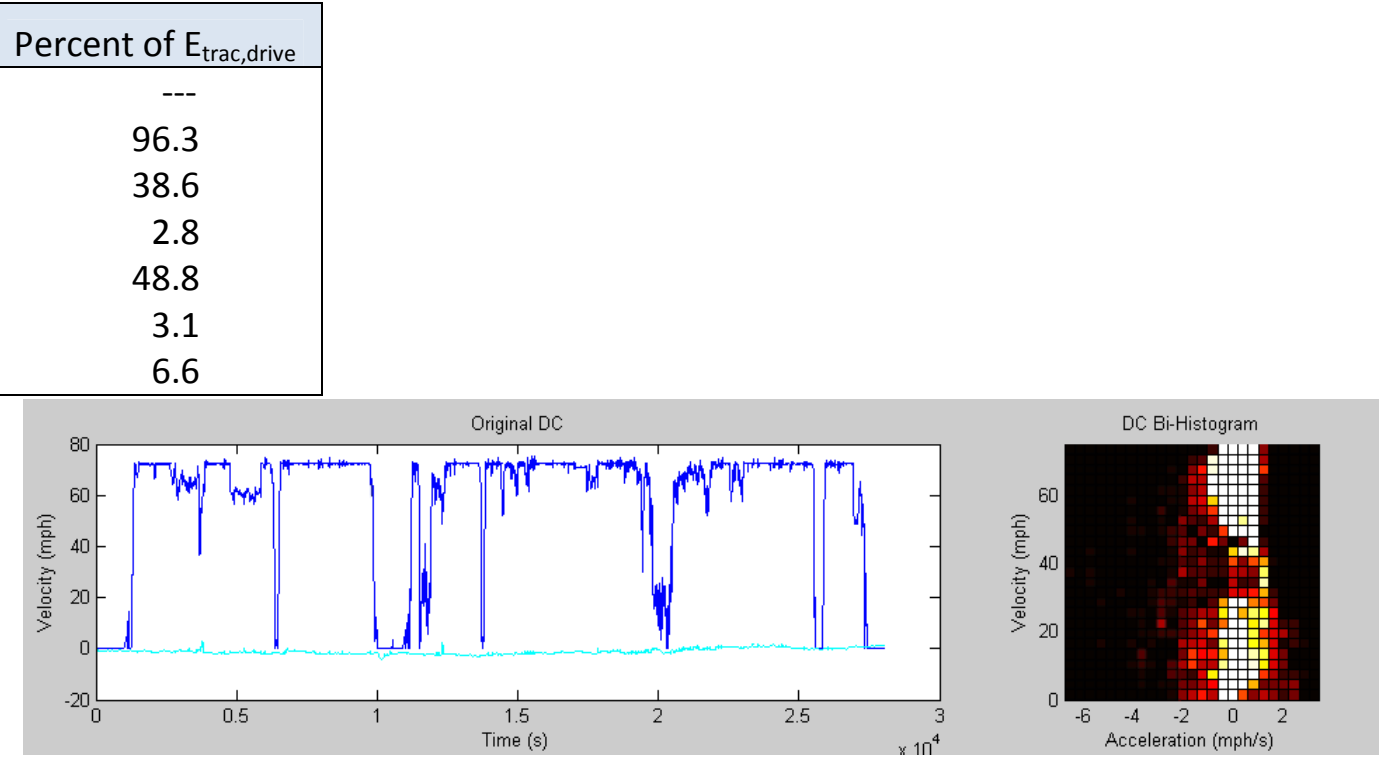


\subsection{Estimation of Vehicle Mass from Engine Torque and Acceleration Data}

In addition to presenting the tractive energy and drive cycle analysis approach and demonstrating its utility for the LSDC project, one of the objectives of this report is to show that the data that will be collected for the project is sufficient to perform all of the intended analyses. The primary data that will be collected for each vehicle in the project is very simple: speed and position data will be measured as a function of time, with a measurement interval of 1 second. Using the position information, elevation data can be obtained from a database. Although much more data was available from the HTDC database for comparison with the tractive energy analysis, all of the analysis presented in this report has been conducted using precisely this data set as inputs. The higher time resolution data collected for HTDC (all data were recorded at $5 \mathrm{~Hz}$ ) was modified so that only the data points at one second intervals were included in the input files.

Other inputs used in the model include reference values for the coefficient of rolling resistance, the coefficient of aerodynamic drag, vehicle frontal area, the transmission and engine efficiency values, and vehicle mass; and many of these parameters will be provided by the user when performing the technology assessments. Although some results will depend on the actual values used for these parameters, the variational analysis that the tractive energy approach uses minimizes the effect of specific parameters used in the model. Normal values for the various parameters in the model do not span a very broad range, so the maximum errors that can occur are rather limited in practice, and it is differences in the drive cycles themselves that tend to dominate the relative importance of the various contributions to the driving tractive energy. Since the intent of the model is to provide first order evaluations of the impacts that different technologies and technology combinations can provide for fuel savings, any errors due to inaccuracies in the selected parameter sets are not expected to alter the significant trends obtained from the analysis.

The one aspect for which the intended purpose of the project does rely upon accurate characterization of the measured vehicle's operational parameters is in characterizing the overall drive cycles for each application. The speed cycles and elevation changes define the vehicle's drive cycle, and these will be measured with an accuracy that allows the final results to be accurately calculated. Nonetheless, for applications in which freight is hauled (most notably for class 8 combination trucks, which represent the largest portion of fuel consumption among all medium- and heavy-duty vehicles), the mass is also of primary importance. Since the loads carried can vary significantly between trips for a given vehicle, an approach is necessary to allow the total vehicle mass to be quantified so that load distributions can be quantified and the characteristics of duty cycles during operations at different vehicle loads can be evaluated. For applications in which vehicle loads change significantly over time, it is proposed to collect supplemental data for the purpose of evaluating the load carried. For the simplest and most cost effective approach, it is desirable to use data channels that are typically available from the vehicle's data bus and to avoid the need for specialized instrumentation. The project team proposed using vehicle acceleration data, along with measurements of the output engine torque, to estimate the vehicle's mass by using Newton's $2^{\text {nd }}$ law of motion. Since acceleration data is implicit in the velocity, which is already included in the planned measurements, this approach would require only one additional data channel, the engine output torque. Upon investigating this approach and pursuing other directions, it was 
determined that engine speed data is also necessary, as will be shown below. Both of these data channels are regularly available for heavy duty vehicles on the vehicle data bus, so its inclusion in the project for vehicles with large potential mass variations is not expected to involve significant additional cost, if any. The remainder of this section develops the equations necessary for estimating the mass using measured engine torque and engine speed data and demonstrating the accuracy of the approach.

\subsubsection{Method for Vehicle Mass Estimation}

The most direct and obvious approach for estimating the mass is through an instantaneous evaluation of forces and accelerations using Newton's $2^{\text {nd }}$ law of motion. Eq. (1) could therefore be used to develop an estimation of mass, but it should be realized that evaluations using instantaneous data are very sensitive to errors in the input data, and averaging over long periods of time can help to reduce such errors. As opposed to considering the forces directly, evaluation of the energy input requirements over periods of acceleration provides a means to automatically average the instantaneous variations. A second consideration is the fact that the torque data available is not a wheel torque, but rather an engine output torque, and the energy transferred to the wheels is thus reduced as a result of accessory power requirements and frictional losses in the drivetrain, as shown in Eq. (7). While these effects are not known precisely, typical values can be used, and periods of operation where the impact of these uncertainties on the mass estimate are minimized can be selected to achieve the highest sensitivity in the calculation. With these issues in mind, we proceed with the analysis to develop an approach and we will evaluate the accuracy in a couple cases to determine if the approach is reasonable.

We begin by considering the terms of the driving tractive energy from Eq. (4) (repeated here for convenience):

$$
\begin{aligned}
\Delta E_{\text {trac }} & =\frac{1}{2} m\left(v_{2}^{2}-v_{1}^{2}\right)+m g\left(h_{2}-h_{1}\right)+\Delta E_{\text {aero }}+\Delta E_{R R} \\
& =\Delta E_{\text {kinetic }}+\Delta E_{\text {potential }}+\Delta E_{\text {aero }}+\Delta E_{R R} .
\end{aligned}
$$

Since the rolling resistance energy is calculated by multiplying the mass by the rolling resistance coefficient and the distance traveled, we see that all terms on the right hand side of the equation, except for $\Delta E_{\text {aero, }}$ depend directly on the mass. Combining the tractive energy definition of $\Delta E_{R R}$ from Eq. (13) with Eq. (35) and collecting the terms that depend on mass and those that do not, we arrive at the following:

$$
\begin{aligned}
\Delta E_{\text {trac }}-\Delta E_{\text {aero }}= & m\left[\frac{1}{2}\left(v_{2}^{2}-v_{1}^{2}\right)+g\left(h_{2}-h_{1}\right)+C_{R R} g\left(s_{2}-s_{1}\right)\right] \\
= & m\left[\frac{\Delta E_{\text {kinetic }}+\Delta E_{\text {potential }}+\Delta E_{R R}}{m}\right]
\end{aligned}
$$

Since this equation is valid for any time period of the drive cycle, we can sum over any set of segments of interest, so that

$$
\sum\left(\Delta E_{\text {trac }}-\Delta E_{\text {aero }}\right)_{i}=m \sum\left[\frac{\Delta E_{\text {kinetic }}+\Delta E_{\text {potential }}+\Delta E_{R R}}{m}\right]_{i}
$$

Solving for the mass, we obtain 


$$
m=\left[\frac{\sum_{i}\left(\Delta E_{\text {trac }}-\Delta E_{\text {aero }}\right)_{i}}{\sum_{i}\left[\frac{\Delta E_{\text {kinetic }}+\Delta E_{\text {potential }}+\Delta E_{R R}}{m}\right]_{i}}\right] .
$$

The time segments to include in the summations for this evaluation will be selected in an effort to minimize the error in estimating the mass.

For the tractive energy, the measured engine speed and torque data can be used to estimate the brake work performed and the tractive energy can therefore be estimated by using typical values of accessory power and driveline efficiency, by means of Eq. (7):

$$
E_{\text {trac }}=\eta_{\text {trans }}\left(W_{\text {brake }}-E_{\text {acces }}\right) .
$$

Assuming constant values for $\eta_{\text {trans }}$ and the accessory power, $P_{\text {acces, }}$, this equation is given by the following:

$$
\Delta E_{\text {trac }}=\frac{\eta_{\text {trans }}}{2 \pi} \int_{t_{i}}^{t_{f}} N_{\text {eng }} \tau d t-\eta_{\text {trans }} P_{\text {acces }}\left(t_{f}-t_{i}\right)
$$

for any time segment with initial and final times $t_{i}$ and $t_{f}$, respectively. The terms $N_{\text {eng }}$ and $\tau$ are the measured engine speed (in revolutions per minute) and torque, respectively, and $P_{\text {access }}$ is the accessory power. Fortunately, the driveline efficiency tends to be quite consistent at levels close to 0.90 . Furthermore, if the brake power is large in relation to the accessory power, then the relative error in using an average value for the accessory power should remain small, so the overall error in this estimation of the tractive energy also remains small on a relative basis.

Eq. (38) can include any number of segments to estimate the mass. To maximize the sensitivity for any given segment, we intuitively would like the kinetic and potential energy to be the dominant contributors to the tractive energy (i.e. large accelerations or elevation changes relative to the aerodynamic loss and rolling resistance terms). The paragraph above also suggests that engine output power should be as high as possible, which is generally consistent with the criteria to maximize the power associated with kinetic and potential energies. We can therefore set a figure of merit (FOM) based on the ratios of instantaneous power associated with the terms in Eq. (38) and look for drive segments of the drive cycle during which this FOM exceeds a threshold value (say $70 \%$ ) in order to obtain the most optimal results. We define the figure of merit as

$$
F O M=\frac{\eta_{\text {trans }} N_{\text {eng }} \tau /(2 \pi)-C_{D} A_{f} \rho v^{3} / 2}{v\left[d v / d t+g \sin \theta+C_{R R} g\right]} .
$$

\subsubsection{Sample Evaluations for Vehicle Mass Estimation}

To quantify the accuracy of this approach for estimating vehicle mass, the drive cycles in several cases for which vehicle weight data was available were evaluated. (Measurements were made with the Air- 
Weigh system, present on both the tractor and the trailer simultaneously - see http://www.airweighscales.com/ for information about this device. The HTDC report [11] includes detailed information about how the devices were implemented in the measurements). The following shows the approach and the results for one such analysis, the variations for which were typical of all of the cases studied. In order to select the segments of interest based on the FOM, the FOM was plotted as a function of time, along with the speed and total calculated tractive energy, as shown in Fig. 20. Locations where the FOM remained high for extended periods of time were then identified, and the terms in Eq. (38) were calculated for each of the segments of interest. The estimated mass value for each segment selected individually was calculated in order to verify that the calculated result for the segment was consistent with that of other segments so that any outliers could be identified. Finally, an overall estimate of the mass was calculated using Eq. (38) to average over all of the segments selected. Fig. 20 shows the results of the FOM for a brief segment from 1200 to 1450 seconds. The FOM regularly exceeded $70 \%$ for the two segments from $1213 \mathrm{~s}$ to $1250 \mathrm{~s}$ and $1385 \mathrm{~s}$ to $1422 \mathrm{~s}$.

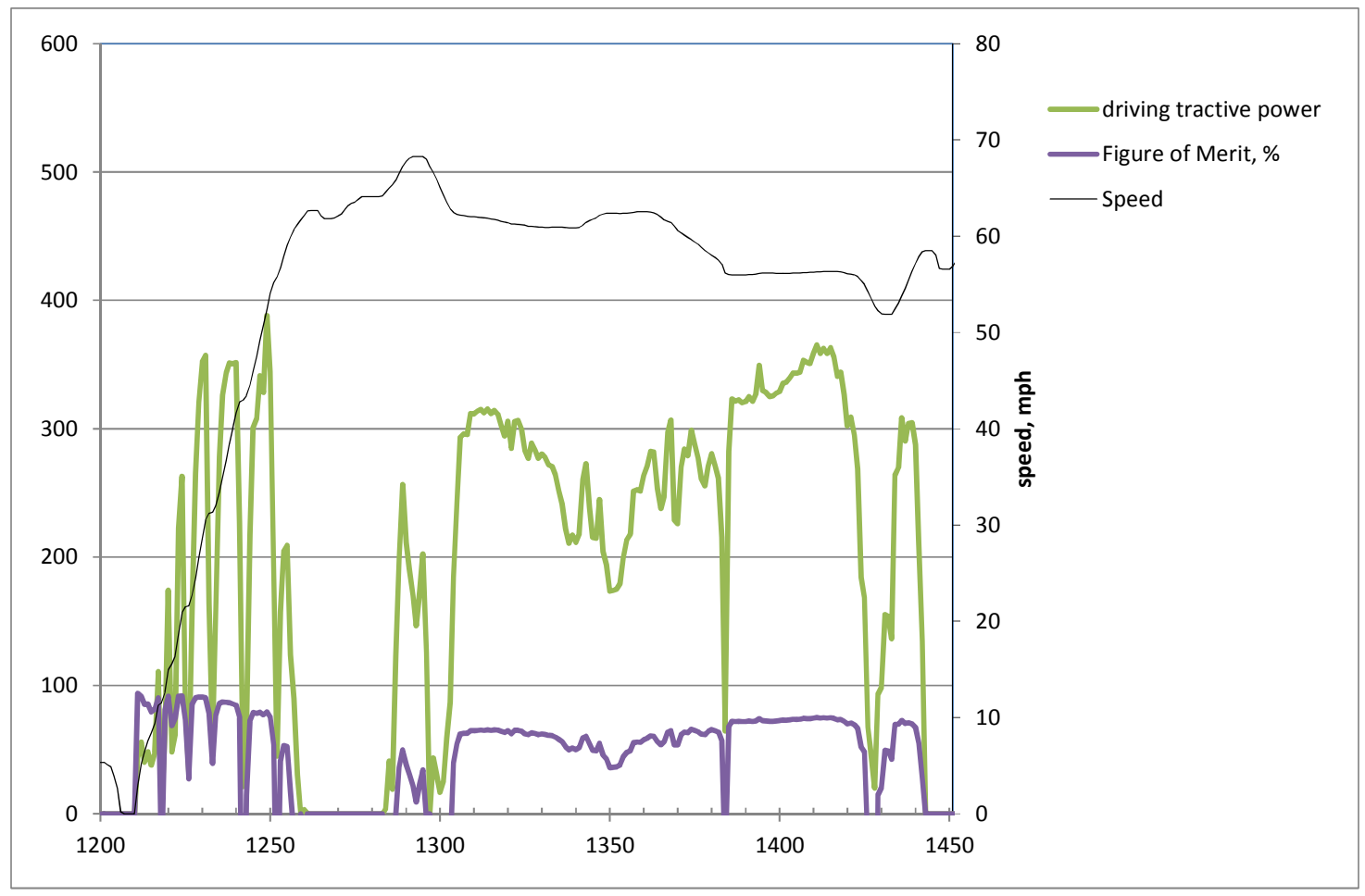

Figure 20. Drive segment showing the figure of merit and calculated driving tractive power for selection of segments for mass estimation.

Several other segments meeting the FOM criteria were also identified over the full drive cycle, and the results for the mass evaluations are shown in Table 1 below. The variation of the predictions made in this way is on the order of $1,000 \mathrm{~kg}$ about the average, and this level of uncertainty is quite satisfactory for the purposes of this project. The average mass estimated based on these segments (using Eq. (38)) was $28,078 \mathrm{~kg}$. From the Air-Weigh data, the average mass was found to be $29,050 \mathrm{~kg}$, indicating an 
error of less than $1,000 \mathrm{~kg}$. It is noted that the Air-Weigh data showed some scatter about the average, also, with variations of several hundred kilograms from one measurement to another.

Table 1. Mass Estimation Calculations for various segments

\begin{tabular}{|l|l|r|r|r|}
\hline $\begin{array}{c}\text { segment } \\
\text { start time }\end{array}$ & $\begin{array}{c}\text { segment } \\
\text { end time }\end{array}$ & $\Delta \mathrm{E}_{\text {trac, } \mathrm{m}}-\Delta \mathrm{E}_{\text {aero }}$ & $\left(\Delta \mathrm{E}_{\text {kin }}+\Delta \mathrm{E}_{\text {pot }}+\Delta \mathrm{E}_{\mathrm{RR}}\right) / \mathrm{m}$ & \multicolumn{1}{c|}{$\mathrm{m}_{\text {calc,seg }}$} \\
\hline 422 & 451 & 5033.67 & 0.1813 & 27770.7 \\
\hline 575 & 722 & 40348.32 & 1.4746 & 27361.8 \\
\hline 1213 & 1250 & 7933.73 & 0.2724 & 29126.3 \\
\hline 1385 & 1422 & 12257.50 & 0.4225 & 29008.6 \\
\hline 2700 & 2810 & 31983.63 & 1.0824 & 29549.6 \\
\hline 3620 & 3812 & 57604.27 & 2.0919 & 27536.6 \\
\hline 23532 & 23578 & 10570.94 & 0.3775 & 28000.6 \\
\hline
\end{tabular}

Average mass, from Eq. (38): $28372.9 \mathrm{~kg}$

\section{Conclusions}

In this report, the theoretical development of the tractive energy analysis was presented along with the methods that will be used for analysis of truck duty cycle data that will be obtained in the LSDC project. An analysis of measured drive cycle data from the HTDC project was performed and several results were presented that concretely illustrate how the analyses will be carried out. These cases serve as examples of the type of fuel savings estimates that can be performed using the tractive energy analysis of drive cycle data. These results clearly demonstrate how the intended analysis for the LSDC project will be completed using the set of data that the project team intends to have measured during the project. This tractive energy analysis approach provides a relatively simple means to quantify the fuel savings potential of various technologies and combinations of technologies for any given drive cycle. With this method, both the driving and braking tractive energies are first calculated for the input drive cycle, and the relative contributions to the tractive energy from tire rolling resistance, aerodynamic drag and braking are determined. Sensitivity values associated with each of the energy loss factors, in addition to that associated with the vehicle mass, are then calculated. Once the tractive energy impacts are quantified in this way, variations in the tractive energy can be very easily estimated using the calculated sensitivity parameters. With the total tractive energy, the fuel consumption is calculated for the drive cycle by using the average engine efficiency, the transmission efficiency, and average accessory power. Fuel consumption during idling can be quantified in a final step, which allows the benefits of idling reduction technologies to be quantified. With this model, key parameters that characterize rolling resistance, aerodynamic drag, engine efficiency, transmission efficiency, hybrid regenerative braking, accessory power and idling can be modified in a series of basic calculations to determine the effects of any combination of parameter changes on the fuel consumption. This provides a relatively simple but powerful method to estimate the fuel savings that are possible with different technologies without the need to perform very detailed and time-consuming analyses, and it provides a means to identify those technologies with the greatest potential for trucking applications for which the vehicle usage is known, i.e. if representative drive cycles are available for the application or trucking vocation. This analysis 
approach, coupled with detailed measurements of drive cycle information from a broad set of trucking applications/vocations, will enable better decisions to be made regarding the technologies that can provide the greatest benefits for fuel efficiency in each trucking application (including cost-benefit analyses), and realistic estimates of the fuel savings potential can be made for different technologies and technology combinations for each application/vocation.

In addition to the tractive energy model, a method was developed for estimating the vehicle mass using measured engine speed and torque along with the drive cycle data. This approach was evaluated for measured drive cycle cases for which the mass was measured directly using the AirWeigh system, and the calculated mass was found to be within $1000 \mathrm{~kg}$ of the measured mass. This level of accuracy is sufficient for the purposes of the tractive energy analyses and to quantify the load variations that occur in medium and heavy duty trucks that haul cargo.

The results from the analysis of HTDC data generated some interesting results relative to class 8 combination vehicle operations. As expected, reducing tire rolling resistance and aerodynamic drag resulted in the greatest fuel savings potential for long-haul operations, with fuel savings on the order of $2-4 \%$ possible with $8 \%$ reductions in aerodynamic drag, and fuel savings of $5-8 \%$ possible with reductions of the coefficient of tire rolling resistance by $1.5 \mathrm{~kg} / \mathrm{T}$. Somewhat surprisingly, however, regenerative braking also shows a relatively high potential for fuel savings in many of the drive cycles analyzed. For drive cycles that are believed to be representative of regional operations, the fuel savings potential for regenerative braking was estimated to be as high as $21 \%$. Even for drive cycles that were almost exclusively on the freeway, in several cases evaluated the braking was responsible for over $6 \%$ of the driving tractive energy, and the fuel savings potential from the regenerative braking by itself was calculated to be over $4 \%$ for the baseline vehicle configuration. If the regenerative braking were implemented for a vehicle configuration in which low rolling resistance tires and optimized aerodynamic drag are in use, the predicted reduction in fuel consumption due to the regenerative braking increases to $5.5 \%$. This result demonstrates the synergies between regenerative braking and other technologies that reduce parasitic energy losses, and the effect is important to consider as new regulations require trucks to use more efficient tires and improved aerodynamics. The fuel consumption benefits resulting from hybridization will actually be greater with these other efficiency technologies in use, and regenerative braking could be attractive from a cost-benefit standpoint for the more efficient vehicle configuration. This analysis suggests that hybridization of class 8 combination vehicles can provide energy savings benefits for regional applications, and perhaps also for long-haul driving, at a level that justifies the added costs and complexity of its use. Further analysis is needed, however, to validate this result for a broader set of fleets and vehicles, and to better understand if there are niche uses or occasional situations when regenerative braking is very favorable.

\section{Recommendations for Future Research for the LSDC Project}

The results of the analysis presented in this report show the value of the tractive energy approach for estimating the fuel savings potential of advanced efficiency technologies. Furthermore, the technical feasibility of applying this approach using the data that will be collected in the LSDC project has been well established with the data evaluated here, both for the tractive energy analysis itself and the mass 
estimation. The greatest potential, however, lies in applying the tractive energy analysis using the comprehensive drive cycle data that the LSDC project plans to collect for a broad range of trucking applications/vocations and numerous trucks within each application. The breadth and depth of data from the drive cycle measurements will allow the tractive energy analysis approach to be applied at a level that yields a very broad understanding of the U.S. trucking industry. It is strongly recommended that this aspect of the project be initiated as soon as possible. The project team will be working with ORNL Procurement to issue a Request for Proposal (RFP) to telematics service providers (TSPs) as the final task of the Feasibility Study. The proposals received from TSPs will provide the cost estimates for completing the data collection and establish a clear path forward for completing this task. Given the scale of the planned data collection, it is recommended that a phased approach be used to allow development and refinement of the database and management tools that will automate data screening and quality assurance when test data is being collected in real time. The testing phase certainly cannot begin before the current Feasibility Study is completed (with favorable proposals from the TSPs), but it is desirable to proceed rapidly with the phased testing and development after that point so that the database tools can be put in place and the actual data collection initiated. The full data collection will be a long-term effort requiring considerable preparation efforts, and it is preferable to not extend this process any longer than necessary.

A second area for which additional research is needed within the LSDC project is the generation of synthetic drive cycles from large sets of drive cycle data. For this purpose, the goal is to develop a single "representative drive cycle" (or a small set of drive cycles representing multiple load ranges in the case of vehicles that haul freight and experience variations in the load carried) that is characteristic of the entire set of measured data for each application/vocation. The representative drive cycle should be of a duration that can be used for normal analysis purposes (a target would be for a drive cycle lasting less than one hour) and it should yield very similar results for the predicted fuel economy as would be obtained from the entire initial drive cycle or set of drive cycles. Since the full set of measurements for each application/vocation will consist of many thousands of hours of test data, synthesizing this data into a single representative drive cycle that is on the order of one hour in duration is not a trivial task. The tool that will be used for synthesizing the information contained in the large sets of measured drive cycle data has not been entirely finalized, although a statistical sampling approach has been developed that provides a good starting point for the full procedure that will be necessary. For the synthetic drive cycle creation, it is planned to use the DCGen Tool, which is still in development as part of the MTDC project. This tool uses a statistical sampling approach based on the bivariate distribution of the acceleration and speed of the input drive cycle in order to create a synthetic drive cycle for which the statistics for the speed and accelerations are similar. The elevation variations of the drive cycle, however, are currently not accounted for in the tool, and this is an important detail that needs to be correctly implemented in the tool. Completion of the DCGen Tool is therefore a high priority for both the MTDC and LSDC projects.

In addition to creating representative drive cycles for each application, it is also planned to develop an approach that allows typical variations of drive cycle characteristics to be incorporated into "variational drive cycles" that will allow users of the tractive energy tools to quantify not only the average level of 
fuel savings for each application, but the range of variations that can be expected among normal users. In this sense, the approach attempts to quantify $1 \sigma$ and $2 \sigma$ types of variations with respect to different vehicles whose drive cycles were measured within the same application/vocation. This will allow differences in driving style to be accounted for in the analysis, and the impacts on the fuel economy benefits that can be achieved from the efficiency technologies can quantified not only for the average case, but for normal ranges of driving style that are observed within the application. To develop these variational drive cycles, the project team plans to develop representative drive cycles for each vehicle that participates in the LSDC project, and statistical analysis of the fuel economy results among the vehicles in each application will be used to quantify the variations precisely. Although the basic direction for this approach has been defined, further research is needed to develop the detailed methods and algorithms and to automate the procedure for final analysis of all of the data sets.

One of the final deliverables planned for this research program is a set of web-based tools that could be used by fleets and owner-operators, as well as transportation planners, that will present the fuel economy benefits of different technologies and technology combinations in a clear way. The tool will effectively contain all of the results of the project, including drive cycle information and the tractive energy analysis results. The tool needs to be easy to use and at a level appropriate for the intended audience, but should also be flexible enough to allow the users to evaluate cases that are representative of their specific operations. Developing the interface for this tool will require careful consideration, and the project team plans to work directly with fleets and other intended users to develop a high quality tool that will provide the greatest benefits to all of its intended users. 


\section{References}

1. National Research Council, “Automotive Fuel Economy: How Far Can We Go?" National Academy Press, Washington, D.C. 1992.

2. F. An and M. Ross, "A model of fuel economy and driving patterns," SAE Paper 930328, 1993.

3. T. LaClair and R. Truemner, "Modeling of fuel consumption for heavy-duty trucks and the impact of tire rolling resistance," SAE Paper 2005-01-3550, 2005.

4. C. Cooper, F. Kamakaté, T. Reinhart, M. Kromer, R. Wilson, "Reducing Heavy-Duty Long Haul Combination Truck Fuel Consumption and CO2 Emissions," NESCCAF, ICCT, Southwest Research Institute and TIAX Final Report.

5. L. Gaines, A. Vyas, J.L. Anderson, "Estimation of Fuel Use by Idling Commercial Trucks," Transportation Research Record, v. 1983, 91-98, 2006.

6. N. Lutsey, C.J. Brodrick, D. Sperling, C. Oglesby, "Heavy-duty truck idling characteristics: Results from a nationwide truck survey," Transportation Research Record, v. 1880, 29-38, 2004.

7. Stodolsky F, Gaines L, Vyas A, "Analysis of technology options to reduce the fuel consumption of idling trucks," Argonne National Laboratory Report ANL/ESD-43, 2000.

8. Z. Gao, V.K. Chakravarthy, and C.S. Daw, "Comparisons of the simulated emissions and fuel efficiencies of diesel and gasoline hybrid electric vehicles," Proc. IMechE, Part D: J. Automobile Engineering, 2011, v. 225, in press.

9. National Research Council, "Technologies and Approaches to Reducing the Fuel Consumption of Medium- and Heavy-Duty Vehicles," Committee to Assess Fuel Economy Technologies for Mediumand Heavy-Duty Vehicles, Transportation Research Board, 2010.

10. The Alternative Fuels and Advanced Vehicles Data Center (AFDC), "Properties of Fuels" Data Table, http://www.afdc.energy.gov/afdc/pdfs/fueltable.pdf. Accessed 2/17/2011.

11. Capps, G., O. Franzese, B. Knee, M.B. Lascurain, and P. Otaduy, Class-8 Heavy Truck Duty Cycle Project Final Report. Report No. ORNL/TM-2008/122. Oak Ridge National Laboratory, 2008. 